Florida International University FIU Digital Commons

$11-13-2013$

\title{
The Effect of Reciprocal Mapping on High-Risk Sixth-Grade Students' Social Studies Achievement
}

Tina Cash

tcash001@fiu.edu

DOI: $10.25148 /$ etd.FI13120620

Follow this and additional works at: https:// digitalcommons.fiu.edu/etd

Part of the Curriculum and Instruction Commons

\section{Recommended Citation}

Cash, Tina, "The Effect of Reciprocal Mapping on High-Risk Sixth-Grade Students' Social Studies Achievement" (2013). FIU

Electronic Theses and Dissertations. 1001.

https://digitalcommons.fiu.edu/etd/1001 


\section{FLORIDA INTERNATIONAL UNIVERSITY}

Miami, Florida

\section{THE EFFECT OF RECIPROCAL MAPPING ON HIGH-RISK \\ SIXTH-GRADE STUDENTS' SOCIAL STUDIES ACHIEVEMENT}

A dissertation submitted in partial fulfillment of the

requirements for the degree of

DOCTOR OF EDUCATION

in

CURRICULUM AND INSTRUCTION

by

Tina Cash

2013 
To: Dean Delia C. Garcia

College of Education

This dissertation, written by Tina Cash, entitled The Effect of Reciprocal Mapping on High-Risk Sixth-Grade Students' Social Studies Achievement, having been approved in respect to style and intellectual content, is referred to you for judgment.

We have read this dissertation and recommend that it be approved.

Leonard B. Bliss

Lynne D. Miller

Isadore Newman

Joyce C. Fine, Major Professor

Date of Defense: November 13, 2013

The dissertation of Tina Cash is approved.

Dean Delia C. Garcia

College of Education

Dean Lakshmi N. Reddi

University Graduate School

Florida International University, 2013 


\section{DEDICATION}

Dedicated to my children: Erin, Lee, and Brian.

Be inspired by what you love.

Follow your passions, you have the strength to achieve your goals. 


\section{ACKNOWLEDGMENTS}

I would like to thank God for his many gifts.

To my family, Nick, Erin, Lee, and Brian, your support has been "the wind beneath my wings." Erin, thank you for your encouraging words, constant support, and unflagging faith. Lee, you have helped me achieve this goal with your upbeat words of support. Brian, "the paper" has been a part of your life; soon, it will be your turn. Nick, thank you for so much help in so many ways. My parents, Tim and Katy, who live within me. To my brothers and sisters for their continued support, thank you all. Teri, thank you for listening, advising, editing, guiding and believing.

To my professional family, I hesitate mentioning names, because for each one I list, ten will be neglected; however, I would be remiss not to mention my "sisters" who started the journey with me, Lisa H. Goidelic Taylor (what would I do without you) and Mac, Kathleen, and Ana. Elena, Melanie, Michelle, Sandra, Janet, and Rozann, thank you for your support. To administrators and office staff at both Upper Keys schools, thank you. Dermot, you never doubted this day would come.

To my dissertation committee, thank you for your support and advice: Dr. Bliss, as both a committee member and a wonderful statistics professor; Dr. Miller, your advice and comments as both a committee member and an insightful reading professor, thank you. Dr. Newman, this journey began with boot camp, and my days were blessed by your enduring support, advice, direction, and wonderful humor. It is almost impossible for me to truly thank Dr. Joyce Fine. There are not enough words to express the amount of support, encouragement, time, and constant help no matter what time of day you gave me. Thank you. Thank you to the many others at F.I.U., who supported me perhaps 
without even realizing it. Dr. Linda Bliss, thank you not only for your advice during boot camp and beyond, but for your kind and supportive comments which meant so much to me at a pivotal time. Caprila A. and staff, Jennifer M., Angeline, Liz Hawk, Dr. Barbetta and Dr. Plahotnik, thank you. In closing, my gratitude to those named and unnamed, thank you for your support. 


\title{
ABSTRACT OF THE DISSERTATION \\ THE EFFECT OF RECIPROCAL MAPPING ON HIGH-RISK SIXTH-GRADE STUDENTS' SOCIAL STUDIES ACHIEVEMENT
}

\author{
by \\ Tina Cash
}

Florida International University, 2013

Miami, Florida

Professor Joyce C. Fine, Major Professor

Reading deficits in students in Grades 4 to 12 are evident in American schools. Informational text is particularly difficult for students. This quasi-experimental study $(\mathrm{N}=138)$ investigated sixth-grade students' achievement in social studies using the Reciprocal Mapping instructional routine, compared to sixth-grade students' achievement taught with a traditional approach. The Reciprocal Mapping instructional routine incorporated explicit instruction in text structure using graphic organizers. Students created their own graphic organizers and used them to write about social studies content. The comparison group used a traditional approach, students' reading the textbook and answering questions.

Students for this study included sixth-graders in the seven sixth-grade classrooms in two public schools in a small, rural south Florida school district. A focus of this study was to determine the helpfulness of the intervention for at-risk readers. To determine students considered to be at-risk, the researcher used data from the reading portion of the Florida Comprehensive Assessment Test (FCAT), 2011-2012, that considers Level 1 and 2 as at-risk readers. The quasi-experimental study used a pretest-posttest control group 
design, with students assigned to treatment groups by class. Two teachers at the two rural sites were trained on the Reciprocal Mapping instructional routine and taught students in both the experimental and control groups for an equivalent amount of time over a 5-week period.

Results of the $3 \times 2$ factorial ANCOVA found a significant positive difference favoring the experimental group's social studies achievement as compared to that of the comparison group as measured by the pre/post unit test from the social studies series (McGraw-Hill, 2013), when controlling for initial differences in students' reading FCAT scores. Interactions for high-risk struggling readers were investigated using the significance level $p<.05$. Due to no significant interaction the main effects of treatment were interpreted. The pretest was used as a covariate and the multivariate analysis was found to be significant. Therefore, analysis of covariance was run on each of the dependent variable as a follow-up. Reciprocal Mapping was found to be significant in posttest scores, independent of gender and level of risk, and while holding the pretest scores constant.

Findings showed there was a significant difference in the performance of the high-risk reading students taught with the Reciprocal Mapping intervention who scored statistically better than students in the control group. Further study findings showed that teacher fidelity of implementation of the treatment had a statistically significant relationship in predicting posttest scores when controlling for pretest scores. Study results indicated that improving students' use of text structure through the Reciprocal Mapping instructional routine positively supported sixth-grade students' social studies achievement. 


\section{TABLE OF CONTENTS}

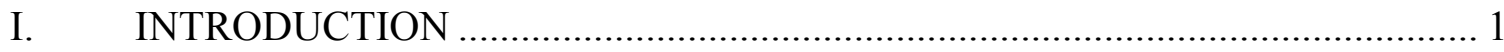

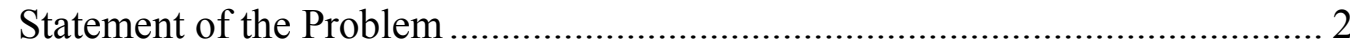

Purpose of the Study .................................................................................... 4

Research Questions and Hypotheses................................................................. 4

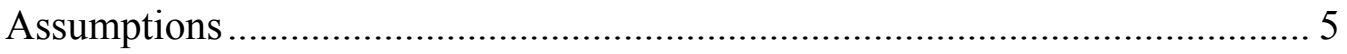

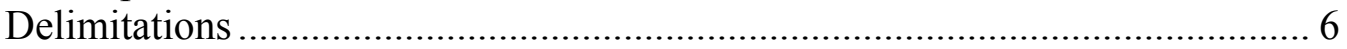

Definitions and Operational Terms ……………………………………........ 6

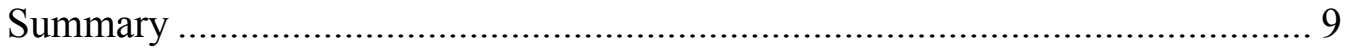

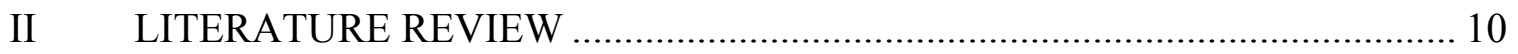

Federal and State Implications and Informational Text.................................... 11

Importance of Informational Text in School, Workforce, and Internet ............. 13

Informational Text in School.......................................................................... 13

Informational Text in the Workforce.............................................................. 14

Informational Text and Internet .................................................................. 16

Informational Text in the Classroom.............................................................. 18

Difficulties with Informational Text in the Classroom ...................................... 21

Textbook Dominance in the Classroom ............................................................. 21

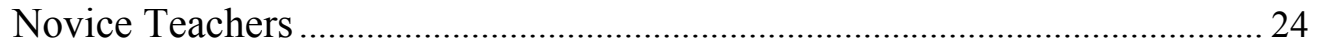

Text Structure and Comprehension .................................................................... 26

Effective Ways to Support High-risk Readers ………………………………….... 31

Multidimensional Instructional Frameworks ......................................................... 32

Effective Classroom Practices for Teaching Informational Text....................... 37

Principles for Use of Graphic Organizers ........................................................ 37

Graphic Organizers Aid in Development of Relational Knowledge................ 38

Graphic Organizers Focus Students on Central Ideas......................................... 41

Graphic Organizers: an Efficient Way to Help Retrieve and Store Knowledge

Graphic Organizers Aid Students of Varying Abilities .................................... 44

Graphic Organizers Provide a Window into Students' Thinking...................... 52

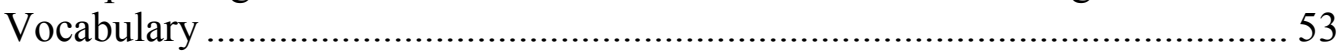

Building Background Knowledge................................................................... 55

Reciprocity of Literacy Processes ………………........................................ 56

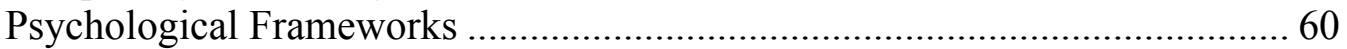

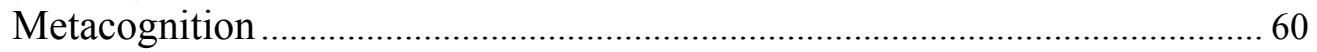

Scaffolding and Vygotsky's Zone of Proximal Development .......................... 62

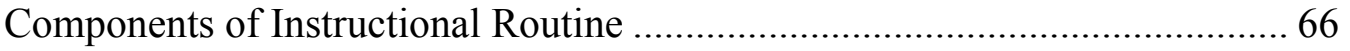

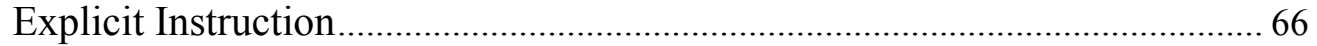

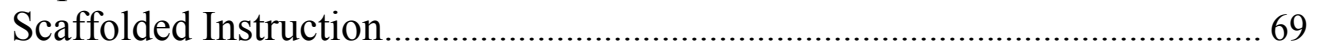

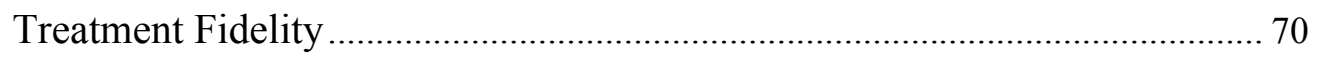

Teacher and Student Affinity .............................................................................. 74 


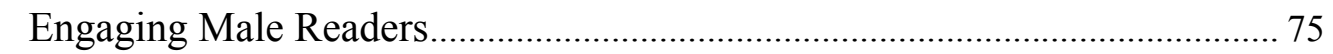

Developing Historical Literacy ............................................................. 76

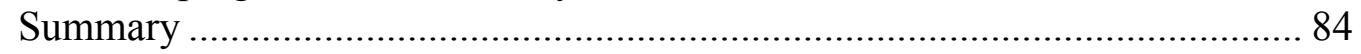

III METHODOLOGY .............................................................................. 89

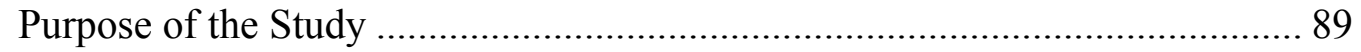

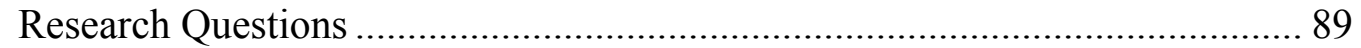

Hypotheses ....................................................................................... 90

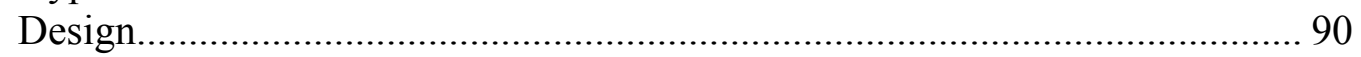

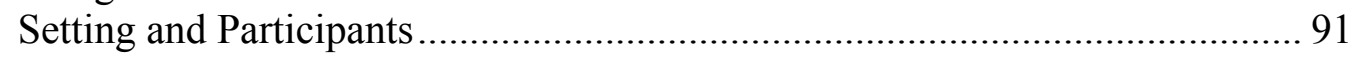

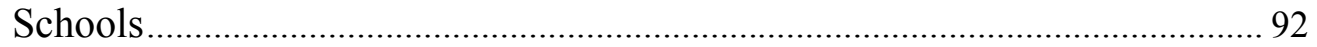

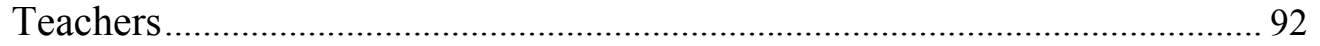

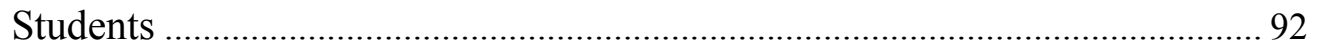

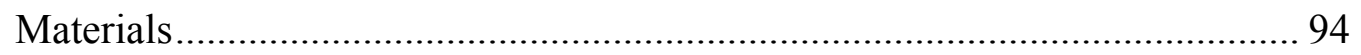

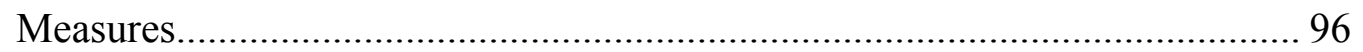

Teacher Training Procedure ...................................................................... 98

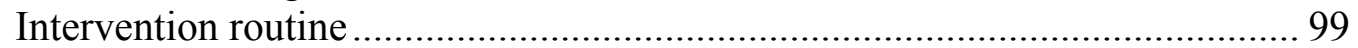

Reciprocal Mapping Instructional Routine ................................................ 99

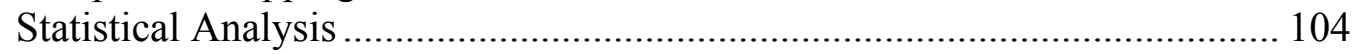

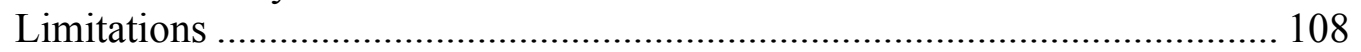

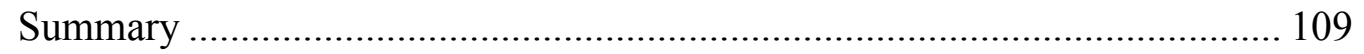

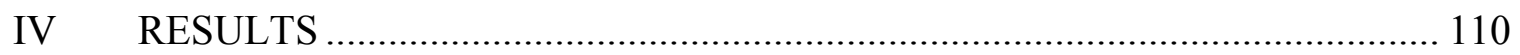

Description of the Sample ...................................................................... 110

Results and Examination of the Hypotheses ................................................ 111

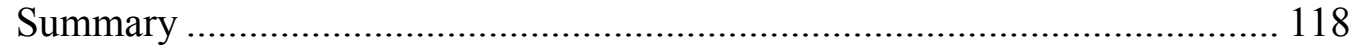

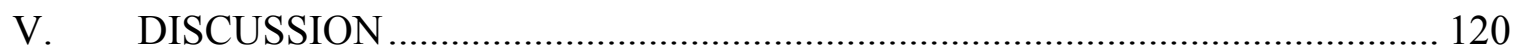

Summary of Study .......................................................................... 123

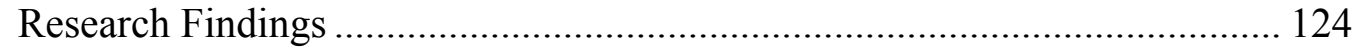

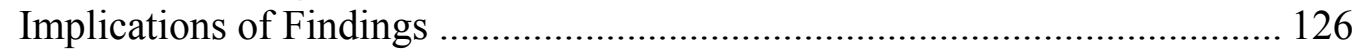

Implications for Future Research ........................................................ 127

Significance of the Study .................................................................... 129

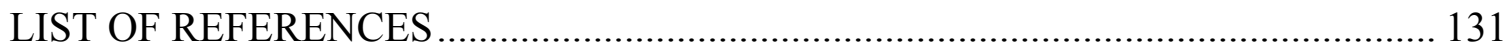

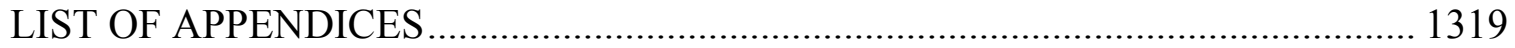

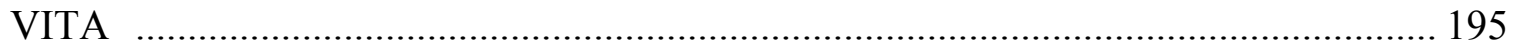




\section{LIST OF TABLES}

TABLE

PAGE

1. Descriptive Data on Sixth-Grade Students ......................................................93

2. Lessons and Sections from Florida Discovering Our Past. ..................................95

3. Means and Standard Deviations of Test Scores, Fidelity, and Affinity Disaggregated by Treatment

4. Demographic of Participants

5. Internal Consistency of Measures

6. Summary Table for a Three-Way Analysis of Variance of the Effects of Reciprocal Mapping, Gender, and Risk on Post Test Scores.

7. Differences Between the Control and Treatment Group on Posttest Gain Scores .116

8. Regression Analysis Summary for Teacher Fidelity predicting Posttest Scores While Controlling for Pretest Scores

9. Regression Analysis Summary for Teacher and Student Affinity predicting Posttest Scores While Controlling for Pretest Scores 


\section{CHAPTER I \\ INTRODUCTION}

Informational text is ubiquitous in today's society. Therefore, it is imperative that children, from the earliest grades, read and comprehend informational text competently so that as they progress through school, they are able to make effective and efficient use of their classroom instructional materials. Bernhardt, Destino, Kamil, and RodriguezMunoz (1995) found that inadequate comprehension of informational text in early grades impacts a student's entire academic career. The lack of ability to read proficiently in the elementary grades continues to plague students as they move through middle and high school, college, the workplace, and into today's technical society (Montelongo \& Hernandez, 2007; Moss, 2008). Given the importance of being able to expertly read and integrate the use of informational text in daily life applications, it is critical that teachers implement effective instructional routines to support all readers, but especially students who struggle with reading comprehension, in developing their abilities to deal well with this type of text.

The current study was designed to investigate how the development of students' knowledge of text structure, through a Reciprocal Mapping instructional routine, would impact their ability to comprehend informational text in the disciplinary area of social studies. This chapter includes the statement of the problem, purpose of the study, research questions and hypotheses, significance of the study, delimitations, definitions and operational terms. 


\section{Statement of the Problem}

For many years curriculum in Florida has been driven and influenced by state and national standards. Relatively recently Florida adopted the nationally-developed Common Core State Standards (CCSS) to guide curriculum in the state at all grade levels. The CCSS were designed with the intent to prepare America's students to be college and career ready. The CCSS initiative emphasizes the importance of informational reading and writing. In addition to standards for English Language Arts and Mathematics, the CCSS situates literacy development directly in disciplinary (Standards for Literacy in History/Social Studies, Science, and Technical Subjects; Common Core State Standards Initiative, 2010).

Florida's implementation of the CCSS seems particularly timely in that many students have difficulty reading and comprehending informational text for a number of reasons. Several of the reasons stem from the textbooks themselves. Students may lack the background knowledge and vocabulary that the textbook authors have written in these materials. Further, informational text is often technical, dense, and abstract, with each discipline having its own procedural language (O’Brien, Stewart, \& Moje, 1995). Compounding these issues, Allington (2002) found that not only are the reading levels of informational text higher than the reading proficiencies of the students, but also disciplinary teachers over-rely on these textbooks without teaching students effective routines for comprehending the informational text.

Professional literature reveals that students' ability to use text structure routines to construct meaning from information textbooks has been a productive area of research. Typically textbooks are written using a variety of the five most common text structures: 
description, sequence, compare and contrast, cause and effect, and problem and solution. Each of these has its own set of signal words and may be represented by specific types of graphic organizers that capture text patterns.

Researchers have found that only small amounts of classroom time is allocated for engagement with informational texts in the early grades (Duke, 2000). Students in primary grades are more often introduced to and taught with narrative text, highlighting text structures appropriate for this type of material. Some research suggests that once students master the narrative text structure, they may apply it to other narrative reading situations (Dymock, 2007; Pressley and Wharton-McDonald, 2006; Donovan and Smolkin, 2002).

Even students who are able to read grade level narrative text successfully can find informational textbooks difficult to read, because they have had relatively little practice with the various types of informational text structures (Ambruster, 1991). In addition, since both proficient and high-risk readers tend to struggle with the complexity of language found in different disciplinary areas, they frequently miss key concepts which hinders comprehension and acquisition of disciplinary concepts (Moss, 2008). Effective instruction related to teaching text structures may support textbook reading by all students.

Reciprocal Mapping has been found to be an effective strategy to help students develop an understanding and use of narrative text structure for reading and writing (Fine, 2004).

Reciprocal Mapping is an integrated reading/writing strategy, using visual representation to make concrete the process of examining author's craft. Students 
read text, under the direct and explicit instruction of the teacher, as they create graphic organizers depicting the targeted narrative text structure. Students come to appreciate the authentic ways authors write; by appreciating and paralleling the techniques authors use, students indirectly experience an author's apprenticeship. Reciprocal Mapping is designed to be a leading activity, one that takes students to a higher level of cognition (Fine, 2004 p. 89).

\section{Purpose of the Study}

The purpose of this study was to investigate the effect of a Reciprocal Mapping instructional routine on sixth-grade students' social studies achievement. Specifically, this study sought to examine:

1. The effects of a Reciprocal Mapping instructional routine on high-risk sixthgrade readers' ability to comprehend informational text content in the area of social studies.

2. Teachers' fidelity to the Reciprocal Mapping instructional routine and its relationship to sixth-grade students' social studies achievement scores.

3. Teachers' and students' affinity to the Reciprocal Mapping instructional routine and that relationship to students' social studies achievement scores.

\section{Research Questions and Hypotheses}

Specifically, the following research questions were addressed in this study.

Question 1: Is there a significant interaction between sex, treatment (Reciprocal Mapping approach and traditional instruction) and level of risk groups (low, Level 3, and high) in predicting gains on the McGraw-Hill Social Studies unit test, such that the highrisk group will gain more on the test? 
Question 2: If there is no interaction or the interaction is ordinal, is there a significant difference between Reciprocal Mapping and traditional treatments in predicting posttest scores?

Question 3: For the treatment group (Reciprocal Mapping) is there a relationship between the fidelity of implementation and social studies posttest scores when using the McGraw-Hill pretest scores to predict adjusted posttest scores.

Question 4: Does each of the affinity scales (teacher affinity to the condition, and student affinity of the condition) account for significant amounts of unique variance on predicting adjusted posttest scores?

\section{Assumptions}

1. The participants in this study, across the seven classrooms, represent a typical range of abilities that would be found in sixth-grade classrooms in a rural community.

2. The participants in this study have had some instructional exposure to narrative text structure.

3. The participants in this study have had limited instructional exposure to the two more common informational structures, description and sequence.

4. The participants in this study were not taught or exposed to instruction in informational text structures beyond those taught within the context of the study during the time of the study.

5. The participants were not taught or exposed to the social studies content or material in other contexts during the time of the study. 


\section{Delimitations}

This study was delimited to students in sixth grade who lived in a rural community in a county in Florida, and who were taught by experienced teachers. This study used a single intervention. It also used the state adopted social studies textbook and assessments. This study was delimited to the schedule(s) currently practiced at the participating schools. Both class size and time of day that all classes were taught were determined by state mandates. This study was delimited to the students' answers to test questions representing the knowledge they gained using either a Reciprocal Mapping instructional routine or traditional instruction. The results of the tests may not accurately reflect the depth of knowledge gained depending on student motivation during the testing window. Due to the unique sample of students available for the study, the results may be generalizable only to similar schools and student populations.

\section{Definitions and Operational Terms}

\section{Background Knowledge/Prior Knowledge}

Background knowledge/prior knowledge is a combination of the learner's preexisting attitudes, experiences, and knowledge about a topic as measured by teacher observation and questioning (Kujawa \& Huske, 1995).

\section{Disciplinary Subjects}

Disciplinary subjects are core academic disciplines commonly taught in public schools that include social studies, science, and mathematics.

\section{Explicit Instruction}

Explicit instruction is a structured, systematic, and effective methodology for teaching academic skills. "It is characterized by a series of supports or scaffolds. Students 
are guided through the learning process with clear explanations and demonstration of the instructional target and supported practice with feedback until independent mastery has been achieved" (Archer \& Hughes, 2011, p. 1).

\section{Fidelity of Treatment}

Fidelity of treatment is the link between evidence-based interventions and changes in student outcomes. "Higher levels of treatment fidelity are usually associated with greater student improvements." (Collier-Meek, Fallon, Sanetti, \& Maggin, 2013).

\section{Florida Comprehensive Assessment Test (FCAT)}

Florida's state-wide standardized achievement test that is administered annually and measures student performance on selected benchmarks in reading, writing and mathematics. FCAT achievement levels range from 1 to 5. FCAT achievement level policy defines a Level 1 student who has little success with challenging content of Sunshine State Standards; Level 2 a student with limited success; Level 3 a student with partial success. Levels 4 and 5 are considered students who are successful readers. For the purpose of this study, Levels 1 and 2 are considered at-risk for reading difficulties with social studies text.

\section{High-risk Reader}

In Florida, a substantial deficiency in reading is defined by scoring Level 1 or Level 2 on the Florida Comprehensive Assessment Test (FCAT) in reading (Monroe County School District). For the purpose of this study, high-risk readers are considered at high-risk for not mastering social studies concepts. 


\section{Informational Text}

A type of nonfiction text that "differs from other types of nonfiction in purpose, features, and format" (Duke \& Bennett-Armistead, 2003, p. 56). Informational text is organized into text structures; the five most common organizational text structures are description, sequence, comparison, cause and effect, and problem and solution (Meyer \& Freedle, 1984).

\section{Proficient Reader}

A student who can comprehend the meaning of texts more deeply and learn from them more efficiently (Torgesen, 2009). In Florida, a proficient reader would score at a Level 3, 4, or 5 on the FCAT Reading. For the purpose of this study, proficient readers are considered to be at low risk for not mastering social studies concepts.

\section{Reading Comprehension}

Reading comprehension is conceptualized as a meaning-construction process, consisting of the reader, text and classroom context, and teacher. Proficient readers generate mental images of the text which they test and monitor as they read and use strategies to fix misconceptions during the reading process. (Ruddell \& Unrau, 1994).

\section{Reciprocal Mapping}

An integrated reading/writing strategy, using visual representation to make concrete the process of examining author's craft. Students read text, under the direct and explicit instruction of the teacher, as they create graphic organizers depicting the targeted text structure. Students come to appreciate the authentic ways authors write; by appreciating and paralleling the techniques authors use, students indirectly experience an 
author's apprenticeship. Reciprocal Mapping is designed to be a leading activity, one that takes students to a higher level of cognition (Fine, 2004, p. 89).

\section{Scaffolded Instruction}

Instruction that is drawn from the work of Vygotsky (1978). This is a classroom technique that allows students to accomplish an activity with the support of a knowledgeable other, that they may not be able to do alone. As the student masters the activity, the extra support is gradually withdrawn until the student is able to complete the task independently.

\section{Transmediation}

According to Leland and Harste (1994), transmediation occurs when meanings "formed in one communication system are recast in the context and expression planes of a new sign (semiotic) system" (p.340). Transmediation encourages reflection and supports learners in making new connections.

\section{Treatment Affinity}

The tendency to perform better at tasks when there is a perceived preference or general favor associated with it.

\section{Summary}

In this chapter the need to support high-risk adolescents was discussed. In today's technological society, it is important to provide students with the expertise needed to read all types of text. A classroom strategy, Reciprocal Mapping, was described.

Delimitations and definitions of key terms were explained. 


\section{CHAPTER II}

\section{LITERATURE REVIEW}

This literature review examines the relationship of using a reading intervention, Reciprocal Mapping, on sixth graders' comprehension of social studies content in the disciplinary classroom. Relevant research supporting the use of this intervention is presented. Particular focus is paid to informational text for several reasons. Content instruction in the disciplinary classroom has become a focus point for teaching literacy skills in classrooms today due to the adoption of Common Core State Standards Initiative (CCSSI) that stresses the importance of students being "college and career ready at the end of high school" (CCSSI, 2010). Content area instruction is predominately informational text taught almost exclusively from textbooks (Armbruster \& Anderson, 1988; Ciborowski, 1992; Goodlad, 1984). Students have difficulty comprehending informational text (Allington, 2002; Duke, 2004; Moss, 2005) for a number of reasons. However, when students are taught types of text structure, they can be successful with content area textbooks (Alvermann, 1982; Armbruster, Anderson, \& Ostertag, 1987; Meyer \& Freedle, 1984).

Relevant research that explores reading comprehension instruction is included in the literature review as well as theoretical frameworks supporting scaffolded instruction, (Bruner, 1984), construction of knowledge, (Vygotsky, 1978) and metacognition (Baker $\&$ Brown, 1984). Studies focusing of the use of graphic organizers, activation of background knowledge and reciprocity that are important to the reading intervention are discussed. The Reciprocal Mapping instructional routine (Fine, 2004) will be discussed 
with important literature that that shows it to be an effective intervention in literacy acquisition in content area classrooms.

\section{Federal and State Implications and Informational Text}

The Common Core State Standards Initiative (CCSSI), led by the Council of Chief State School Officers and the National Governors Association, is the culmination of "an extended, broad-based effort to fulfill the charge issued by the states to create the next generation of $\mathrm{K}-12$ standards in order to ensure that all students are college and career ready in literacy no later than the end of high school" (CCSSI: www.corestandards.org). These standards have been adopted in the United States by all states except Alaska, Texas, Virginia, Nebraska and Minnesota (CCSSI, January 16, 2012). Designed to prepare American students to be college and career ready by the time they graduate from high school, the standards place literacy and language development within the content areas. The Standards insist that literacy instruction "should not be limited to English Language Arts \& Literacy and should be a shared responsibility within the school." This "shared responsibility" has landed squarely on the shoulders of content area classroom instruction, specifically history/social studies, science, and technical subjects. CCSSI's motivation to this interdisciplinary approach is based in part on the extensive research showing that college and career ready students "must be proficient in reading complex informational text independently in a variety of content areas. Most of the required reading is informational in structure and challenging in content." Since the Core Standards are now driving curriculum decisions throughout most of the United States, it is important to have research-based literacy strategies that can be used in the content area classrooms that are not cumbersome for teachers to use and have effective results in mastering both the literacy and specific content area demands. Reciprocal Mapping is a strategy that is easy to learn and is effective over the range of content area concepts, rooted in literacy methodology. 
In addition, with the passing of United States federal education law, The Elementary and Secondary Education Acts (ESEA 2001), also called No Child Left Behind (NCLB), came an ensuing barrage of high-stakes testing that has inundated classrooms throughout the United States. Text found in these high stakes assessments, range from a low of $30 \%$ of informational text in grade 3 , to $40 \%$ in upper elementary school and by the time students are in eighth grade, the percentage of informational text is $70 \%$. Moss (2002) found that between 50 and $80 \%$ of all standardized test content is informational in informative-type text and that by sixth grade, more than $75 \%$ of student's school reading demands involve non-narrative materials. Moss contends most of what adults read on and off the job is information text.

Another outcome of NCLB along with the Individuals with Disabilities Improvement Education Act of 2004, (IDEA), that focuses on providing all students high quality, research based classroom instruction, and remediation for those students who do not respond to this instruction, emerged Response to Intervention (RtI). Brozo and Puckett (2009) investigated the emerging importance of content literacy with respect to Response to Intervention and the impact it had on Tier 1 classroom instruction. RtI models have three tiers of instruction which differ in levels of intensity: Tier 1 instruction is part of an effective general education classroom, Tiers 2 and 3 deliver more intense, specific and data-driven instruction in more intense intervals as students move through the levels if they do not meet state instructional standard, Fuchs and Fuchs (2005). Brozo and Puckett (2009) note that the diversity of students of color, ELL and ESE students, in our classrooms is higher now than any other time in the history of U.S. schooling, and a specific challenge is to make sure that all students develop skills needed to acquire 
information and concepts in the content areas. The impact of these three programs, Common Core State Standards Initiative, No Child Left Behind, and the Individuals with Disabilities Improvement Education Act, has a direct effect in the area of content literacy. It appears that content knowledge and skills are the "common denominator" for teaching and learning literacy skills in the 21 st century, thus putting the thrust of teaching reading skills into the domain of disciplinary classrooms which are dependent upon informational text.

\section{Importance of Informational Text in School, Workforce, and Internet}

\section{Informational Text in School}

Informational text is important not just for student learning in school, but in the workplace, and society. Yopp and Yopp, (2012) found that "exposure to informational texts in the early years is crucial if students are to succeed in a world that demands the ability to navigate the genres that dominate the later years of schooling and adulthood." Beginning in early elementary classrooms, it is important to include informational text into daily classroom instruction because informational text:

- is key to success in later schooling (Goldman \& Rakeshaw, 2000; Ogle \& Blachowicz, 2002; Venezky, 2000,)

- builds background and literacy knowledge in the content area (Mantzicopoulous \& Patrick, 2010; Sackes, Trundle \& Flevares, 2009).

- is read extensively by adults in work, home and the community (Smith, 2000; Venezky, 1982)

- is preferred reading for some children (Jobe \& Dayton-Sakari, 2002; Kletzien, 1998; Moss \& Hendershot, 2002; Moss, 2005) 
- addresses children's interests (Caswell \& Duke, 1998; Ivey \& Broaddus, 2001; Wigfield, Guthrie, Tonks, \& Perencevich, 2004)

- builds knowledge of the natural and social world (Duke \& Bennett-Armistead, 2003; Pappas, 2006)

- builds and exposes students to specialized vocabulary, (Duke \& BennettArmistead, 2003; Fang, 2008).

\section{Informational Text in the Workforce}

The Common Core State Standards for English Language Arts and Literacy in History/Social Studies, Science and Technical subjects has chosen to situate literacy skill development squarely in the realms of the content area classroom. By doing so, the Board of Governors has shown the importance of comprehension of informational text, both in the classroom and in order to prepare students to be "career ready." Additionally, The Center for Public Education (Center), a research organization supported by the National School Boards Association (NSBA), is a national resource for "accurate, timely, and credible information about public education" and its importance to schooling in the United States of America. The Center's mission statement says that "it serves as America's one-stop shop for clear, concise, and trusted information about public education, leading to more understanding about our schools, more community-wide involvement, and better decision-making by school leaders on behalf of all students in their classrooms." The Center provides up-to-date research on current educational issues and looks at ways to improve student achievement for life in the workforce. When looking at literacy demands in the 21st century workforce, the Center uses a definition found nationally and internationally that defines teenage and adult literacy as "using 
printed and written information to function in society, to achieve one's goals, and to develop one's knowledge and potential" (Kutner, Greenberg, Jin, Boyle, Hsu, \& Dunleavy, 2007). This definition means that adults need to read and comprehend many different types of text, not simply narrative text. The National Assessment of Adult Literacy (NAAL) distinguishes between prose literacy and document literacy, to differentiate the wide variety of text types that adults need to be able to read and understand if they are to be successful in the workforce. NAAL defines prose literacy as text that is arranged in sentences and paragraphs, newspapers articles, brochures, and news stories. Document literacy, however, "requires participants to interpret a kind of document seldom seen in English classrooms," (Jerald, 2009). Document literacy is the knowledge and skills needed to perform document tasks which include searching, comprehending, and using information from noncontinuous text in a variety of formats including job applications, payroll forms, transportation schedules, maps, tables, and drug or food labels, all of which are types of informational text. NAAL (2003) found that adults with stronger literacy skills were more likely to be employed, have higher-status jobs and to earn more income. Interestingly, NAAL (2003) also noted that parents with stronger literacy skills were more likely to read to their children and those children were more likely to enter preschool with alphabetic skills, Kutner et. al (2007). Further, Strong American Schools (2008) found that $43 \%$ of students at 2-year public colleges and $29 \%$ of students at 4-year public colleges failed placements tests and had to enroll in remedial classes in reading or writing. These students had graduated from high school which should signify college preparedness, but for this percentage of students, it had not. This is a problem for the United States because according to Strong American Schools 
(2008), in today's 21 st century workplace, students need a postsecondary degree. Why? Why do so many students need education making them college or career ready? Since the turn of the century, the economy of the nation has been transformed by technological and economic change that requires its students and citizens to have a more rigorous knowledge base. Jobs that required basic levels of education just don't exist in enough numbers to match students who don't have the basic levels of education. Students who can't read well, can't perform well in any college classes, without basic literacy, students are stuck without a collegiate future, Strong American Schools (2008). The significance to schools today is that students need a degree in order to succeed in modern society and the global economy. It is clear that today's schools need to provide classroom strategies that will graduate students who are able to read and comprehend informational text.

\section{Informational Text and Internet}

Leu, Kinzer, Coiro and Cammack (2004) have found that it is more important than ever to integrate information text in daily classroom instruction at a young age because as students progress through the grades, into high school, college, and beyond, they need to know how to read for and critically evaluate information from both traditional reading materials, i.e. textbooks, classroom magazines, but also online sources. The Internet has become one of the most frequently used text base readings that today's students encounter, Leu et al. (2004).

Looking at statistics of how the Internet is used by adolescents shows the impact

of Internet use: $47.9 \%$ of all 12 - to 17 year-olds had access to the Internet at home in the United States in 2001 and has grown to $75 \%$ in 2003. In schools, $98 \%$ of $\mathrm{K}-12$ classrooms have access and use Internet. Using the Internet as the primary resource for 
research made up $30.7 \%$ of children's Internet use in 2001 and grew to $61.8 \%$ in 2003 with email being the next most common use of the Internet at $22.2 \%$ in 2001 and $57.7 \%$ in 2003. Definition of literacy today includes "literacy skills necessary for individual, groups, and societies to access the best information in the shortest time to identify and solve the most important problems and then communicate this information" (Leu, 2000). Since $98 \%$ of the text read on the Internet is informational, (Coiro \& Dobler, 2007; Gambrell, 2005; Kamil \& Lane, 1998; Schmar-Dobler, 2003), students must learn how to access, assess and apply informational and informational text they read on the Internet in order to be successful in both school and later in the workplace. The role of technology in today's economy demands a higher level of literacy than ever before and requires that students be able to read and write in the digital world. Students need to be able to do more than decode text, they now need to be able to develop "the ability to use the Internet to access information quickly, sift through volumes of text, evaluate content, and synthesize information from a variety of sources is central to success at school" (SchmarDobler, 2003). Martha Ruddell, in a personal communication to Swafford and Kallus (2002) also states that the effects of technology and its use of informational text will challenge our views of what it means to be literate: "to be literate will continue to change with the expansion of the Internet and the advancements of technologies, and teachers and theorists alike will need to learn and grow to accommodate these change" Swafford and Kallus (2002) also quote Donna Alvermannn in a personal communication saying that adolescent literacy is on the verge of reinventing itself for two main reasons. First, the social and cultural contexts in which texts and literate practices are situated are 
rapidly changing. Second, new technologies contribute to changes in our conceptions of reading and writing.

\section{Informational Text in the Classroom}

Despite the evidence on the importance of teaching informational text starting in the elementary classrooms, students have limited exposure to informational text types. Duke (2000) in a study with twenty 1st Grade classrooms in Boston, found that teachers spent an average of only 3.6 minutes a day teaching informational text, with correspondingly little informational text such as posters, text on classroom walls or in classroom libraries, in other classroom areas. In addition, she found that the average number of minutes was even less in low-socioeconomic districts in the study.

A more recent study following Duke's (2000) line of research in second through fourth grade classrooms comparing use of informational and narrative text, found that these students spent 16-minute per day using informational text (Jeong, Gaffney, \& Choi, 2010). Jeong, Gaffney and Choi’s 2010 was a descriptive study that observed 15 2nd, 3rd and 4th Grade classrooms; five at each level in both rural and urban districts. Again, following Duke's (2000) data collection procedures, classroom observations included three indicators, classroom library print, classroom environment print and written language activities. It appears from this study, that the amount of time spent with informational text from Duke's 2000 study of 3.6 minutes to Jeong, Gaffney and Choi's in 2010 of 16 minutes in some elementary classrooms has increased by $22.5 \%$ over the much more used narrative text. Jeong, Gaffney, and Choi found that $70.9 \%$ of the classroom libraries they investigated composed of narrative text, $6.2 \%$ narrativeinformational, and 14\% informational, with the final $8.9 \%$ considered other. The authors 
state that while the findings were not randomly selected and a relatively small amount of classrooms were investigated, it does appear that narrative reading still outweighs informational text usage. Further, Stanovich (1986) in his seminal research from which was dubbed the Matthew Effect, clearly showed that once behind their peers, whether due to organic causes or poor teaching, students are seldom able to recover from that gap and continue to lag behind their peers over time and in all subjects. The lack of exposure and practice of informational text in elementary classrooms negatively impact student achievement.

Teachers tend to spend more time teaching and reading narrative texts (Duke, 2000; Duke, 2000b; Pappas, 2006; Wade \& Moje, 2000; Yopp \& Yopp, 2006). Even at home, parents tend to read narrative text more frequently to their children than informational text (Price, van Kleeck, \& Hubert, 2009; van Kleeck, Gillam, Hamilton \& McGrath, 1997). Textbooks in elementary grades are predominately narrative. Hoffman, McCartney, Abbott, Christian, Corman, Curry, Dressman, Matherne and Stahle (1994) investigated new basals adopted in Texas and determined that $12 \%$ were informational. Moss and Newton (2002) examined the amount of information text in six basal readers, Grades 2, 4, and 6 and observed that a range of informational text of $16 \%$ to $20 \%$ across the grade levels. Moss (2008) in a later study comparing text genres in two California adopted basal readers, Grades 1 through 6 , found that only $40 \%$ of the text was informational. While there is a trend toward more informational text than in the past, Flood and Lapp (1986) found that $32 \%$ of the passages were informational, it is still less than what is recommended by the 2009 National Assessment of Education Progress Report. So even though Kamil \& Lane (2004) said "Nothing is more important to a 
student's success in school than the ability to read and write informational text" and even though up to $80 \%$ of reading passages on standardized tests are informational, (Moss, 2008), and the importance of informational text mentioned, the lack of informational text exists in today's classrooms. Yopp and Yopp (2006) studied the amount of types of readalouds in the classroom as well as the types of read-alouds at home in preschool and kindergarten-aged children over a full school year. Results from both studies were similar. Home readings included 1,847 titles of which $77 \%$ were narrative compared with 1,830 read-alouds at school also with $77 \%$ narrative titles. The study indicated that both home and school groups had much more exposure to narrative text than informational; home readings were $7 \%$ and school informational readings were $8 \%$.

Students struggle with informational text in elementary school (Kucan \& Beck, 1997; Alexander \& Jetton, 2000; Goldman \& Rakestraw, 2000). Shanahan and Shanahan (2008) found that the ability to read and write informational text is important to academic achievement across the content disciplines. Bernhardt, Destino, Kamil, and RodriguezMunoz (1995) reported that "without proper attention to informational text in the early grades, students remain unprepared for the comprehension demands that await them." With so much research influencing the inclusion of informational text in school classrooms, school districts and educators know that the amount of informational text must be increased in elementary classrooms, (Duke, 2000; Yopp \& Yopp, 2006). What reasons, therefore, are given for the lack of informational text found in the classroom today? 


\section{Difficulties with Informational Text in the Classroom}

\section{Textbook Dominance in the Classroom}

An overarching difficulty with informational text in the classroom is the overreliance of textbooks to teach disciplinary content. Textbooks are the dominant form of classroom instruction in disciplinary area classrooms (Alvermann \& Moore, 1991; Czerniak \& Lumpe, 1996; Harlen, 1997; Moss, 1991; O'Brien, 1998; Sanacore \& Palumbo, 2009). Textbooks are rarely supplemented by newspapers, library books, magazine articles or other connected text (Allington, 2002; Wade \& Moje, 2000; Walker \& Bean, 2005). Goldman (1977) found that reliance on textbooks is not the best way to teach content area comprehension. First, students do not transfer knowledge to new situations; second, students can misinterpret information from texts depending upon their prior knowledge of the content; and third, more effective strategies and materials are available that are essential in today's classroom, for instance, higher level thinking, and cooperative learning to problem solve.

Allington (2002) suggests two reasons why adolescent students struggle with mastering disciplinary content in the classroom; the first is the mismatch between text book levels and the students' actual reading levels, the second, as Wade and Moje (2000) and Sanacore and Palumbo (2009) also suggest, is the overreliance of textbooks as the main instructional resource for all students. Allington, (2002) calculated the instructional reading level of the texts adopted by most school districts and found that students misread or did not know $5 \%$ of the words in text. While 5\% may not appear to be a large percentage, Allington says that it translates to students missing between five and 20 
words out of every 100 in a typical classroom textbook, and of the words that are most likely misread are the content specific words that are crucial to learning the concepts.

Gunning, (2003) emphasizes the importance of the appropriate match between student's reading levels and actual levels of reading materials provided in the classroom. He found that the most important instructional decision a teacher can make, "is making the appropriate match of appropriate materials for the reader." He states the obvious, students who are given material that is too easy are not challenged and students who get material that is too difficult do not make progress. Worse, the latter group is often off task, may develop behavior issues or become so frustrated that they give up and often end up hating reading.

Alger (2009) investigated first-year teachers' in-class and out-of-class reading assignments in both rural and suburban settings, with both high and low students on free or reduced-lunch, and with and without schools meeting Annual Yearly Progress in the high school classroom. Alger (2009) found that the beginning teachers interviewed were aware that students were unable to read and comprehend the textbooks independently. Some of the remarks from these novice teachers in the interview included the following statements:

My 11th and 12th Graders have difficulty making meaning of the text. You can assign a paragraph with what you think is very clear explanations and then ask them a question, and they can't pull the information out of the reading. (p. 62)

You can't send them (students) home with a reading assignment, know that they can read the words but not well enough to understand the content. A lot 
of times once they read (the text) and I ask them what they read, they have no idea. (p. 63)

"I have plenty of problems getting my students to read and I know there is a correlation between my students earning Ds and Fs and their below-grade-level reading abilities" (p. 63), "I can't assign more than a page and a half because I believe my students will get lost in the text" (p. 66), and "[t]he fit between the textbook and my students is so far off the mark that the text is used more as a reference than as a major source of transmission of information" ( p. 66).

Alger (2009) determined that novice teachers are well aware of the difficulty of using textbooks in the classroom. Her findings found that novice teachers will find a variety of ways to transmit knowledge and concepts rather than or in addition to using the textbooks because "time is better spent" developing multiple strategies and texts to ensure knowledge acquisition and in order to reduce the amount of reading required by their students.

Not only is American education textbook-dominated (Armbruster \& Anderson, 1988) but social studies text in particular "have exerted greater influence on the regular education curriculum than any other factor" and are among the most difficult reading materials that students come across; and textbook quality continues to be a professional concern in educational research and practice (Harniss, Dickson, Kinder, \& Hollenbeck, 2001). Reciprocal Mapping uses a variety of informational text sources which can serve to minimize this difficulty. 


\section{Novice Teachers}

Further complicating the issue of dominant textbook use in content area classrooms as the main source of instructional delivery coupled with teacher lecture, is the fact that novice teachers often abandon effective methodologies previously learned in teacher colleges. First, there is a dichotomy between what they are taught in teacher colleges and what they actually see in their field experiences. "Many preservice teachers report observing mainly textbook lessons in their student teaching placements. This notion is reinforced with the mental models these students bring with them from their own years in elementary classrooms" (Burstein, 2009). This phenomenon, attributed to Dan C. Lortie, is called apprenticeship of observation because the practices, practices that are in opposition to what they have been taught as effective teaching strategies, are "so ingrained due to students' past experiences in their own schooling make it difficult to change their thinking." Novice teachers will fall back on these traditional teaching models, which include teacher-centered, textbook-based and memory and fact-based assessment because they see master teachers at their school site teaching that way, and are often overwhelmed by the minutiae of beginning teachers stressors and give way to the perceived easier path. DeWitt \& Freie (2005) note that novice teachers find it difficult to incorporate more effective teaching practices because "state curricula and traditional approaches deal with content in specific ways." Novice teachers do not feel confident to try the newer strategies and techniques that they were recently taught.

Meuwissen (2005) found that beginning teachers' practices may not reflect what

they were taught at teacher colleges to be myriad and include "the presence of traditional student and teacher accountability measures and a hesitance to work outside them, a lack 
of strong models, not rewards for innovative teaching, and the belief that secondary students are incapable of handling complex analytical thinking." Novice teachers lack that authority and expertise to turn purpose into process, no matter how much they want to follow the methodologies taught at college, they are not yet able to travel the road between their teacher education classes and the true classroom context encountered in their daily lives. Reciprocal Mapping can help bridge this road because it provide a entrance ramp that novice teachers can use to teach social studies concepts in a way that they learned in college and that is able to be taught without an inordinate amount of time, expertise or buy-in.

Science educators find similar tendencies among novice teachers as they search for more effective ways of teaching science based on the reform perspectives of the National Science Education Standards. Swars and Dooley (2010) say that there is a need for a "substantial paradigmatic shift" about learning how to teach science in the classroom for many teachers, "particularly because this is often not how they learned as students of science." Similar to finding with social studies teachers being victims of apprenticeship of observation, Swars and Dooley (2010) found that studies in teacher apprenticeship in science have shown that "many beginning teachers tend to engage in conservative, teacher-centered approaches to science instruction."

Informational text structure is more challenging. While narrative text structure tells a story and follows a pattern; typically with characters, setting, plot, a problem and solution, and is temporally ordered, it becomes a predictable pattern and is relatively easy for students to master (Venezy, 2000; Williams, 2003; Yopp \& Yopp, 2006). On the other hand, informational text gives factual information in a number of different ways; 
compare and contrast, lists of information, cause and effect and more. The variety of informational text, coupled with its unpredictable pattern, can cause difficulty for students. Not only is the informational text itself difficult, but the textbooks that students are required to use are often inconsiderate (Armbruster \& Anderson, 1988). Inconsiderate text includes items such as poor organization, a high rate of unknown vocabulary that is content specific, little background knowledge and random text structures. These factors are the reason so many students experience difficulties as they struggle to read and comprehend informational text. However, research has shown that by directly teaching text structure students can comprehend informational text with success The following research clearly establishes the relationship between students' knowledge of text structure and comprehension of informational text.

\section{Text Structure and Comprehension}

The following four studies examined how direct instruction of informational text structure positively impact student comprehension of that text (Bakken et al., 1997; Hall, Sabey, \& McClennan, 2005; Meyer \& Poon, 2001; Reutzel et al., 2005). Studies were selected from different age levels in order to look at the impact on participants along the spectrum of College and Career Ready, as mentioned in the Common Core State Standards Initiative.

Meyer and Poon (2001) examined informational structure training on the recall, memory of key ideas, and use of top-level structure on adults. A total of 121 adults, 56 young adults ( 21 men and 35 women) and 65 older adults ( 25 men and 40 women) participants were paid to take part in ten 90-minute sessions. Participants were evaluated and categorized as very low, low, average, high, or very high in reading skills and were 
randomly assigned to either structure strategy training, interest strategy training, or no training using a stratified random assignment procedure. Meyer and Poon (2001) were investigating whether a particular text structure would affect recall of text in each of the groups.

One-half of the participants read texts with signaling and the other half read texts without signaling. The strategy training group learned to identify the text structures and then use the specific structure to aid recall of text. The interest-list group evaluated their interest in the reading material and practiced remembering what they read. Four recalls and five summaries were completed by each participant. Memory of text was scored on three main criteria: (a) total recall, (b) recall of the gist, and (c) top-level structure.

Meyer and Poon (2001) found the while the all hypothesized effects were supported, three significant main effects were found: training on total recall, identifying the gist and using top-level structure. They found that both younger and older adults benefited from the structure training more than the interest-list strategy training. Structure strategy training had a larger affect than signaling and although they both impacted the recall and the consistency of use of the strategy, only the instruction with the text structure substantially increased recall on total and gist recall. The authors found that it appears necessary to provide readers with instruction in how to identify and use text structure to aid recall and to determine important information.

Bakken, Mastropieri, and Scruggs (1997) compared the effects of comprehensionfostering strategies on science and social studies text with 54 8th Grade students with learning disabilities who were stratified by sex randomly assigned to a text-structured based strategy, paragraph restatement strategy, or traditional instruction. Bakken et al. 
found that the explicit teaching of comprehension strategies did increase comprehension of both science and social studies text for these 8th Graders.

In the text- structured based strategy condition, students were taught a new textstructure based strategy a day, for three days. First, they were taught that informational text has specific, but different organizational patterns. They were shown how to identify three main types of informational text structures, main idea and supporting detail, listing, a main topic followed by a list of characteristics, and order, a main topic with specific steps or order of events. Then each subsequent day, the students were explicitly taught each of the three text types in more detail with practice. Each of the three days began with a review of previously taught text types, followed with instruction with the new text type. On the last day, identification procedures for the three text types were reviewed and the strategies for identification discussed.

The paragraph restatement strategy began with comparison between leisure reading (narrative text) and science reading (informational text). Then the students were taught the paragraph restatement strategy and practiced it with both narrative and informational passages, the informational passage used the main idea and supporting details text type. Students were asked to write down everything they could remember about the passage. Each subsequent day, review was provided and students then read each of the other two text types under investigation, list and order. Students were again asked to read the text and then restate the paragraphs.

Traditional instruction strategy provided students with an explanation of the difference between narrative and informational passages, identical to those read in the paragraph restatement condition. Students were then taught how to read an informational 
passage and answer questions about the content of the passage. Students practiced with narrative and informational text, beginning with main idea passages, and on each subsequent day, after a review, the list and order passages. The researchers felt that this was similar to the type of instruction students receive in typical classroom-based activities.

Results of the study showed that students in the text-structure based strategy condition performed better than students in either of the other two conditions. Students in the text-structure based strategy were better able to recall more ideas from the text they had read. These students were also able to transfer and apply this skill to social studies passages and perform well. Students in the paragraph restatement condition did outperform the traditional group, but did not do as well as the text-structure based group. In fact, students in the traditional group did not make any significant gains in comprehension.

In a study with younger students, Hall, Sabey, and McClennan (2005) investigated the effects of teaching text structure, specifically compare and contrast, to 2nd Grade students to comprehend informational text. Seventy-two 2nd Grade students were first homogeneously placed into instructional guided reading groups and then randomly assigned to one of three instructional treatment groups: text structure, content, and no instruction. For all three, teachers first introduced the text, read it, and revisited and discussed the text with the students. The first students were taught target words associated with compare and contrast informational text, such as alike, both, similar and in contrast to. Students read the text aloud, and as they read, the teacher pointed out the signal words and aided with difficult vocabulary. Then, teachers and students discussed 
the reading focusing on comprehension, text connections and comparisons. Students were instructed to complete a compare and contrast graphic organizer showing the important parts of the informational text. Finally, students were instructed to write a summary of the reading using the compare and contrast graphic organizer.

After the initial instruction on the compare and contrast text structure, a content instructional program began that had three components: 1) introducing, 2) reading and discussing, and 3) revisiting the text. The difference between the text structure and content instructional groups was the focus on instruction - content or text structure. The text structure group focused on text structure awareness, the content group focused on background knowledge and vocabulary.

Findings of the study suggest that young children benefit from both text structure and content specific vocabulary, using reading strategies such as graphic organizers. In addition, when students were taught the target words in association with the graphic organizer, students' comprehension of informational text improved.

In another study with 2nd Graders, Reutzel, Smith and Fawson (2005) investigated two instructional approaches, either a series of single comprehension strategies taught one at a time, or a family of comprehension strategies in a collaborative, interactive, instructional routine. Participants were 2nd Grade students in a high poverty, low performing school with over $50 \%$ of the children qualifying for free or reduced lunch. The students were randomly assigned to the two treatment groups in a study that lasted 16 weeks.

There were some similarities between the two treatments. In both students were taught the comprehension strategies explicitly, including explanation of the strategy, why 
it was important and where and when to use it. Both treatments scaffolded the use of strategies from teacher to student, in a gradual release of responsibility. Both groups engaged in verbal interactions and cooperative learning activities in order to complete group activities. The chief difference between the two approaches was a focus on how cognitive comprehension strategies work together. In the single strategy instruction, the students learned the skills in isolation and were left to figure out how to coordinate and use the individual strategies. In the multiple strategy instruction, the students were helped to coordinate the use of the set of strategies while engaging with multiple informational texts over time.

Findings showed that teaching a family of comprehension strategies coupled with the use of graphic organizers positively impacted the students acquisition of content knowledge from text. The students in the family of strategies were able to produce elaborate retellings for both near and far transfer of texts than students who were taught the single strategy.

\section{Effective Ways to Support High-risk Readers}

Effective comprehension strategies have been frequently researched in recent decades. From this research, it has been clearly documented that proficient readers can decode words quickly, use background knowledge, recognize vocabulary, and monitor comprehension before, during and after reading with skilled readers, Paris, Wasik, and Turner, (1991) take comprehension to the next level as they interact with text and use an array of strategies such as predict, visualize, question, summarize, clarify and connect to prior knowledge. This takes the use of metacognitive strategies which is best done by older and higher achieving students (Baker, 2005). There is evidence that metacognitive 
knowledge can begin to be developed at an early age (Duke \& Pearson, 2002). However, developing metacognition takes the use of working memory resources (Pinprich \& Zuhso, 2002). Therefore, young children and novices need to be scaffolded to learn to use metacognitive strategies (Pinprich \& Zuhso, 2002). Successful readers spontaneously acquire the use of metacognitive knowledge and control (Borkowski, Carr, and Pressley, 1987). But most students need explicit instruction (Baker, 2005). Therefore, not all students learn how to implement metacognitive strategies independently; they need direct, explicit instruction and practice using the strategies in meaningful contexts. Abadaino \& Turner (2002), in their summary of the RAND Reading Study Group Report on reading comprehension conclude that good instruction is the most powerful means of developing proficient comprehenders and preventing reading comprehension problems.

\section{Multidimensional Instructional Frameworks}

Examples of multidimensional instructional frameworks for developing comprehension in the middle grades that have adequate research evidence to support their use have been clearly documented and include Reciprocal Teaching, Transactional Strategies Instruction, Collaborative Strategic Reading, and Concept Oriented Reading Instruction. This study examines Reciprocal Mapping, another multidimensional instructional strategy framework.

Rosenshine and Meister (1994) reporting on effects of Reciprocal Teaching found overall effect sizes of .32 when using standard tests of comprehension and .88 when measures were teacher-developed. One important educational feature of Reciprocal Teaching is the scaffolding involved in the teaching process and the gradual release of responsibility until the strategy is used independently, both of which are components of 
Reciprocal Mapping. Critics say that Reciprocal Teaching is rigid, time consuming and has become routinized and is not as effective as its original intention. Reciprocal Mapping uses comprehension strategies in its learning sequence, is taught in a scaffolded instructional method but is less rigidly formatted and more easily adapted to a wide range of informational text.

A second instructional framework that has been found to develop higher order comprehension for adolescent learners is Transactional Strategies Instruction. This approach to reading comprehension teaches students to be active participants in their own learning. It is based on Sturnberg's $(1985,1997)$ triarchic theory of componential reading comprehension which includes analytic, practical, and creative aspects. Effective readers choose a variety of ways to navigate and master text. As with reciprocal teaching, students learn comprehension strategies, predicting, clarifying, visualizing, summarizing, connecting information with background knowledge and monitoring comprehension; but the students learn "the how, why and when to a set of comprehension strategies" as they are actively engaged in the reading process.

Studies investigated the effects of transactional strategies instruction directly; one with 2nd Grade children's reading, the second with 5th and 6th Grade readers and the third on students with reading disabilities in Grades 6 through 11. In all three studies treatment groups were found to outperform their peers in control groups, and also teachers reported a growth in students' self confidence, enjoyment of reading, were more willing to read and to read more difficult text and finally more likely to work in collaboration with classmates to understand text and react to and elaborate upon text, i.e. to become metacognitive readers in the comprehension process. 
Reciprocal Mapping uses the comprehension strategies in Transactional Strategies Instruction in a recursive nature as students work between the printed text and the new text they are generating as they acquire informational knowledge to complete their individual work. Students use classroom text, information from the Internet, content area publications, informational books typically found in content area classrooms.

A third strategy, Collaborative Strategic Reading (CSR) is a reading comprehension method that uses active strategy instruction combined with a social and collaborative learning environment developed by Klingner, Vaughn and Schumm (1998). CSR uses brainstorming, predicting, comprehension monitoring and questioning as the core of its reading comprehension strategies to help students understand informational text. Similar to both Reciprocal Teaching (RT) and Transactional Strategies Instruction (TSI) teachers initially explain and model the different strategies first and gradually release responsibility as the students become proficient using the different techniques. Students work in small group settings to continue to practice the strategies until they are ready to use them independently.

Studies investigated the effects of Collaborative Strategic Reading with upper elementary and middle school students and found that students in the CSR group made significantly higher scores as assessed on a reading comprehension test. A second study in a co-teach middle school class found that both general education and exceptional education students made gains. In a year-long study in 4th Grade, gains were significant in the high/average group and, while other students did show growth, the differences were not statistically significant. 
However, CSR requires a high level of teacher involvement and follow through. Klingner, Vaughn and Schumm (1998) found that the way collaborative strategic reading was taught was directly related to the gains students made in the pre and post test. As with Transactional Strategies Instruction, Klingner, Vaughn and Schumm recognizes that collaborative strategic reading is time consuming and challenging and requires a certain level of expertise to ensure the strategy is taught effectively. Klingner, Vaughn and Schumm questions whether this strategy can be used by all teachers.

Reciprocal Mapping mirrors Collaborative Strategic Reading in that it is an active processing routine that entails a social and collaborative learning environment. However, Reciprocal Mapping, once learned, does not require a high level of direct teacher involvement in the same way that the Collaborative Strategic Reading does. Reciprocal Mapping does not require an inordinately high level of expertise and can be taught across content area classrooms, as well as in language arts classrooms.

Concept Oriented Reading Instruction (CORI) developed by Guthrie,Van Meter, McCann, Bennett, Poundstone, Rice, Fabisch, Hunt and Mitchell (1996) is a framework that combines reading strategy instruction with content area knowledge. Originally, it was developed for use in science conceptual knowledge. This framework integrates and supports student motivation. Concept Oriented Reading Instruction melds the teaching of reading strategies with motivational engagement and social interaction to enhance the learning process and to develop an intrinsic motivation for students to choose to read.

Investigations using CORI in 3rd and 5th Grade over the course of a year, reported positive findings in comprehension and motivation. In addition, students taking part in the study reported reading more often and were more motivated to participate in 
reading comprehension activities. A second study by Guthrie et al. (1996) again with 3rd Graders found that students in the concept oriented reading instruction group outperformed peers on several measure of reading comprehension, although not all comparisons reached statistically significant levels.

As with the previously mentioned frameworks, CORI depends on well-trained and devoted teachers who both understand and support the model. It appears from the studies on these frameworks that teacher training and commitment to each framework is an important aspect of its success. Although Reciprocal Mapping uses many of the core tenants of CORI including observing, personalizing, searching, retrieving, integrating, and communication with peers, with Reciprocal Mapping students perform these activities in a naturalistic, self-driven way. While Reciprocal Mapping is based on research-based reading strategies, there is less of an onus on "teacher buy-in" in order for students to be successful. Like Collaborative Strategic Reading and Concept Oriented Reading Instruction, Reciprocal Mapping used authentic reading materials found in most content area classrooms. One of Reciprocal Mappings strengths is that it can be used with such a wide range of informational text. The majority of the studies conducted to research effective intervention in the content area classroom typically use only one informational text type; just compare contrast, or just cause effect. Reciprocal Mapping can be used with any of the informational text types. Since Reciprocal Mapping can be used with any type of informational text, it is much more flexible, and does not require the depth of teacher training that these research-based strategies do. 


\section{Effective Classroom Practices for Teaching Informational Text}

\section{Principles for Use of Graphic Organizers}

In 1997, Congress formed a national panel on reading in order to determine the effectiveness of different reading instruction approaches used in the United States. The panel was created by the Director of the National Institute of Child Health and Human Development and the Secretary of Education. This panel, the National Reading Panel (NRP, 2000), studied research-based reading programs over a two year period and found five topics that merited further intensive study; alphabetics, fluency, comprehension, teacher education and reading instruction, and computer technology and reading instruction. Within the area of comprehension, a subcategory listed was text comprehension instruction. The panel found 16 categories of text comprehension instruction of which seven "appear to have a solid scientific basis for concluding that these types of instruction improve comprehension" and the panel cited the use of graphic and semantic organizers as an important part of the process of reading comprehension.

Graphic organizers have been defined in many ways that include important nuances for the purpose of this study. DiCecco and Gleason (2002) describe graphic organizers are visual portrayals or representations that depict relationships among the key concepts in learning tasks; Chmielewski and Dansereau (1988) found that they depict a variety of relationships and structures in a single display; and Stull and Mayer (2007) found that they depict the organization plan of the text - all of which help student construct and understand relational knowledge. Graphic organizers aid students to determine the main idea of narrative text and central idea of informational text (Williams, 2003). Alvermann (1982) found that students were able to efficiently retrieve and store 
information through the use of graphic organizers. Graphic organizers can aid in comprehension because they provide a non-linear representation of linear text which can help students visualize concepts, which can be especially important for a variety of highrisk readers (Chang, Sung, \& Chen, 2002). Graphic organizers give teachers a way to see what the students know, what kinds of relationships they are making and the ability to correct errors of student understanding, (Clarke, 1991). Graphic organizers aid disciplinary learning in many ways and in the next section research is reviewed that demonstrates this.

\section{Graphic Organizers Aid in Development of Relational Knowledge}

Types of questions found in many middle school textbooks are within the lower fields of Bloom's Taxonomy and Webb's Depth of Knowledge, that is, recall or retell. Questions at the top of Bloom's and Webb's that require deeper thinking skills such as analysis, synthesis or strategic thinking, are less frequently featured resulting in students' inability to understand how facts in textbooks relate to each other. Using, constructing, and implementing graphic organizers during academic instruction will help students learn the basic objectives, and, also, to understand important relationships among them.

Ausubel (1960) in a seminal study found that the use of advanced organizers facilitated the retention of concepts read from passages, provided optimal anchorage, promoted effective initial schema formation and relations, and promoted long-term memory. With regard to visual relationships between central ideas, he found that when students are presented with new concepts without being provided with a background of conceptual information, students use their closest approximate conceptualization of the learning task. Because it is unlikely that students have a clear understanding of new 
concepts being taught, especially in disciplinary classes, the learner tends to use the most proximate and relevant concepts they have that they can associate with the new content. Ausubel (1960) found that it was highly improbable that the students would have an accurate concept of the new content and that "the most dependable way to ensure that students are using appropriate concepts is to provide the appropriate cognitive structure prior to the actual presentation of the learning task." Ausubel showed that cognitive structure has a hierarchical organization; with new concepts being subsumed under broader more inclusive concepts until "learning" occurs. This is continual process students use to refine and assimilated new knowledge. Providing students with a visual representation of how concepts are related allows the student the ability to "draw upon and mobilize relevant subsuming concepts already established in the students cognitive structure making them part of the subsuming entity" (Ausubel, 1960).

Mayer's theory of cognitive learning, (2001), is consistent with Ausubel's findings on the academic benefits of graphic organizers. Mayer's research shows that student's face a constant barrage of information. This information gets filtered through the brain in one of two ways. Either it is of "no importance" to the student, even though it may be the exact concept the teacher is trying to convey, and the student allows the information to pass through their cognition and it is lost, or the student will actively select that information as being important, interesting, or of impact. Once selected, the new information is organized (or subsumed) with current information the student already has about the topic. This process can be strengthened in many ways, one of which is with visual representations. Finally, as the student manages the organizational activity, he or she then has to integrate and store this new knowledge into long-term memory, and so 
learning has occurred. Providing students with a visual representation of important concepts prior to or during learning, helps them visually make the connections needed between the known and the new knowledge being taught so the student can use his cognitive capacity more efficiently to store knowledge into long term memory and facilitate concept retrieval.

Researching the impact of using graphic organizers to achieve relational knowledge from informational text in middle school learning disabled students, DiCecco and Gleason (2002) found the use of graphic organizers showed a significant difference in relational learning. Their study, a pretest-posttest control group design, was conducted in a social studies classroom with middle school learning disabled students. The treatment group received instruction with the use of graphic organizers, while the control group did not. The time frame of the study was four weeks, the instructional format was the same for both groups with the experimental group receiving the graphic organizers showing the relationships among topics on an overhead, while the control group discussed relationships only. The results of study supported their conclusion that the use of graphic organizers aided students with learning disabilities in their recall of relational knowledge. They explained "using graphic organizers to aid student learning is effective in many ways. Students are able to see relationships between and among concepts without having to navigate lengthy or complicated text. The spatial format of a graphic organizer conveys conceptual relationships. Graphic organizers that are presented prior to new or difficult information allow the learner to activate their schemata about the topic which enhances the learning experience. Graphic organizers used during instruction help to refine misconceptions while those used after readings are an effective summarizing 
tool." Although the students showed significantly higher posttest scores on relational knowledge, the graphic organizers did not appear to aid the students in recall of factual information. DiCecco and Gleason (2002) suggest that graphic organizers should be coupled with the use of verbal rehearsal strategies that promote memorization. Reciprocal Mapping uses graphic organizers with collaboration giving students opportunities to verbalize the content.

Additionally, Clarke (1991) suggested that by using graphic organizers such as an inductive tower, students can more easily connect factual statements and draw inductive inferences, a task that is often difficult for students, and give them the ability to assemble information for predictions. Gallavan and Kottler (2007) noted that graphic organizers in social studies classrooms expand critical and higher-order thinking skills, especially analysis, synthesis and evaluation.

\section{Graphic Organizers Focus Students on Central Ideas}

In addition to aiding students identify relationships between and among ideas, graphic organizers can help student to focus on the main ideas of text. Novak (1990) developed concept maps, a type of graphic organizer, based on Ausubel's (1960) assimilation theory of cognitive learning. The primary function of concept mappings is to help the learner focus on the main idea of narrative text and the major concept of informational text. Two studies based on Novak's (1990) concept maps using two different types of graphic organizers found that their primary function is to focus the students on the selection of the main idea and key words of text, while the second study depicted main ideas and informational concepts in a post organizational knowledge map. 
Chalarut and DeBacker (2004) posit that creating and using graphic organizers in learning activities serve to focus students' attention on relevant information in reading passages. In this study, 79 English language learners (ELL) students ages 15 to 22 at a second language learning center in the Midwestern United States, were randomly assigned to a concept mapping group, (the experimental group) and an individual study plus discussion group, (the control group). Materials used for the study were informational passages ranging in length and difficulty that ELL students normally use for instruction. After 4 weeks, the participants were given an achievement test developed to assess understanding of the five passages. Results from a split-plot analyses of variance showed there was a main effect for the concept mapping group over time than the individual study group. The authors contend that use of graphic organizers helped both with relational knowledge but also served to focus the student's attention on relevant information in the informational reading passages to a greater extent than individual study and discussion.

The second type of graphic organizer similar to Novak's concept mapping is knowledge maps that emerged from the work of Chmielewski and Dansereau (1998) which specify the display of key ideas as well as relationships between the key ideas using nodes to show directionality. Hall, Hall and Saling (1999) found that when students were asked to write down main idea and concepts from reading material while viewing a copy of the structure of the knowledge map, scored significantly higher than students who did not. In this study, Hall, et al. (1990) had 90 participants from a medium-sized public university participated in the study with half the students in the control group, which only read the passage, and half in the experimental group that read and put the 
main ideas and concepts on the knowledge map. Both groups took a free-recall test based on the information that had read and studied, but not their general knowledge of the content. Results of the ANOVA showed a significant effect size for the experimental group which the authors say demonstrates that the graphic organizer aids students to select and focus on main idea and concepts from their reading.

Additionally, semantic maps a type of graphic organizer that resembles a sun with rays coming out of it, (Graney, 1992) actually put the main idea or key concept in that central area with words, ideas, and other items linked around it. This type of graphic organizer and its obvious placement as the center of this type of organizer, forces the student to either find the main idea or concept or find supporting details about the main idea or concept. Kim, Vaughn, Wanzek, \& Wei (2004) in a research synthesis, found the use of semantic organizers improves students' comprehension skills.

\section{Graphic Organizers: an Efficient Way to Help Retrieve and Store Knowledge}

Graphic organizers have been shown to be an effective tool to aid students see relations between ideas and concepts. Graphic organizers also help students hone in on the most important ideas and concepts in both narrative and informational text. Graphic organizers are also helpful for students to use to effectively retrieve information and store facts in long term memory. O'Donnell, Dansereau and Hall (2002) note that students have to concentrate on the most relative information in the text as they construct or use graphic organizers, and that the concentration alone increases ability to recall. Studies have examined how graphic organizers can help students retrieve information from memory because of the relations that they formed during the reading process. It appears that when stored in memory, the relational connections aid in efficient retrieval. 
Robinson, Katayama, Dubois and Devaney (1998) investigated the use of graphic organizers as a study aid for tests with 110 undergraduate psychology students in a state university using a $3 \times 2$ design. The first variable was study materials with text only, text plus outlines, or text plus graphic organizers with the second variable being study occasion. The material was a 6,500-word text on abnormal behavior taken from an undergraduate psychology textbook. Results from the ANOVA showed that the main effects of text-plus-graphic organizer to be significant. Robinson et al posit that since graphic organizers are stored in memory in a spatial format, it allows for easier recall because of the type of processing that graphic organizers encourage. Graphic organizers allow students the opportunity to learn concept relationships and text structure rather than a series of surface facts.

\section{Graphic Organizers Aid Students of Varying Abilities}

Graphic organizers have been shown to increase relational knowledge, focus on central content, and helps store knowledge in students of all ages. Graphic organizers may also be of special help for students with a variety of abilities including exceptional education students, high-risk readers, and English Language learners.

Horton, Lovitt and Bergerud (1990) in a study that investigated the effectiveness of graphic organizers for three classifications of secondary students in heterogeneous content area classes: exceptional education, remedial, and general education students. Their study composed of three experiments, the first a teacher-directed graphic organizer treatment, the second a student-directed graphic organizer with text references and the third a student-directed graphic organizer with a list of clues. For the purpose of this 
study, the results for the high-risk readers and exceptional education students were of specific interest.

Participants for the experiments were three middle school science and social studies classes and three high school social studies classes. Two of each of the three classes were experimental classes, one self study treatment, one graphic organizer treatment, and the 3rd class was the control, or neutral group. Materials for each of the three experiments were content area textbooks from which reading passages were selected that started with a major heading; the lengths of the reading passages across textbooks were within 50 words in length of each other.

Since the purpose of the self-study group was to see how well students could read and comprehend the selected text, no formal training was given to them. They were instructed by the teacher to read and reread the passage for 15 minutes, study the passage in a manner of their own choosing, for example, the students could make a diagram or outline, write study notes, make questions, define key word, or use the glossary; as long as they worked independently, did not write in the book or passage or end up with a written product, and then complete the 15-item student graphic organizer and take the test. This group did not have a specific amount of time to study the graphic organizer, it was considered part of the independent study process and included in the time of treatment.

The teacher-directed graphic organizer group began the same as the self-study group, reading and rereading the passage for 15 minutes. Students were given the same blank graphic organizer as the self-study group, but the teacher directed the completion of the graphic organizer during the whole group session as each student completed their 
own organizer, modeling it on the teacher's whose was visible to the whole group on the overhead projector. This group then studies their graphic organizer for 5 minutes and took the test. Both groups were given 10 minutes to take the test.

The researchers noted that the direction and magnitude of change between treatments was similar for the exceptional education group, so scores were pooled for the analysis. The teacher-directed graphic organizer group scores were significant for the exceptional education group who averaged $73 \%$ correct with teacher-directed and $30 \%$ correct for self-study. Results for the remedial students also significantly favored the teacher-directed group of the self-study group. Remedial students averaged $80 \%$ correct with teacher-directed and 39\% correct with self-study.

The purpose for the second experiment was to determine if the effects of the first experiment could be replicated but with student-directed graphic organizers that had specific directions where to find the answers in the text, so it was a more independent activity. The second group was the self-study group and reading comprehension was the assessment. As in the first experiment, the teacher gave directions, students read the passage and completed the maps with the written directions. Results for the second experiment were again pooled due to the consistency in the direction and the magnitude of change between treatments for the exceptional education students. The studentdirected graphic organizer with text references scores were significant with the exceptional education students scoring $71 \%$ correct with the graphic organizers and the self-study group scoring 19\% correct. The mean performance of the remedial students was significantly higher than that of the student-directed graphic organizer with text 
references than with the self-study group. Remedial students answered $75 \%$ correctly with graphic organizers and $44 \%$ correctly with self-study group.

The purpose of the third experiment was to investigate the effectiveness of a variation of a student-directed graphic organizer where students were provided a list of clues that contained the facts and ideas they would need to complete the organizer, rather than the specific page and paragraphs provided in experiment two, compared to the selfstudy group. Participants were middle school social studies and science classes and high school health classes who were exceptional students or in general education, however the investigators did not include the remedial group in this experiment. Since the present study was interested in exceptional education students and high-risk readers, the results of experiment three were not taken into consideration except to note that the exceptional education students using the student-directed graphic organizer with text references over self study was significant, with students in this group scoring $67 \%$ correctly while the self-study group scored $10 \%$ correctly.

This study showed that both exceptional education students and high-risk readers performed significantly better on follow up tests in content area subjects when using graphic organizers than those who were self-study students. Perhaps more significantly was the fact that all three types of graphic organizers were delivered in a typical, heterogeneous, content area classrooms found in the majority of school districts. Also of significance is that the content was taught to all participants without separating the exceptional education students, watering down the curriculum, using atypical texts or instruction sequences. It is worthy to note that a specific instructional tool, graphic organizers, can be used effectively in a typical school setting with success. 
Additionally, DiCecco and Gleason (2002) found that the use of graphic organizers aid learning disabled students with relational knowledge and recall of social studies concepts. Students' scores showed they were able to retrieve relational knowledge because they used graphic organizers during the learning phase of concept acquisition. DiCecco and Gleason (2002) note "the graphic organizers group of students were able to retain and recall significantly more relational knowledge and to apply this knowledge by responding with relevant statements." DiCecco and Gleason note that the explicit instruction was likely a factor in the experimental group's success with the graphic organizers as well as the fact that the graphic organizer facilitated the content knowledge acquisition by the exceptional education students.

A growing number of English Language Learners (ELL) have entered classrooms. Florida has the fourth highest number of ELL's in the United States, (Batalova, \& McHugh, 2010). ELL population in the county of the study grew from $.9 \%$ in the $2000 / 01$ school year to $9.2 \%$ in $2011 / 2012$. It is hypothesized that these students would benefit from the Reciprocal Mapping intervention, in a similar vein to results of experiments using graphic organizers.

Koumy and Salam (1999) investigated the effects of three types of graphic organizers use on the reading comprehension of college freshmen English in Foreign Language (EFL) classes over a five month intervention study, using a pretest posttest design. Students were randomly assigned to one of three treatment groups, teacherinitiated mapping, student-mediated mapping, and teacher-student interactive mapping. Participants were randomly divided into the three treatment groups and used the intervention one hour a week during the regular English classes for a five week period. 
Materials were a variety of informational reading passages that averaged 800 words. Pretest and posttest instruments were the Test Of English as a Foreign Language (TOEFL), Model Test One as the pretest.

As with Horton, Lovitt, and Bergerud (1990), the researchers wanted to see what students would do without teacher intervention. Students were instructed on the use of the graphic organizers in three different ways. In the teacher-mediated group, the students were asked to copy the teacher's drawn organizer from the board, study it and then independently read the passage. Upon completion, students added new information gained onto the map. In the student-mediated condition, students received training in the use of the organizer the week prior to the start of the experiment. During the experiment, the students followed the same procedures as teacher-mediated, but it was done independently, with no teacher model on the board. In the teacher-student interactive condition, the teacher worked directly with the students first to activate background knowledge about the topic by asking questions. The information was then organized onto the organizer on the board. Each student read the passage independently and were to ask the teacher if they had questions about the content. Finally, the new information gains from the passage were added to the map. All students then took the posttest, TOEFL Model Test Two of reading comprehension.

Data were analyzed using a one-way analysis of variance and a t-test at the .05 level of significance. Results showed that all subjects scored equivalently, and that the results were relatively poor, the researchers posited that this result was probably due to students being taught to read at the decoding level, rather than reading for meaning. On the three experimental results, students in the teacher-student interactive group scored 
significantly higher than both the teacher-initiated and student-mediated groups. The researchers explained that activating students' prior knowledge was important in the results. Additionally, students in the teacher and student mediated group engaged in dialog about their prior knowledge with that of the teacher, which built upon their store of knowledge before reading the passage, which is one of the major strengths of graphic organizers as discussed in this review. Finally the teacher-student interactive strategy was successful due to the actual interaction between the teacher and students dialog during the whole lesson, not only with the activation of prior knowledge. Two important outcomes are noted here. With ELL students, (a) teacher modeling of the map, the recursive process that the teacher and the students used to build and refine knowledge during the reading and (b) the actual use of the graphic organizer impacted positively on student learning. Chularut and DeBacker (2004) investigated the effectiveness of concept mapping as a learning strategy with ELL students on achievement, self-regulation, and selfefficacy versus individual study plus discussion group. For the purpose of this study, the results of the achievement of concept mapping with the use of graphic organizers is of interest. Seventy-nine students who attended a center for learning English on a university campus in the Midwest participated in a study that lasted four weeks. Students ranged in age from 15 to 22 years with approximately half high school students and half college undergraduates. Participants represented four levels of English proficiency: 19 students were beginners, and 20 each at the intermediate, advanced, and expert levels. Students were randomly assigned to the two experimental groups, 40 students to the concept mapping group and 39 to the study plus discussion group. Students were given an 
achievement test to serve as a pretest, which consisted of reading passages and multiple choice items.

The individual study plus discussion group studied the same five passages in the same sequence as the concept mapping group. However, their instructional routine was a commonly encountered session that included preteaching the vocabulary, instructor help during the reading of the passage, and a 30-minute whole group discussion of meanings and implications after reading was complete. During the reading phase, students were encouraged to use any study strategies that they were familiar with and were able to ask the instructor for help as needed. Posttests were administered week four over two sessions in the same manner as the pretest.

Chularut and DeBacker (2004) conducted split-plot analyses of variance to determine results using an $x$ level of .05 which resulted in a significant main effect for method of instruction for concept mapping higher than the individual study plus discussion group. The concept mapping group showed greater gains over time, 35 percentage points than the individual study plus discussion group who scored 20 percentage points, with the lower proficiency groups scoring higher, 22 percentage points, that the higher proficient group, 22 percentage points.

Chularut and DeBacker's (2004) study demonstrated that using concept mapping, a type of graphic organizers, students were able to comprehend reading passages more effectively than the study only counterparts. Of interest to the current study is that even with a 30 minute explicit lesson on the use of the concept map, students were able to show significant gains in reading comprehension of informational text over teacher led discussion. The use of the graphic organizers have shown that students are able to 
comprehend and remember more effectively than student who are taught with traditional approaches. It appears that the construction of the graphic organizer facilitates learning for exceptional education students, high-risk readers, and English Language Learners.

\section{Graphic Organizers Provide a Window into Students' Thinking}

Teachers need to be able to continually assess their students' knowledge acquisition, both to ensure learning is taking place and, perhaps, more importantly, to be able to address misconceptions as quickly as possible. The sooner a teacher can "unpack student thinking" (Mackinnon \& Keppell, 2005), the sooner they can redirect and reteach the concept.

Mackinnon and Keppell (2005) in a study with 90 college teacher-study undergraduates who worked on creating concept maps during instruction with each other and with the maps being viewed by the whole group, found that the maps provided a framework for the students and the instructor to address misconceptions right away. In an interview with the participants, Mackinnon and Keppell (2005) notes the following types of statements:

- 'Scaffolding students' learning is important, but I can't do this effectively without knowing the way students think.

- "The concept map lets me as a teacher get inside the student's head".

- "I can see where their thinking is going when the students articulate their understanding in a drawing".

Mackinnon and Keppel (2005) note that as the teacher sees the same types of mistakes the students consistently make, particularly conceptual connections, the 
emerging maps being co-constructed allows the teacher to adjust their instructional sequencing, or change the manner in which they introduce or teach the topic initially.

\section{Vocabulary}

Vocabulary has been noted to be among the chief culprits barring the way for students' success with informational text (Beck, McKeown, \& Kucan, 2002; Hall \& Sabey, 2007; Nagy, 1988; Palmer \& Stewart, 2005). Chall (1983) further observed these demands increase across content areas and spiral up through the higher elementary grades and on into middle and high school. Vocabulary plays an important role in a student's ability to understand text. There is a long-standing acknowledgment that vocabulary knowledge strongly influences reading comprehension. Comprehension can dramatically decrease if a reader skips or ignores unfamiliar words that seem difficult, (Hall \& Sabey, 2007). However, exposure to and understanding of new vocabulary is of major importance in the selection and reading of informational text for students. The NRP (2000) noted the importance of vocabulary in the development of reading comprehension citing Whipple's (1925) research that found that growth in reading power means continuous growth in word knowledge. Vocabulary is critically important in the development of reading comprehension. In order to enhance comprehension of informational text, students need to be able to make meaning of new words. (Bos, Anders, Filip, \& Jaffe, 1989). Lyda and Duncan (1967) found that high-risk readers made gains if they were pre-taught vocabulary before they began their reading.

Content area vocabulary is especially difficult for students to master. Because the language used in these specific domains is so specific, many students, especially highrisk readers and English-language learners, have difficulty learning content (Brozo, 
2010). Fang, Schleppegrell, and Cox (2003) specifies several reasons why content area vocabulary is so difficult: the vocabulary itself is technical, sentence length is often long and complex, nouns are abstract and lengthy, passive voice is used, confusing subordinate clauses and a variety of difficulties with how proposition, conjunction, pronouns and ellipsis are used. Fang (2006) notes that while social studies teachers can offer students ways to make history "come alive," due to abstract concepts and interpretations needed to master historical thinking, students need language resources, especially high-risk readers and English language learners. Students need to be able to master social studies specialized vocabulary, grammatical patterns, typical genres and rhetorical traditions.

In a mixed-method study conducted by Wood, Vintinner, Hill-Miller, Harmon and Hedrick (2009), teachers' concerns about vocabulary instruction were addressed. They asked 390 middle school teachers in three different states were asked what skills they needed to teach vocabulary more effectively. The results of teacher responses were compared with three pre-service literacy methods textbooks to compare if what the teachers felt were important were contained in the textbooks. No explicit instruction was found on how to teach vocabulary. However, teachers' concerns were addressed indirectly within the chapters in the textbooks, but not directly taught or in a specific chapter. Preservice teachers wanted more specific information regarding why, when, and how to teach vocabulary strategies. The authors determined that preservice teachers need to be explicitly taught the strategies, how to use the strategies in content area classes and also when to use the strategies. 


\section{Building Background Knowledge}

Background experience or prior knowledge, knowing that comes from previous experience has been identified as being a critical component in comprehension according to schema theory (Anderson \& Pearson, 1984) but in practice it is rarely addressed outside of assessment (Fisher \& Frey, 2009; Kamil, Borman, Dole, Kral, Salinger, \& Torgesen, 2008). But, it is an essential component of attaining new knowledge. According to Anderson and Pearson (1984), schema theory explains that new knowledge must be connected to existing knowledge. Keene and Zimmermann (2007) found one of the most effective ways to improve reading comprehension is to activate a student's prior knowledge before reading new or difficult text. Fisher and Frey (2013) noted that background knowledge mediates how and the extent to which other reading comprehension strategies are used. Alfassi (2004) stated that the more extensive a reader's background knowledge is, the easier it is to acquire new information offered by the text.

Brozo (2010) commenting on the importance of prior knowledge, on his studies on the relevant recent advent of Response to Intervention (RtI) programs, notes that "four decades of research in reading comprehension support the primacy of relevant prior knowledge." Brozo also asserts that reading is domain specific, as evidenced by the "so called" fourth-grade slump; saying that while children in the younger grades who do acquire reading skills are often unable to transfer those skills to content text because of the relevant prior knowledge for that content. He says the "force of domain-specific knowledge on comprehension cannot be dismissed." 
Strangman and Hall (2004) note that "by far, the most frequent curriculum application of interest for studies of background knowledge is content-area reading." The majority of the students cited by Strangman and Hall explored outcomes relating to reading informational text with a narrow range of subjects in science, social studies and reading. Langer's (1984) findings suggest that a student's background knowledge is a significant and reliable predictor of passage-specific comprehension, perhaps more so than reading ability.

One of the most crucial processes during comprehension is the students' ability to activate their schema, or background knowledge, in order to cement new knowledge with previously learned concepts. Cakir (2008) suggests the importance of the classroom teacher in providing background knowledge for students, especially with informational text. Cakir suggests pre-reading, including activities for different types of texts, helps activate appropriate schema in learners.

\section{Reciprocity of Literacy Processes}

Two strong connotations of the reciprocal nature of learning are prevalent in reading research literature. Perhaps the clearest and most evident is the reciprocity in the broad realm of language arts, reading, writing, listening, oral language, viewing and visually representing; but more specifically between the reading and writing, decoding and encoding process. The RAND Reading Study Group (2002) defined reading as the process of simultaneously extracting and constructing meaning through interaction and involvement with written language.

Effective teaching research has shown that language arts, i.e. listening, talking, reading, writing, viewing and visually representing, should be taught simultaneously and 
reciprocally; that there should be no division among them and should be taught and practiced together (Lapp, Flood, Brock \& Fisher, 2007). Loban (1976) documented the language growth and development of a group of 338 students from K-12. Loban was researching how speech, reading, writing were correlated. Three of Loban's findings are especially noteworthy; positive correlations among listening, talking, reading and writing; students with less-effective oral language abilities tended to have less-effective written language abilities; there is a strong relationship between students' oral language ability and their overall academic ability. Loban's study demonstrates a clear relationship among the language arts.

Bear, Invernizzi, Templeton and Johnston (2000) call literacy a braid of interwoven threads, with reading, oral language, writing and orthography twisting together which yields literacy. Teachers must know how to direct children's attentions to the relationships about the way these literacy braids weave together to produce language. Central to the crux of the reciprocity of reading and writing is evidenced in decades of research in the development aspects of word knowledge with children that have documented the "convergence of spelling errors in clusters that reflect children's confusion over certain recurring orthographic principles.” Bear et al. (2000) elaborate that the "harmony in the timing of development is a synchrony of reading, writing and spelling development."

Butler and Turbill (1984) and Bear et al. (2000) have similar graphic organizers showing the synchrony of literacy development that are similar. Butler and Turbill (1984) note five stages of the interrelatedness of reading and writing. Their comparison looks at what readers and writers $d o$ during the iterative process and reading and writing; 
processes such as prereading/prewriting, reading/drafting, responding/revising, exploring/editing and applying/publishing. The end product of both reading and writing processes is to construct meaning which is a recursive process between the two. Bear (1991) saw the link between fluency and orthographic knowledge as a relatively new connection at the time. The link though, suggests an integrated model of literacy development where there is a synchrony in development among reading, writing and spelling.

Goswami (2000) notes that phonological and lexical development have parallels and that research suggests that phonological development may be closely connected to lexical development. Goswami found that "phonological awareness is tied to the quality of the representations of words that children have in their mental lexicons and that the quality of these representation at the speech-based level, seems to be critical for reading development."

Barone and Morrow (2003), say that young children "once viewed as preliterate, are now more widely perceived as emergent readers and writers. There is no formal time in which literacy acquisition begins; rather, a recursive fluid process of literacy development takes place from the time children are born."

Treiman and Rodriguez (1999) found that young children search for "systematic relations between print and speech from an early stage" from a study conducted with preschoolers and kindergarteners. The study further found that young children can begin to grasp the relationships between what they hear with how the word looks and that the young learners actively seek to make sense of the writing system. 
Juel and Minden-Cupp (2000) in research on effective teaching strategies for 1st grade instruction to learning to read words, note that when children use invented spelling or "writing for sounds" it appears that when children process both the writing and segmentation of sounding out the word simultaneously, it promotes both letter-sound knowledge and phonological awareness. They say that "learning to read and write involves attending to these sound units and connecting them to spelling patterns." Juel and Minden-Cupp (2000) noted that children who have middle-range literacy skills when entering 1st grade, benefited from a classroom with more trade books and time for writing text in learning to read.

Allington (2002) commenting on what the NRP did not consider among the most important pillars of scientific reading instruction says that writing and reading have reciprocal positive effects and should be considered absolutely essential when considering scientific reading instruction. The more integrated and transparent the reading/writing, composing/comprehending, decoding/encoding processes are to students, the more effectively will they take advantage of the "natural reciprocity" between and among the reading and language processes.

Wallace, Pearman, Hail and Hurst (2007) note that many teachers continue to treat reading and writing as separate content area subjects. However, reading and writing are considered to be interrelated; both reading and reading are strongly interconnected. Using writing to help students connect with text will increase their comprehension of text - whether it is fiction, nonfiction, or content area textbooks.

Brozo (2010) commenting on the dichotomy between learning to read and reading to learn, comments that this idea "must surely be put to rest. Whether about the structure 
of language or the structure of a molecule, about what motivates a main character or what motivates a political leader, about places in the heart or places in Africa where French is spoken, all reading is learning” ( p. 149). With the changes in federal laws, specifically ESEA (2001) and IDEA (2004), it is imperative that educators realize that the reciprocity in the language arts in general, listening and oral communication, and reading and writing specifically is a mandatory teaching technique in today's classroom.

It is clear that the reciprocity of reading and writing are clearly linked in the beginning instructional phases of both. Fine, (1997) found that "because reading is one aspect of literacy development and writing is the reciprocal process of reading, these cornerstone concepts also impact students' intention to write."

\section{Psychological Frameworks}

\section{Metacognition}

In order for students to take new knowledge to long term memory a number of factors must be present. Students must be active learners. Mayer's (2001) activeprocessing theory states that in order to learn new information the learner must take information already known, from their bank of knowledge in long-term memory, and move it to their working memory. Working memory is limited in the amount of information it can process at any given time. However, when a learner actively selects previously known information and organizes it cognitively with new knowledge being taught, a synthesis occurs where the new knowledge and previously known information combine to create the new, or refined knowledge, which is then stored once again into long-term memory. Active learning occurs when the student applies their cognitive processes to make sense of incoming material and one of its most crucial aspects is that 
the student must make the connections between the word and image-based representations in an integrative process that occurs as the learner continually shifts among the selecting, organizing, and synthesizing during the learning process. Reciprocal Mapping mirrors this process as the student uses the already published material as the scaffold that provides the information that they continually process cognitively by selecting the information individually needed to create the new and long term knowledge as they synthesize the new information with their previous knowledge. The recursive nature of the Reciprocal Mapping activity strengthens the cognitive channels and promotes deep knowledge.

Green and Azevedo (2007) when looking at students who are able to participate in recursive cycles of cognitive and metacognitive activities which is central to learning and knowledge construction, found that those students, who were learning a difficult science concept through the use of a hypermedia learning environment, were more likely to experience a significant positive qualitative shift in their mental models of the content, specifically inference and feelings of knowledge, than students who were taught in a linear, textbook or lecture based instructional model. Inference is typically one of the more difficult reading comprehension activities that high-risk readers and non-English speakers face. Green and Azevedo describe "feelings of knowledge" as a metacognitive monitoring activity that students employ as they realize, during the reading process, that they are familiar with a concept, yet not able to either fully recall or have integrated into long term memory. They assign "feelings of knowledge" with the ability to synthesize new or difficult concepts with previously mastered ones. 


\section{Scaffolding and Vygotsky's Zone of Proximal Development}

Scaffolding, (Wood, Bruner \& Ross, 1976) is a process that enables a child or novice to solve a problem, carry out a task or achieve a goal which would be beyond his unassisted efforts. This definition segues effectively as a bridge between scaffolding and Vygotsky's theory of cognitive learning. Vygotsky's theory includes the zone of proximal development which is the zone in which a student is successful with the help and support of a knowledgeable other. Reciprocal Mapping, at its essence, joins these two theoretical frameworks. The students use the published work of authors, i.e. scaffolding, as they complete the graphic organizer, another scaffold, to create a published work in the company of either peers or through the direct instruction and intervention of the classroom teachers as they work within their zone of proximal development to produce a published work.

Scaffolding instruction, the temporary support given to students as they learn new or difficult information, is paramount in effective reading instruction (Duffy, 2002; Duke \& Pearson, 2002; Palincsar, 2003). It is perhaps one of the single most recommended versatile instructional techniques used in constructivist teaching. Taylor, Pearson, Clark, \& Walpole 2000; Wharton-McDonald, Pressley \& Hampson, 1998 have found that scaffolding is widely used by some of the best teachers. In the same study, it was noted that the most effective teachers used scaffolding to help their students become independent learners; they encourage self-regulation by teaching metacognitive strategies so the student can independently fix problems encountered as they read. Effective schools had teachers who used authentic texts as a way to engage students in reading and writing opportunities. Reciprocal Mapping engages students in the reading of authentic texts as 
they continually return to the published text, select important information, transcribe it to their reciprocal maps in an iterative process that promotes close reading and deep learning.

There is virtually universal agreement that scaffolding plays an essential and vital role in fostering comprehension. However scaffolding is a complex instructional concept and takes many forms. A significant part of the scaffolding process is the gradual release of teacher responsibility for the learning task, moving it, through careful observation and monitoring, to the responsibility of the student. Reciprocal Mapping is a leaning sequence that makes it clear to the teacher the amount of scaffolding needed because of the visual nature of the maps, and its gradual release until the student is able to read the text independently. Clark and Graves (2005) describe three types of teacher scaffolding; moment-to-moment verbal scaffolding, instructional frameworks that foster content learning, and instructional procedures for teaching reading comprehension strategies. Reciprocal Mapping is a type of instructional framework that fosters content learning. This is described as "the teacher's role is to structure and orchestrate the reading experience so that students can optimally profit from it."

Brown and Broemmel (2011) note that while providing ELL students with scaffolding before-, during- and after-reading, it often is seldom sufficient, noting that even successful ELL students struggle with reading comprehension, and are often unable to close the gap between native English speakers and themselves. They suggest instruction based on deep scaffolding which emphasizes the importance of each of the levels of scaffolding on the reading comprehension of ELLs. Deep scaffolding reduces the difficulty of content area text by providing a higher intensity of scaffolding coupled 
with more frequent scaffolding. The process of deep scaffolding mirrors the more common before, during and after comprehension monitoring that native English speakers are taught, but are deeper and more frequently taught during the reading process to increase the likelihood of success. Reciprocal Mapping uses the deeper scaffolding during its iterative process between teacher and student, student and student and student and text.

Fine (2004) found that processing abstract information to place concepts on graphic organizers provides a scaffold for students to internalize meaning. As students construct their reciprocal maps, they are identifying the parts of the text that they consider to be important and are refining their knowledge about how the concepts are related as they develop comprehension and store it into long term memory.

Jonassen and Carr (2000) suggest that when students are able to take advantage of cognitive tools as they learn new or difficult information, they are able to free their cognitive capacity so they can engage in higher-order thinking. This is true for any activity that students can either perform to automaticity, or have a scaffold - they are then able to use the "free space" within the short-term memory, or cognitive capacity to process more deeply the content that is being taught. The graphic organizer that is part of the Reciprocal Mapping instructional routine, would act as the cognitive tool for students; they use the concrete organizer to put the main ideas, supporting details and other relative information which they can then process at a higher level of recall.

Englert et al. (2007) found that scaffolding has been found to be an effective method to use in order to improve learning disabled students' writings. Their study used scaffolding techniques to break down the writing process for learning disabled students in 
order to help them better organize and compose their essays. In Englert's study, the scaffolding consisted of a step-by-step series of prompts, organizers, and questions. At each step the student would check to see if he had covered all the requirements before continuing in the writing. Using a computer scaffolding program Englert noted an increase of $135 \%$ from pre-test to posttest in student's informational text structure, compared with paper and pencil condition, i.e. graphic organizers, who also showed improved scores by 57\%. Again, Reciprocal Mapping would allow students to offload the information from their short term memory to the graphic organizer allowing the cognitive capacity to process more fully the content information.

Holton and Clarke (2006) in a study that mapped the progressive relocation of scaffolding based on the learner's direction during instruction, found that self-scaffolding was an effective way to develop metacognition in the mathematics classrooms through numerical problem-solving. In an earlier study, Holton and Thomas (2002) proposed that this "student self-scaffolding" is essentially the equivalent to metacognition. They say "that the self-interrogating questions of metacognition strongly resemble the prompts of the process that we have termed heuristic scaffolding" The theory behind both scaffolding and metacognitive instruction is for the student to gradually move from social supports, i.e. teacher and peers; to the inner voice, or self-monitoring of behaviors, in this case, learning from textbooks what can be called difficult content concepts. Holton and Clark (2006) define this reconception of scaffolding "as a move from the perspective of multiple agencies by recognizing that the constructive role of peers in the process we have called reciprocal scaffolding and the role of the teacher in scaffolding not only the students' construction of mathematical knowledge, but also the students' construction of 
scaffolding practice, for use in both reciprocal scaffolding and self-scaffolding (i.e. metacognitive contexts). Their study focused on mathematical problem-solving and found the intimate relationship between scaffolding and metacognition is a mechanism that the student can apply in various situations in learning. Scaffolding and metacognition are the same set of actions that are used by the individual to learn; "the external dialogue of scaffolding become the inner dialogue of metacognition." Reciprocal mapping epitomizes this connection across disciplinary classroom instruction as it allows the student to move from the outward support to the inner voice as they navigate connected text in the classroom.

\section{Components of Instructional Routine}

The following components of instruction were used in this intervention study. Explicit instruction was used to teach the Reciprocal Mapping instructional routine. Scaffolded instruction provided a high level of support to students as they developed proficiency in learning and applying the mapping process involved during instruction of the informational text types. Fidelity of implementation and teacher and student affinity to the Reciprocal Mapping treatment measures were important. Gender was of interest for the Reciprocal Mapping treatment. Developing historical literacy in the disciplinary classroom in order for students to become college and career ready, which is key to the CCSSI (2010) previously discussed, was of utmost importance to this study.

\section{Explicit Instruction}

Educational researchers have identified a range of instructional behaviors and elements that characterize explicit classroom instruction which can maximize students' academic growth (Archer \& Hughes, 2011). Explicit instruction is unambiguous and 
includes both instructional design and delivery procedures. Direct instruction is often followed by modeling, teacher and student interaction with targeted content, strategies or processes, and guided practice (Duffy, 2002).

Mason (2004) investigated whether fifth grade struggling readers would perform better with a self-regulated strategy that combined explicit instruction and a selfregulation procedure that helped these readers become aware of the process of learning how to read. The study used informational text passages as students were explicitly taught to integrate and self-regulate the comprehension strategy throughout the reading process. Mason extended the findings of Bednarczyk (1991) in a study that had been proven effective in reading comprehension with narrative passages. The narrative-based study with implemented with fifth and sixth-grade struggling readers and findings indicated that comprehension improved among all of the students. Results from Mason's study with informational text found that students who were explicitly taught the selfregulation reading strategy were significantly more aware of the skill and improved their informational reading comprehension as measured by five oral measures at posttest. While the focus of the study was a combination of explicit instruction with the strategy itself, it was noted that the explicit instruction of the strategy aided in its effectiveness in improving informational reading comprehension performance.

Duffy et al. (1986) conducted two studies that examined whether teachers trained to be explicit when teaching reading comprehension strategies would be more effective than teachers who did not. The first study was with fifth grade students in low-level reading groups and the second was with third graders in similar reading groups. Duffy et al. posited that the focus in "direct explanation" (DE) is on developing teachers' ability to 
explain the mental processes used in successful reading comprehension in an explicit manner would result in higher student comprehension. Students' reading comprehension achievement on standardized tests were also measured. The results of the first study indicated that students of the teachers trained to use the explanation model had significantly greater awareness of strategies taught, why these strategies were important, and how to use them during the reading process than the untrained teachers. However, there was no difference in performance in the standardized test comprehension measure. Duffy theorized the results may be related to the fact that standardized tests may measure aptitude more than application of strategies. But the study did establish a connection between increased teacher explanation and student awareness of targeted skills and strategies.

Since the results of the first study were promising in the gains of the direct explanation model, in the second study, Duffy et al. (1987) included a more elaborate program of teacher preparation. The second study emphasized the effects of training teachers to give student explicit descriptions about the types of mental processes that skilled readers use, as opposed to simply explaining how to perform the skills. Students were given two additional tasks that asked students to use a specific skill and respond to a question about their thinking while using the skill. Students were asked to explain how they determined meaning from the reading passage. Results indicated that there were no differences between students in the two groups, however, the students of treatment teachers were found to have a greater ability to reason strategically when reading. The implication of Duffy's studies suggest that explicit instruction is useful for increasing student awareness of strategic thinking while reading. For the purpose of this study, it 
appears that explicit instruction helps students to develop an understanding of targeted skills which in turn can applied to an classroom instructional routine such as the one described in this study.

\section{Scaffolded Instruction}

Scaffolded instruction, previously described, is a process that enables a teacher to provide the right amount of instruction and the right time. For the purpose of this study, a high degree of scaffolding is used at the implementation stage, with students copying the teacher's examples of informational text types exactly. Once the students are able to replicate the teacher's direct examples, they are able to work in small groups, dyads, triads, or other combinations of grouping as they engage in copying and creating maps from a variety of easy reading materials. Scaffolding continues to be provided at the textbook level because the teacher continues to provide the initial map the student need to as they apply the steps learned to the textbook application. The Reciprocal Mapping instructional routine is a representation of Fisher \& Frey's (2009) framework of the gradual release of responsibility model. (see Figure 1) 


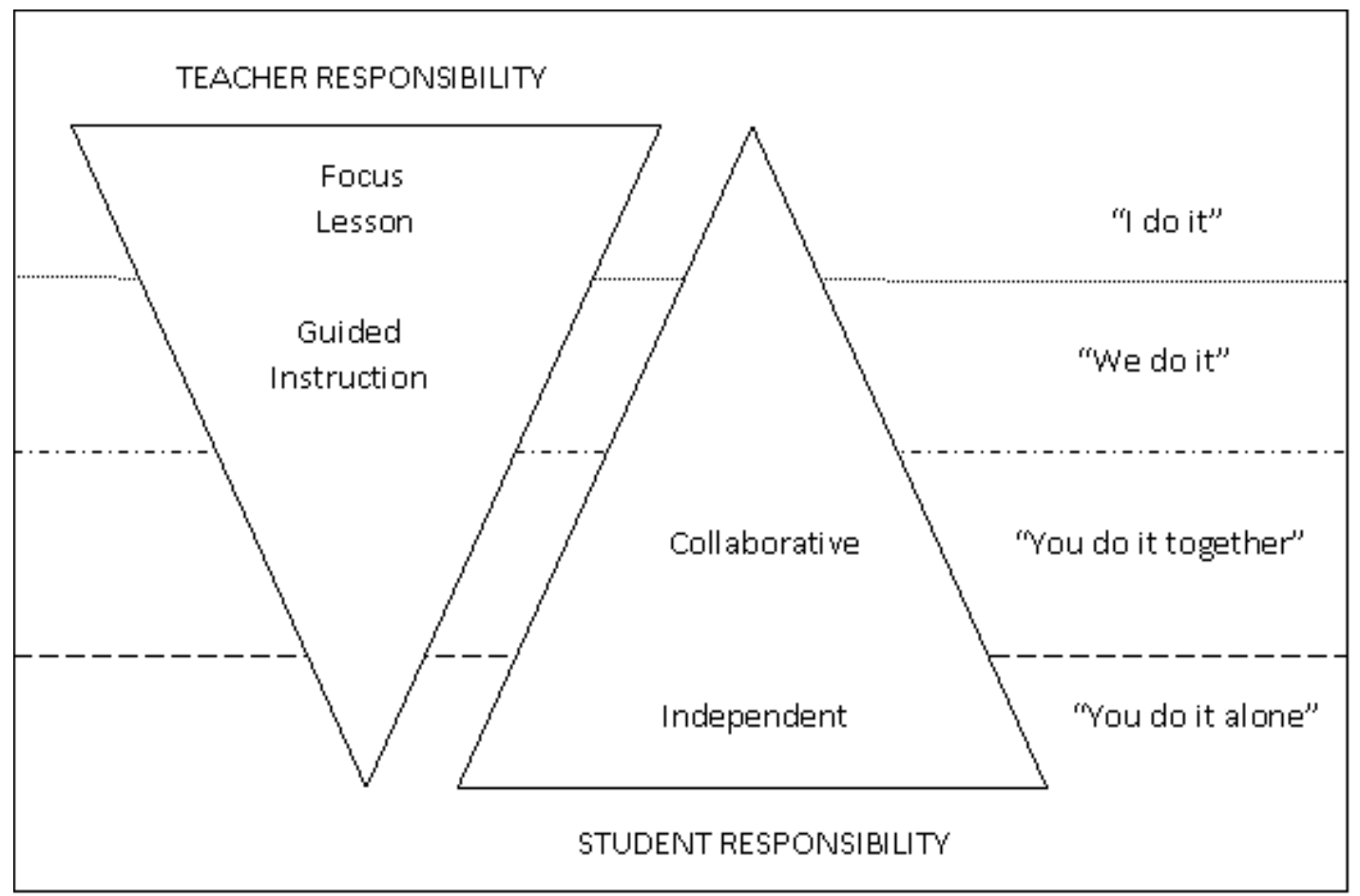

Figure 1. Fisher \& Frey's (2009) framework of the gradual release of responsibility model

\section{Treatment Fidelity}

Fidelity, is the link between evidence-based interventions and changes in student outcomes (Collier-Meek, Fallon, Sanetti, \& Maggin, 2013) was important to include to ensure the testing outcome was based on the Reciprocal Mapping instructional routine intervention in order to attribute the outcome to the treatment. Studies that examine in detail the objectives of the programs and extent of program objectives that are actually implement in the classroom are known as fidelity of implementation (FOI) studies. O'Donnel (2008) generated a list of definitions of FOI, and its equivalent synonyms, to K-12 core curriculum interventions that include:

- "the extent to which the project was implemented as proposed (or laid out)"(Loucks, 1983, p. 5). 
- "a measure of the basic extent of use of the curricular materials. It does not address issues of instructional quality. In some studies, implementation fidelity is synonymous with 'opportunity to learn"” (NRC, 2004, p. 114).

- "to implement it [an already developed innovation] faithfully in practice that is, to use it as it is 'supposed to be used,' as intended by the developer"(Fullan, 2001, p. 40).

- "the extent to which the project was implemented as originally planned" (Berman \& McLaughlin, 1976, p. 350).

- The extent to which the program components were implemented (Scheirer \& Rezmovic,1983)

- The extent to which teachers enact innovations in ways that either follow designers' intentions or replicate practices developed elsewhere, or the "extent to which the user's current practice matched the developer's 'ideal"' (Loucks, 1983, p. 4).

The researcher had to make certain that the Reciprocal Mapping instructional routine was implemented correctly, that is to be implemented "faithfully in practice - to use it as it is 'supposed to be used,' as intended by the developer" (Fullen, 2001, p. 40). There are not many FOI studies in the education field; it appears that researchers in the field of health who first developed and refined approaches to assessing and characterizing FOI and that point out the complexity and multidimensional nature of FOI (Sen, 2011).

Dane and Schneider (1998) and Dusenbury, Brannigan, Falco, and Hansen (2003) reviewed studies on prevention programs and found most studies did not measure "program integrity" but the ones that did, measured characteristics such as adherence, 
exposure, quality of delivery, responsiveness, and program differentiation. Through their studies, Dane \& Schneider were able to bring consensus and definition of five aspects of FOI that, while the later researchers revised, the essential meaning of the wording of Dane \& Schneider was not changed. Dane \& Schneider's five aspects of FOI that have been measured on diverse evaluation studies are: (1) adherence, (2) exposure, (3) quality of program delivery, (4) participant responsiveness, and (5) program differentiation. These researchers suggested that all five of these characteristics should be measured in order to understand the integrity found in the intervention and are now widely used in fidelity studies in the field of education.

A conceptual framework to measure FOI of instructional implementation was developed by Century, Freeman, and Rudnick (2008) based on the aspects suggested by Dane \& Schneider (1998). Mowbray, Holter, Teague, and Bybee (2003) defined FOI as the "extent a program is consistent with its intended model" and identified a working set of critical components in mathematics and science instructional materials that would help in measuring FOI.

\begin{tabular}{|l|c|c|c|}
\hline \multicolumn{3}{|c|}{ Categories of Critical Components } \\
\hline \multicolumn{2}{|c|}{ Structural Critical Components } & Instructional Critical Components \\
\hline Procedural & Educative & Pedagogical & $\begin{array}{c}\text { Student } \\
\text { Engagement }\end{array}$ \\
& $\# 3, \# 4, \# 5, \# 6, \# 7$ & $\# 2, \# 3, \# 6, \# 7$ & \#1, \#4, \#5, \#7, \#8 \\
\hline
\end{tabular}

Figure 2: Critical components measuring FOI based on (Century et al, 2008; Dane \& Schneider, 2008). 
In developing the Fidelity of Implementation instrument for this study, Appendix D, Fine (2007), incorporated these aspects. The categories in the above framework include the structural critical components, which are the developers' decisions about the design and organization of the printed materials. These are further subdivided into procedural and educative components. The procedural components are procedures of the instruction and physical organization of the program. Educative components are expectations about how to structure and organize the information for teachers or their expectations of what the teachers need to know in order to use the program as intended.

Instructional critical components are expectations about teacher and student interactions during the actual classroom instruction. Pedagogical components reflect expectations about the instructional strategies teachers use in the classroom. Student engagement components include the student participation in the instructional process.

Fine's Fidelity of Implementation of the Reciprocal Mapping instrument characteristics fall within each of the above components as follows:

- Characteristic 1: has set to interest students on social studies topic of study.

- Characteristic 2: has allowed students to read trade books on topic prior to beginning textbook.

- Characteristic 3: has explained the concept of text structure and signal words.

- Characteristic 4: has provided guided practice in identifying the text structure and students; ability to put information on a map.

- Characteristic 5: Materials: has provided text that matches the type of text structure being studied. 
- Characteristic 6: has identified vocabulary words that might be used on students' Reciprocal Mapping map and text.

- Characteristic 7: has explained writing process and read and given feedback to support the students as they write informational artifact.

- Characteristic 8: has supported the presentation of informational artifact of student's social studies writing.

By collecting and measuring data to determine the fidelity of implementation to the Reciprocal Mapping instructional routine, a comprehensive picture of the fidelity of the program for the needs of this study, was provided, and it can be assumed that the results of the measures was directly the result of the Reciprocal Mapping instructional routine.

\section{Teacher and Student Affinity}

Teacher and student affinity, the degree to which the teacher and students like the strategy and are willing to engage with the strategy, are important because it is related to motivation to engage in the activities that are integral part of the treatment. For instance, teachers tend to teach what they like, and students tend to work hard on activities they like. Researchers have found that learning in school is more than "cold cognition" or simply "information processing" (Pintrich, Marx, and Boyle, 1993). An array of variables are involved which include personal choice, individual needs and motivational beliefs. Turner and Meyer, (2000) found that the perceived psychological climate or structure of the classroom contributes immensely to how both learning and motivation occur in academic settings. Examples of students' perceptions of a supportive classroom environment are linked to the well-being (Colarossi and Eccles, 2003), motivation and 
adjustment (Eccles, 1993), and achievement (Roeser, Eccles, and Sameroff, 1998). All of these variables would be important to ascertain for this study to ensure that students felt comfortable with the intervention being presented to them in their instructional setting.

\section{Engaging Male Readers}

There is a disparity between boys and girls in reading test achievement, Brozo (2010) notes that the 2000 PISA exam showed that girls outperformed boys in reading by an average of 32 points. "To put this number in perspective, Brozo says that the point difference is equivalent to a year and a half difference between boys and girls in reading achievement. These gaps may be due to a number of reasons, but Brozo says that there are practical ways to encourage boys to read, including giving them a variety of selections that they can choose from, reading to and with boys, and offer a wide range of informational text, which is often a preferred choice for boys. Irwin, (2003) found that boys read better with "clear, structured instruction, short bursts of intense work, specific goals, praise, hands-on learning, and use of humor. McFann (2004) interviewed Joe Scieszka, an author of books geared for boys, creator of Guys Read, a web-based literacy program for boys whose mission is to help boys become self-motivated, lifelong readers, suggested that boys need to know that nonfiction reading is reading. "Magazines, newspapers, websites, biographies, science books, comic books, graphic novels are all reading material."

Bearing these suggestions in mind, the Reciprocal Mapping instructional routine provides boys with many of the alternatives mentioned. First of all, the reading material associated with the routine, is by default, informational text. Many of the types of reading that Scieszka mentions are an integral part of the instructional routine, including but not 
limited to magazines, Internet websites, biographies, social studies books, and contentbased connect texts. Another aspect of the Reciprocal Mapping instructional routine follows Irwin's suggestions of hands-on learning, structured and explicit instruction, with short bursts of intense work. It is with these leading suggestions that the researcher sought to question whether the Reciprocal Mapping instructional routine proved to be statistically significant in the posttest scores.

\section{Developing Historical Literacy}

With the inception of the Common Core State Standards in all but five states, disciplinary teachers joined English Language Arts teachers in preparing students to read and comprehend informational texts. The Common Core State Standards have situated literacy directly in the content area classrooms as the emphasis on reading has focused on close reading of complex texts where students will be asked to read critically, make judgments, and support their ideas. All students will likely be challenged by the high standards Common Core State Standards bring, but especially high-risk reading students, who already struggle with informational text. And since the demands on background knowledge accelerates as students progress through the grades, it becomes ever more important for students to activate and apply previously learned concepts in novel ways (Fisher \& Frey, 2013). Goudvis and Buhrow (2011) have worked with adolescent students in the social studies classrooms and have noted that instruction in reading and thinking strategies has produced more engaged and active readers, but they noted that a focus on comprehension instruction in the disciplinary classrooms is needed. Pearson, Moje and Greenleaf (2010) argued systematic attention to reading and writing in disciplinary classrooms is not implemented, especially in the various disciplines, students 
will graduate from school with an "impoverished sense of what it means to use the tools of literacy for learning" (p. 460).

Juel, Hebard, Haubner, and Moran (2010) suggest that students use "a disciplinary lens" as they focus and refocus on nuances of the informational text they read (and write) in the disciplinary classrooms. The authors use the analogy of the lens to indicate that students are looking at text from both the standpoint of a reader, i.e. comprehension, and as a scientific/historical reader questioning and wondering about concepts in text that they read in the disciplinary classroom. The authors state there are two crucial reasons to include these disciplinary frames in classroom instruction reading comprehension and the inclusion of technology in disciplinary classrooms. Regarding reading comprehension, the authors state that "disciplinary habits of mind can extend students reading comprehension by providing scaffolds for thinking." This is important for students to be able to look at a variety of information on a single topic and to be able to select literary evidence that supports instructional concepts. The second reason, technology in the classroom follows the comprehension closely - how does a student know what to believe and how do they evaluate information found on the Internet? The authors state that student need to know the standard for evidence in a given disciplinary arena are based on evidence. The authors suggest that when students look at informational text through a disciplinary lens the practice of the specific content area, for the purpose of this study, history, is a "profoundly literate activity" and one that allows students to think like a historian and a writer, both activities support the development of critical literacy that is demanded in today's classroom. 
Levstik and Barton (2001) support the idea that the disciplinary classroom is an ideal place to integrate disciplinary concepts, again, for the scope of this study, social studies and examined ways that teachers can integrate literature, art, writing, discussion, and debate, all of which are components of the language arts curriculum while investigated authentic historical issues and concepts. Levstik \& Barton suggest that disciplined inquiry can provide students with an in-depth understanding of historical concepts rather than memorizing dates and names. They believe the authentic historical investigations deepen understanding of the curriculum while strengthening students reading and writing skills.

Zarnowski (2006) believe that good instruction of social studies concepts should include historical thinking, historical literature, and hand-on experiences. Historical thinking continues Jeul et al (2101) and Levstik \& Barton (2001) ideas that students can learn to use the familiar, that is events that happened in their own histories, their families, or with current events with unfamiliar contrasts that they encounter in social studies books. They suggest using "thought experiments" to answer questions provided by the teacher, but also ones that the student themselves think about as they encounter new information. Historical thinking acknowledges that the past is a part of their own history, and that while it may appear "difficult," it acknowledges that demonstrates that there are multiple ways of finding answers to questions, events, and interpretations. Historical literature is a successful way to provide information about the concepts through "the eyes of several characters." Historical literature is also important to consider in social studies classrooms because it extends the "now and then" in historical thinking, contributes to the way students think about historical contexts, and can help students select nonfiction 
history literature that they can relate to personally. Finally, hands-on experiences encourage active construction of knowledge, disciplined inquiry, and values beyond the classroom.

Harvey (2011) described the need for more time engaged with reading, thinking, and learning about history that reflects the Common Core State Standards Initiative of situated literacy in the disciplinary classroom. Goudvis and Buhrow (2011), and Pearson et al. (2010) call this a "clarion call," a call that is needed in order to ensure that the students in today's disciplinary classrooms receive instruction that provides engaging and effective literacy instruction. McConachie, Hall, Resnick, Ravi, Bill, Bintz and Taylor (2006) premised that students can develop deep and complex conceptual knowledge in a discipline by using the literacy habits of reading, writing, talking, and thinking within the discipline specific to its values. But, students must first have opportunities to read, extensively with a variety of text and to reason, investigate, speak, and write about the overarching concepts within that discipline. But to build students' literacy in a specific discipline, instruction must do both at once. Goudvis and Buhrow (2011) suggested embedding reading and thinking strategies into social studies teaching by "merging thoughtful, foundational literacy practices with challenging, engaging resources to immerse kids in historical ways of thinking" (p. 130). In order to meet this goal, Goudvis and Buhrow (2011), drew from historians knowledgeable about teaching history in the elementary grades, and key concepts from the national core curriculum standards to create eight practices for developing historical literacy. Each key concept is integrated with instructional practices that teach students ways to read and think about history so 
they can more fully understand the ideas and issues central to the topic through effective literary practices.

Ritchhart and Perkins (2008) devised a variation of one of the major concepts behind the use of graphic organizers as a way to show what an individual is thinking or what they know - or think they know. Ritchhart's thinking routine, visible thinking, posited that learning is a consequence of thinking and is a social endeavor and should be made public in order to provide a window into students' thinking. Ritchhart said that when effective thinkers make their thinking visible, the students externalize and share thoughts through one of the language arts, (speaking, writing, drawing, or another method). Once visible, thoughts can be shared as a social endeavor with teachers and other students to deepen understanding. Graphic organizers are a way, as discussed previously, that students can show their thinking. Once thoughts are expressed on the organizer, teachers and peers can interact and refine and build knowledge. What is especially pivotal here, is that when students begin the process of Reciprocal Mapping, one of the first parts of the instructional routine is to write what you \{think you know about a topic on the organizer. This provides a clear window into students' thinking, right or wrong, and gives the teacher and peers an opportunity to provide instructional feedback. Richhart noted that data from schools using methods to make thinking visible, showed gains on state and district tests in reading, writing, and social studies (Richhart, Hadar, \& Turner, 2008). The Reciprocal Mapping instructional routine and it use of graphic organizers throughout the unit of study, is an effective way that students' show their thinking as well as document learning in the discipline. 
A second practice Goudvis and Buhrow (2011) noted that strengthened comprehension of social studies content was to give opportunities to read extensively and to interact repeatedly with that text. Many researchers have found that by providing students a wide variety of texts can build background knowledge and vocabulary, but when students interact with the text using literacy activities, new knowledge is attained and retained more effectively (Beers, 2002; Duke, 2004; Duke \& Pearson, 2002; Moss, 2005). When students interact with text they are in effect rereading the text, with potential benefits for both increasing comprehension to a deeper level of understanding as well as increasing reading enjoyment (Faust \& Glenzer, 2000). Millis and King (2001) conducted a study with college freshmen who were good readers and found that rereading the text helped with retention of poorly-structured text, which students might face considering Armbruster and Anderson's (1988) study on inconsiderate texts. Pressley and Wharton-McDonald (2006) found that successful citizens depend heavily on implementing reading comprehension strategies to understand disciplinary information expressed in textual form. Text interactions may include marking the text, coding personal thinking in the text, connecting to previous and ongoing readings, reacting to previous learning, and more. Garcia (2011) said,

By immersing children in authentic texts with rich images $\{$ which students get when they read and are exposed to multiple texts and multiple text types\} gives them the opportunity to develop a mental picture or map of what history is. So often the historical concepts we teach to children are very abstract and we assume they can follow. Why not spend the time to build background knowledge through the use of a myriad of materials that give them access to the time period? 
Helping build these images is of particular importance of students who are learning English as a new language because it gives them a framework from which they can base both their own background knowledge and the work ahead of developing new schema and working with new vocabulary (p. 135).

The instructional routine of Reciprocal Mapping includes continual referral to trade, text, and other appropriate materials, as they complete their graphic organizers. Not only do students continually refer back to the texts, but as they complete their organizers, knowledge is made visible, it can be refined and changed as students reread and revisit text, and since the organizers are visible to all students, questions and refinements are discussed and refined. Students assume ownership of the learning process when they are so deeply involved in text processing and interaction with text (Goudvis \& Buhrow, 2011).

Meyer's theory of cognitive learning, previously discussed, describes the learning acquisition of new knowledge as the students select pertinent information, organize it with what they already know about the topic, and integrate it into their new knowledge repertoire. Goudvis and Buhrow (2011) list this merging of new information with previously known understandings, as one of the eight effective instructional practices of historical literacy. Goudvis and Buhrow called this type of activity building background and constructing knowledge on the topic. As students read multiple texts, children's interest in the process heightens. Engaging students with investigations from the beginning of the unit of study and charting their information creates a community of learners. While they encouraged students to create charts and maps of their learning, in effect, the students created graphic organizers to show new and existing knowledge. 
Graphic organizers are an integral part of the Reciprocal Mapping instructional routine and form the base upon which students record their learning.

Goudvis and Buhrow (2011) next looked into ways that students could focus on distinguishing between more and less reliable sources of information by investigating lessons on reading, asking questions about, and evaluating different sources. They found that by asking questions for different purposes, students were able to create charts and questions that they were later organized into question types and these types of questions lead to reasoning through the different purposes of text. This type of questioning led to a more critical and evaluative stance toward what they were reading. (Busching \& Slesinger, 2002) developed a literacy curriculum designed for middle school teachers that teach topics of social justice and democratic citizenship with units of study that combine literacy, student inquiry, and collaborative learning. The program has broken from the traditional textbook and through questioning, text selection and variety of text types, and ongoing inquiry into the role and purpose of democratic citizenship and social justice. The authors contend that with programs designed to incorporate these concepts, students will be better prepared to think critically about societal issues on their way to becoming democratic citizens. Reciprocal Mapping also encourages the use of multiple text with questioning routines. Teachers using the Reciprocal Mapping instructional routine can select from a wide range of books and materials that will provide students with this type of questioning and investigation of social issues and democratic citizenship.

Goudvis and Buhrow (2011) complete the integration of literacy strategies with social studies content with four more practices. These include the idea that students should read and discuss different kinds of sources using a variety of text with authors 
who have different perspectives and purposes. By using a number of primary sources, original materials and artifacts created at the time of the unit of study, teachers can ensure that they are exposing their students to many points of view on a single topic, producing students who are more willing to read between the lines and draw from all sources to get a better idea of what really happened or caused events to happen in historical readings. A logical next step that Goudvis and Buhrow (2011) use is viewing and responding to works of art, many of which are primary source art pieces or representations. Art is a discreet part of the Florida's English and Language Arts curriculum, and with the Common Core States Standards Initiative, fine arts courses have been updated and aligned to the Next Generation Sunshine State Standards for the Arts in Florida. The courses are still in draft form but are being used by districts for planning purposes for the 2012-2013 school year awaiting approval of the Commissioner of Education (FDOE, 2012). Discovering surface themes and important historical ideas in fiction and nonfiction reading and interpreting historical fiction by synthesizing information across sources are the final two literacy integrations that are suggested. Reciprocal Mapping incorporates these additional literacy applications in its instructional routine.

\section{Summary}

Content instruction in today's disciplinary classrooms are undergoing changes because of the most recent implementation of Common Core State Standards Initiative (CCSSI) that has been adopted in all but five states. CCSSI is designed to prepare students to be college and career ready by the time they graduate from high school, and have placed literacy and language development standards within disciplinary classrooms. This is a major shift of focus to the integration of literacy skills with disciplinary content. 
It makes sense to merge these skills together, in theory, literacy would be taught and practiced across all content area domains. However, disciplinary instruction is taught predominately with informational text and almost exclusively from textbooks (Allington, 2002). This is problematic since $66 \%$ of students are unable to read textbooks with success.

Besides the overreliance on textbooks, there are many other reasons why students struggle with informational text, including the mismatch between the level of the textbook and the actual reading level of the students, which can be as much as a two grade levels. Textbook structure is difficult because there are several types of informational text used in many different ways in textbooks, each with a discreet set of signal words and sentence structures. Since most of the disciplinary classes teach with textbooks which are difficult for students to read and comprehend and since the majority of teachers use textbooks, students struggle.

Disciplinary content vocabulary is another reason students struggle with informational text. Language used in each content area class is specific to that discipline and not frequently encountered in other areas or outside classroom instructional time. Fang (2006) suggests there are several reasons why the vocabulary is so difficult in addition to its technical nature. Often sentence length is long and complex which exacerbates the decoding and context skills students might otherwise be able to apply. Further, abstract concepts are a part of the informational text passages which poses problems in comprehension.

While there are many obstacles students face when reading and comprehending informational text, it is important that they learn how to successfully read this type of 
text. Informational text is key to later schooling success, it helps build background knowledge and is read extensively by adults outside of school. Informational text can be a preferred genre for some students and can address a wide variety of student interest and helps build knowledge of the natural and social world. Informational text in important in the workforce, is used in most educational Internet applications, and is an integral part of today's expanding global economy.

Studies have shown evidence that graphic organizers are an effective classroom application that helps students better comprehend disciplinary text. Since graphic organizers are graphic displays of key ideas from textbooks and associated text, showing conceptual hierarchy as well as relationships and connections between ideas, facts, and concepts, they are effective for students to visualize their learning, as discussed in this section. Graphic organizers can help students visually portray relationships among key concepts, a variety of concepts can be represented in a single display. They aid students in determining the main idea and/or central concept of text. Graphic organizers also aid in the retrieval and storage of information. Graphic organizers provide a non-linear representation of text which has been shown to be especially helpful for a variety of highrisk readers. Also graphic organizer can help teachers get a snapshot into what their students are thinking, so teachers can either reinforce correct knowledge or correct students' misconceptions. Reciprocal Mapping uses graphic organizers in its instructional routine as well as other research-based methodologies.

One such methodology is the integration or reciprocity of reading and writing and is one that Alexander and Jetton (2001) believe cannot be underestimated. They say that the process of learning to read, that is both decoding and encoding in oral and written 
language are inextricably tied together. Theoretical frameworks that are an integral part of the Reciprocal Mapping instructional routine include scaffolding and metacognition. Classroom instructional strategies are important to consider when teaching in the disciplinary classroom. For the purpose of this study especially important were the use of explicit teaching, scaffolded instruction, and metacognition. Also important for the study was the importance of both teacher and student affinity to the intervention, as well as ensuring teacher fidelity to the Reciprocal Mapping instructional routine.

Finally, Reciprocal Mapping is closely aligned to the development of historical literacy, one of the disciplines that the Common Core State Standards have situated literacy instruction. Goudvis and Buhrow (2011) describe eight instructional practices that "teach kids new ways to read and think about history so they more fully understand key concepts." These eight instructional practices mirror the steps of the Reciprocal Mapping instructional routine. 


\begin{tabular}{|c|c|}
\hline $\begin{array}{c}\text { History Lessons, Goudvis \& } \\
\text { Buhrow (2011) }\end{array}$ & $\begin{array}{c}\text { Reciprocal Mapping, Fine } \\
\text { (2004) }\end{array}$ \\
\hline $\begin{array}{c}\text { Make students' background } \\
\text { knowledge about the topic visible. }\end{array}$ & $\begin{array}{c}\text { Initial steps of the RM routine } \\
\text { have students activate prior knowledge. }\end{array}$ \\
\hline $\begin{array}{c}\text { Students need to read } \\
\text { extensively and interact with texts. }\end{array}$ & $\begin{array}{c}\text { Reciprocal Mapping uses a } \\
\text { variety of informational text and } \\
\text { students are constantly referring back to } \\
\text { the text as they build their maps. }\end{array}$ \\
\hline $\begin{array}{c}\text { Merge thinking with new } \\
\text { information. }\end{array}$ & $\begin{array}{c}\text { Students add new information to } \\
\text { their maps. }\end{array}$ \\
\hline Ask questions. & Questions permeate lessons. \\
\hline $\begin{array}{c}\text { Read and discuss different types } \\
\text { of resources. }\end{array}$ & $\begin{array}{c}\text { RM incorporates a variety of } \\
\text { different kinds of resources. }\end{array}$ \\
\hline $\begin{array}{c}\text { Viewing and responding to } \\
\text { different kinds of primary sources. }\end{array}$ & $\begin{array}{c}\text { Primary sources are one of the } \\
\text { types of material that students use } \\
\text { during RM. }\end{array}$ \\
\hline $\begin{array}{c}\text { Discover surface themes by } \\
\text { reading the narrative and stores of } \\
\text { others. }\end{array}$ & $\begin{array}{l}\text { Themes are identified during the } \\
\text { reciprocity process of teacher and } \\
\text { student. }\end{array}$ \\
\hline $\begin{array}{c}\text { Interpreting historical fiction } \\
\text { and synthesizing information across } \\
\text { sources. }\end{array}$ & $\begin{array}{c}\text { Students are asked to read } \\
\text { historical fiction. }\end{array}$ \\
\hline
\end{tabular}

Figure 3. instructional practices which mirror the steps of the Reciprocal Mapping instructional routine

This chapter presented and reviewed research studies that suggests the importance of informational text and related difficulties that students have as they attempt to comprehend it. However, Reciprocal Mapping, is a way to provide explicit instruction to aid students comprehend informational text. Chapter III presents the methodology for this study. 


\section{CHAPTER III \\ METHODOLOGY}

\section{Purpose of the Study}

This study was designed to examine the effect of a multimodal intervention, Reciprocal Mapping (RM), on the social studies reading achievement of sixth graders.

After providing explicit instruction in the Reciprocal Mapping instructional routine students can graphically represented their new knowledge onto individual graphic organizers, or maps. With the important impact of the Common Core State Standards (CCSS), it was important to learn whether students who used the Reciprocal Mapping instructional routine were able to master social studies concepts more effectively than students taught with a traditional approach. The following questions and hypotheses framed the study:

\section{Research Questions}

Question 1: Is there a significant interaction between treatment (Reciprocal Mapping instructional routine and traditional instruction), level of risk groups ( highrisk, Level 3, and low risk), and sex in predicting gains on the McGraw-Hill Social Studies unit test, such that the high-risk group will gain more on the test?

Question 2: If there is no interaction or the interaction is ordinal, is there a significant difference between Reciprocal Mapping and traditional treatments in predicting posttest scores?

Question 3: For the treatment group (Reciprocal Mapping) is there a relationship between the fidelity of implementation and social studies posttest scores when using the McGraw-Hill pretest scores to predict adjusted posttest scores. 
Question 4: Does each of the affinity scales (teacher affinity to the condition, and student affinity of the condition) account for significant amounts of unique variance on predicting adjusted post-test scores?

\section{Hypotheses}

Hypothesis 1: There is a significant interaction between the treatment (Reciprocal Mapping instructional routine and traditional instruction), level of risk groups ( highrisk, Level 3, and low risk), and sex McGraw-Hill social studies unit test, such that the high-risk group will gain proportionally more on the test, when controlling for pretest scores.

Hypothesis 2: If there is no interaction or the interaction is ordinal, there is a significant difference between Reciprocal Mapping and traditional treatments in predicting posttest scores adjusting for pretest scores on the McGraw-Hill pretest score.

Hypothesis 3: For the treatment group (Reciprocal Mapping) there is a relationship between the fidelity of implementation and social studies posttest scores when using the McGraw-Hill pretest scores to predict adjusted posttest scores.

Hypothesis 4: Each of the Affinity scales (teacher affinity to the condition, and student affinity of the condition) accounts for significant amounts of unique variance on predicting adjusted post-test scores when adjusted for the McGraw-Hill pretest scores.

\section{Design}

This study used a pretest/posttest control group experimental design with the Reciprocal Mapping intervention, Level of Risk, and sex as the independent variables with social studies achievement as the dependent variable. The experimental-control, preand posttest design is a relatively strong design for two reasons, first because of the 
pretest used for both groups. Second, the researcher does not manipulate any of the placements of the students or instructors. Also, since the students were randomly assigned both to classes and to instructors, the pretest added to the strength of the study because of its information about group equivalence producing a more refined analysis (Newman \& Newman, 1994). The pretest gave an idea of how similar the groups were at the inception. Newman \& Newman (1994) and Newman, Newman, Brown and McNeely (2006) noted this is a practical design because it allowed the students to remain in their intact classes and eliminated many of the history factors that might have influenced results as well as maturation.

A relative weakness of this design is the degree to which the groups are not equivalent with respect to other demographics such as gender, social economic status, or ethnicity. If the groups are not equivalent, it cannot be assumed that the independent variable is causing the difference. However, this research design has high internal validity. Internal validity "is concerned with correctly concluding that an independent variable is, in fact, responsible for variation in the dependent variable" (Kirk, 1995, p. 16). The high internal validity in this study is due to the use of the pretest and randomization by class allowed the researcher to control for history. (Newman et al., 2006).

\section{Setting and Participants}

The setting was a school in a rural south Florida county. The participants were sixth-grade students and two social studies teachers at two rural K-8 schools in the district. 


\section{Schools}

The participating sixth-grade students attended two K - 8 schools. School A had two experimental and one control class. School B had two each of experimental and control classes. School A had three social studies instructional periods, each class was scheduled in 45 minutes blocks and met daily. School B had four instructional periods for social studies instruction, each class is scheduled in 90-minute blocks and meet every other day, therefore the instructional time was similar. The classes had relatively equal numbers of high-risk and low-risk students and class sizes were between 19 and 25 students. One teacher at each school taught both the experimental and control classes.

\section{Teachers}

The two participating social studies teachers had similar backgrounds. Ms B and Ms W are White women. Ms. B had a bachelor of science in Elementary Education K-6, Social Sciences 6-12 certification and ESOL certification. Ms. W had a bachelor of science in Elementary Education K-6, Social Sciences 6 - 12 certification, Reading Endorsement and ESOL certification. These teachers were selected because they were the current teachers of social studies instruction at the respective schools. Both teachers had over 15 years of experience, one in the same school in the rural county and the other with 7 years in an urban setting at one school, and 8 years in the rural setting at School B.

\section{Students}

The student participants were 138 sixth-grade students from two K-8 schools in rural southern Florida. Descriptive data on the students is provided in Table 1. 
Table 1

Descriptive Data on Sixth-Grade Students

\begin{tabular}{lcc}
\hline & \multicolumn{2}{c}{ Group } \\
\cline { 2 - 3 } Condition & Traditional & Reciprocal \\
& Treatment & Mapping \\
\hline Low-Risk readers (FCAT Levels 3, 4, 5) & 45 & 50 \\
Hi-Risk readers (FCAT Levels 1 \&2) & & 28 \\
\hline
\end{tabular}

Note. Low-Risk readers - FCAT level only. May include ELL and/or LD students who score Level 3, 4, or 5 on FCAT. Hi-Risk readers -FCAT level only. May include ELL/LD students who score Level 1 or 2.

All students enrolled in sixth-grade general education social studies classes at the two schools were included in the study. Each student was randomly assigned to a class using Chancery Scheduler, a web-based student scheduling management system resulting in heterogeneous classes. Classes selected by participating teachers were also randomly selected; Both School A and B had block schedules with A Day and B Day classes with periods in the morning and afternoon. Class times were equivalent and experimental and control classes were taught at both the morning and afternoon sessions each. Ms B randomly selected first period for control and periods two and three for experimental. Ms W randomly assigned the control group to her A Day classes and the experimental group to B Day classes. 


\section{Materials}

Both the sixth-grade social studies experimental and control classes used the county adopted social studies textbook from McGraw-Hill, Discovering Our Past: A History of the World Early Ages (Spielvogel, 2013). The control group was taught predominately through the use of this textbook and teacher lecture. In Monroe County, sixth-grade social studies teachers use a pacing guide (Appendix A), based on Florida's Sunshine State Standards. The year begins with instruction in historical thinking skills, geography including map skills, geographic terms, latitude and longitude and six essential elements of geography. Tools of the historian follow, with concepts such as historical terms and archaeology. In the second quarter students are taught beginnings of human societies in the Old and New Stone Age. Students begin the study of ancient civilizations such as Mesopotamia, Egypt, India, China, Greece, and Rome in the third quarter.

The textbook is divided into chapters, with each chapter covering different aspects of content mentioned above. Each chapter was introduced with a chapter overview that outlined the information presented, and was further divided into lessons. Each lesson had a guiding topic or question that helped students focus on specific information.

The time frame of the study coincided with Monroe County District's pacing guide for Unit 3, Chapter 9, Ancient India. This chapter included geographic features, key figures and contributions of the civilization as well as a focus on religions, empires and dynasties, key figures and achievements of Ancient India as shown in Table 2. 
Table 2

Lessons and Sections from Florida Discovering Our Past: A History of the World Early Ages with Text Structure.

Lessons

Informational Text Structure

Ancient India

Lesson 1 - Early Civilizations

The Geography of India

Mountains, Plains and Rivers

Cause \& Effect

The Indus Valley Civilization

Compare \& Contrast; Cause \& Effect

Mohenjo-Daro and Harappa

Compare \& Contrast; Cause \& Effect

Aryan Migrations and Settlements

Cause \& Effect

The Indo-Europeans

Cause \& Effect; Problem \& Solution

Ancient Indian Society

Compare \& Contrast; Problem \& Solution

Lesson 2 - Religions of Ancient India

What is Hinduism?

Compare \& Contrast; Cause \& Effect; Problen \& Solution

Rise of Buddhism

Compare \& Contrast

The Buddha

Cause \& Effect

What did the Buddha teach?

Compare \& Contrast; Cause \& Effect

Mahayana Buddhism

Compare \& Contrast

What is Ahimsa?

Cause \& Effect; Problem \& Solution

Lesson 3 - the Mauryan Empire

Origin of an Empire

Cause \& Effect

India's First Empire

Cause \& Effect; Problem \& Solution

What did Ashoka Accomplish?

Cause \& Effect

The Gupta Empire

Compare \& Contrast

Culture in Ancient India

Compare \& Contrast; Cause \& Effect 


\section{Measures}

Administration of the pretest took place during week one of the study. The pretest measured social studies content found in the county adopted social studies textbook from McGraw-Hill, Discovering Our Past: A History of the World Early Ages (Spielvogel, 2013), chapter 9, Ancient India. The posttest was administered to both groups during week five of the study.

McGraw-Hill provides two forms of question sets for each chapter. Students in both the control and experimental groups took Form A question sets for the pretest. The pretest and the posttest each had 20 multiple choice questions that measured social studies content found in chapter 9, Ancient India, from the from McGraw-Hill, Discovering Our Past: A History of the World Early Ages (Spielvogel ,2013). Each question had answer choices (a), (b), (c), and (d).

In order to obtain measures of fidelity, a rubric was designed by the major professor who developed Reciprocal Mapping instructional routine (Fine, 2004) and the researcher. The rubric included the characteristics of the Reciprocal Mapping instructional routine and were scored by the researcher on a scale of (1), limited, (2), sufficient, and (3), mastery. Teachers in both school sites were observed six times each during the Reciprocal Mapping classes. Observations were conducted during weeks two through four ensuring that each experimental class was observed twice. Each observation was recorded using the fidelity rubric for both fidelity to treatment and consistency in recording observations. Weeks one and five were not chosen for observations because they were devoted to pretest and unit introduction and review and posttest, respectively. Teachers were given a copy of the fidelity rubric during the training session and were 
informed that the experimental classes would be observed for fidelity of treatment during the study. Further, teachers were told that the observation would occur weeks two through four, but were not told specific date and time, so teachers would not perform for the observation, but were following the Reciprocal Mapping instructional protocol. The researcher had been in each of the classrooms prior to observations in an informal basis prior to the beginning of the study, so both students and teachers were familiar with her presence and it was felt little, if any, notice was observed when she entered the classrooms for the fidelity of treatment rubric observations. The researcher remained in the classroom for the duration of the lesson for each of the six observations.

Student affinity to treatment (Appendix F) was measured by a four item, 5-point Likert scale instrument also designed by the major professor who developed Reciprocal Mapping instructional routine (Fine, 2004) and the researcher. The Likert scale ranges from (1), for "strongly disagree," to (5), for "strongly agree." A measurement of (3) represents "neutral." The Likert scale is one of the most widely used scales, statements are included with a positive or negative direction, that the participants indicate agreement or disagreement. Likert scales are useful for measuring participant attitudes. Participants used the Likert scale rubric as they responded to the use of Reciprocal Mapping on four of its' characteristics, (1) to learn informational text types, (2) to collaborate with peers, (3) to write informational text, (4) to discuss social studies disciplinary content. Student affinity was administered week five after review and posttest were completed by the participants. Students completed the affinity to the intervention by indicating the score(s) for each of the four characteristics. These scores were then entered into a data sheet, 
inputting each score for each student in a spreadsheet, and then transferred to and analyzed using statistical analyses of the survey data with SPSS 21 software.

Teacher affinity to Reciprocal Mapping (Appendix E) was a similar four item, 5point Likert scale instrument designed by the major professor who developed Reciprocal Mapping instructional routine (Fine, 2004) and the researcher; with similar measures, (1) for "strongly disagree", to (5) for "strongly agree," with (3) being neutral. Each teacher completed a teacher affinity to Reciprocal Mapping week five, after review and posttest. In the same way as the student affinity instrument was coded and entered, teacher affinity scores were entered into a data sheet and analyzed using the statistical analyses of the survey data with SPSS 21 software.

\section{Teacher Training Procedure}

The intervention, Reciprocal Mapping, (Appendix G for specific routines), was taught to the participating social studies teachers in a training session at the onset of the academic school year. Both teachers participated in a 3-hour training session learning the Reciprocal Mapping instructional routine. The intervention was taught by the researcher, a doctoral student at Florida International University. Fine (2004) provided training for the researcher, which consisted of an instructional phase, followed by practice and practical application. In a similar way, the researcher instructed the participating teachers following a similar procedure, i.e., instructional training, practice, and demonstration. Participating teachers showed the researcher the completed maps and associated informational text reading passages that were examples of the three targeted informational text types. Participating teachers were deemed competent to instruct their students using Reciprocal Mapping upon successful completion of the training session. 
Participating teachers and the researcher reviewed the Reciprocal Mapping instructional routine the weekend prior to week one implementation of the study.

\section{Intervention routine}

Sixth-grade students are expected to master concepts in Ancient Civilizations, in order to meet Florida's Sunshine State Standards as set out in Monroe County's social studies pacing guide (Appendix A). The Reciprocal Mapping intervention was implemented during the third quarter of the academic year with Unit 9: Ancient India. A pretest from Monroe County's adopted social studies series was administered to all participants during week one of both the control and experimental classes. After completing the pretest, the participating teachers taught control groups as they have traditionally done, including such activities as teacher lecture, note taking, worksheets, text reading and answering questions, and video presentation. Participating teachers implemented the Reciprocal Mapping intervention in the experimental classrooms using procedures taught in the sessions as described in the intervention time frame (Appendix B). Both the experimental and comparison groups studied the same content from the school district's benchmarks, used the same textbooks and had the same amount of instruction time for the unit of study. Upon completion of the unit, a post test was administered. An overview of the five week study and detailed lesson plans for each week are included in Appendices B and G-I.

\section{Reciprocal Mapping Instructional Routine}

The Reciprocal Mapping instructional routine is a scaffolded iterative process that is explicitly taught by the classroom teacher and uses informational text structure that focuses on author's craft. As the instructor demonstrates the process, she is making a 
production scaffold (Fine, 2004). This process is transmediating information between two coding systems (Paivio, 1986). The following is an overview of the Reciprocal Mapping instructional routine (Appendix G); detailed lesson plans used in this study are found in Appendices H-J.

\section{Reciprocal Mapping Steps}

Explain that Informational writing has 5 major text structures. They are the following:

a. Descriptive - The author describes a topic by listing characteristics, features, attributes, and examples.

b. Sequence - The author lists items or events in numerical or chronological sequence, either explicit or implied.

c. Compare/ Contrast- Information is presented by detailing how two or more events, theories, or things are alike, and or different.

d. Cause and Effect - The author presents ideas that explain why (cause) something happened and what happened (effect).

e. Problem and Solution - The author presents a problem and one or more solutions.

An overview of the routine follows.

Select targeted informational text type. Use an age or grade-level appropriate life example to teach the text type. As the teacher describes the life example, she uses a graphic organizer associated with it to depict the details. This is done in such a way that the students can both watch, and listen, as the teacher puts each event in the organizer. Teachers can use document cameras, overhead projector, large chart paper, or similar 
ways so all students can see. Students then create their own graphic organizer, or map, showing the example that they were just taught. The students copy the teacher's example exactly, thus the start of the reciprocal nature of the instructional routine. Students then use the teacher's map to write a brief paragraph that summarizes what was just graphed. The final step of this initiating practice is for the students to then create their own example of a life situation using the targeted informational text type. They map their own example, using the teacher's original map as a scaffold, to complete the map as the teacher observes for mastery. Students then use their map to write a brief paragraph that summarizes the map they just created. The teacher-created, real-life, compare and contrast graphic organizer is shown in Figure 1 and the reciprocal student created map is shown in Figure 4.

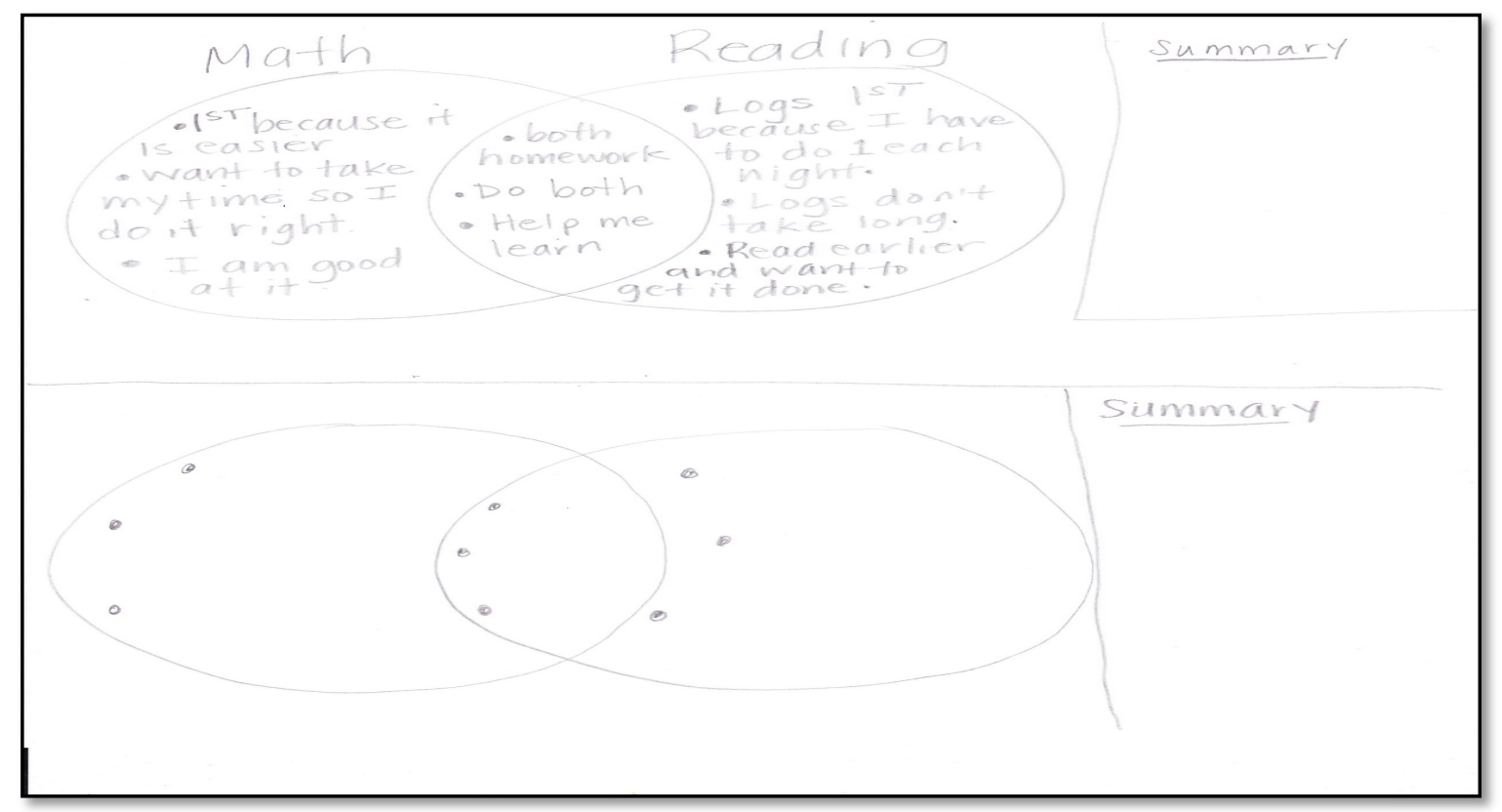

Figure 4: Teacher created Compare and Contrast Real-Life Example. 


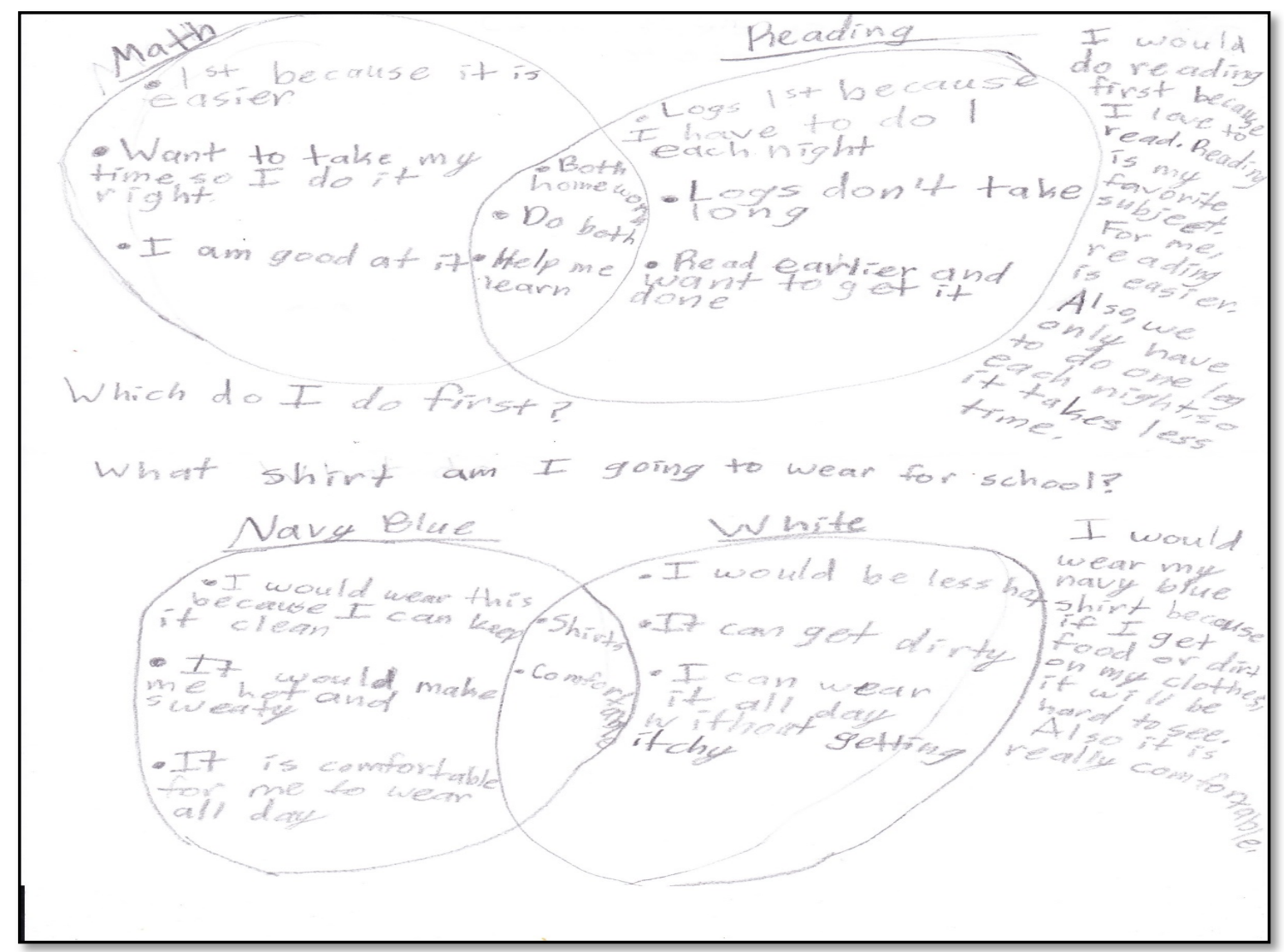

Figure 5: Student created Compare and Contrast, with summary of teacher example and originally generated Compare and Contrast map with summary.

Once students grasp the use of the targeted informational text type through personal life examples, the teacher selects either a picture book or connected text of the targeted text type. Picture books that are written using the informational text structure are effective materials to model the informational text pattern without adding a possible burden of text that is too difficult for high-risk students to understand. In much the same way as the life example, the teacher models the process of placing the events on the graphic organizer as the students watch. When the teacher is done, the students create their own maps, creating an exact copy of the teacher's example. Ensuring text that has 
the same structure to create a map is guided practice. This takes close rereading of the text and continues the reciprocity of the instructional routine. The students are asked to write, in their own words, what the text says. Students then use the teacher's map to write a brief paragraph that summarizes what was just graphed. The students are given their own picture book or an informational text passage to map. Students should complete the maps individually, but as part of a scaffolding process, can pair up, in triads, dyads, and in small groups. Explicit teacher directions can be given again if necessary, until students show mastery. Scaffolding is gradually withdrawn until the students are able to show independent mastery. Teachers should ensure that they explicitly teach the signal words that go with targeted informational text type as well as reviewing commonly used graphic organizers and common text features as appropriate. Students then use their map to write a brief paragraph that summarizes the map they just created Appendices (M, N, $\mathrm{S}, \mathrm{T}, \mathrm{Y}, \mathrm{Z})$.

The final step is to give students informational text on the targeted topic, which could include passages from the textbook. In the same manner as the life experiences and picture books, the teacher will display an example of the targeted informational text type from text that the students will be using during the lesson, and models the process of placing text on the graphic organizer, continually moving between the text and the map, demonstrating the reciprocity process - text to map. Again, students create their own maps modeled exactly on the map that the teacher demonstrated. Students then use the teacher's map to write a brief paragraph that summarizes what was just graphed. Upon completion, students are given a similar text, which could be a passage from the textbooks, and using the teacher's map as a scaffold, create their own map with the 
information from the text. Students then use their map to write a brief paragraph that summarizes the map they just created. At this time, students can create Reciprocal Maps from the original examples matching text structure maps and can begin to add vocabulary and social studies concepts to their map from classroom materials. These maps become prewriting documents that the students use to write summaries, as described. Students are then asked to create written artifacts using their maps to write informational text about the social studies content, in this study, students were asked to create a Power Point presentation.

\section{Statistical Analysis}

\section{Analysis of Hypothesis 1}

A three-way between groups analysis of covariance (ANCOVA) was conducted to compare the effectiveness of two different instructional methods on social studies achievement. The independent variables were type of teaching method, traditional instruction (TI) or Reciprocal Mapping (RM), level of risk, and sex and the dependent variable was unit posttest scores in social studies achievement. Students' scores on the unit pre-test were used as a covariate in this analysis. The ANCOVA determined if there was a significant difference between the two instructional methods on unit posttest scores, after controlling for pre-test scores, level of risk, and sex. In other words, it determined if students in the RM instructional method classrooms had higher social studies achievement scores than students in the traditionally taught classrooms when

controlling for initial differences on the pretest. A one-tailed test of significance at the $p<$ .05 level was used. 
The $F$ test was used to test the statistical significance of the relationship between traditional teaching approach with the Reciprocal Mapping intervention. The $F$ test is a robust statistical analysis and assumes the random selection of the subjects and the normal distribution of the variables can be violated without doing serious harm to the procedure (Newman, Klein, Weis, \& Benz, 1980).

The ANCOVA is the most powerful technique for analyzing this type of data (Campbell \& Stanley, 1963). Analysis of covariance was used for the statistical analysis because it addressed a priori differences between groups in the experiment. The ANCOVA controls extraneous variation, such that in this study any differences in unit pretest scores were adjusted allowing the researcher to better justify the assumption of initial equivalence. Through statistical adjustments, when its stringent assumptions are satisfied, the ANCOVA adds materially to the power and precision of the experiment, (Berliner \& Calfee, 1996). Selecting the ANCOVA was appropriate because the covariates were correlated with the dependent variable and the homogeneity of the variance-covariance matrices were expected to be equivalent (Campbell \& Stanley, 1963). The ANCOVA also allowed the researcher to examine the significance of the differences on the dependent variable for covariate differences, which an analysis of variance does not do. The one-tailed test of significance was chosen because the researcher had noted success with the intervention, Reciprocal Mapping, with narrative text (Fine, 1994). Fine found that students who used the Reciprocal Mapping procedure were better able to comprehend narrative text when asked comprehension-type questions after completing the instructional routine. It would be expected to be similar to the narrative intervention with no reason to expect differences. It was hypothesized that the 
at-risk readers would benefit most from the treatment first because of the scaffolded process of the Reciprocal Mapping instructional routine gives these readers extra practice with the type of text found in social studies textbooks, coupled with explicit instruction. This reciprocity process models the simultaneous extraction and construction of meaning through interaction and involvement with written language that the RAND Reading Study Group (2002) stressed as an important part of language arts acquisition especially important for high-risk reader needs. Further, the Reciprocal Mapping instructional routine engages the student in revisiting text in a meaningful way. Mayer's (2001) activeprocessing theory shows that when a learner selects information in order to make meaningful connections to previously learned material. The recursive process may help high-risk readers to actively engage in the process during rereading the text which in turns helps store new information into long term memory. Finally, Green \& Azevedo (2007) found that students who participated in a recursive cycle of cognitive and metacognitive activities were helpful for students who were learning difficult science concepts.

An alpha level of $<.05$ level of significance was used by the researcher because the consequences of rejecting true null hypotheses for the purpose of the present study was not of the magnitude that a stronger confidence level was needed. The power analysis of this study for an $N=138$ and medium $f=.15 \alpha .05$ power was approximately .98 .

\section{Analysis of Hypothesis 2}

After testing for an interaction between the three variables of risk, treatment and sex, there was no interaction so research hypothesis two was tested to determine if there 
was a significant difference between the Reciprocal Mapping and the traditional treatments in predicting posttest scores adjusting for pretest scores on the McGraw-Hill test.

The scores on initial differences on FCAT were also used to determine the effectiveness of the intervention compared with a traditional teaching approach. A 3 by 2 between-groups analysis of covariance (three-way ANCOVA) was conducted to assess the effectiveness of two different instructional methods in enhancing social studies achievement for low-risk and high-risk readers. The independent variables was type of instructional method, the traditional teaching approach (TI) with the Reciprocal Mapping (RM) intervention and reading level measured by the FCAT (low-risk or high-risk). The dependent variable was unit posttest scores in social studies. Participants' scores on the unit pre-test were used as a covariate in this analysis. The three-way ANCOVA will determine if low and high-risk participants responded differently to the two different instructional methods in terms of posttest achievement. That is, it will assess whether or not the low-risk students benefit more from the Reciprocal Mapping instructional method. If there was an interaction between treatment and level of risk (low and highrisk), in order to determine where the interaction was, the data were plotted and simple effects testing were conducted.

\section{Analysis of Hypothesis 3}

Research hypothesis three tested if teacher fidelity of implementation of the Reciprocal Mapping treatment had a statistically significant relationship in predicting posttest scores when controlling for pretest scores. According to Campbell and Stanley (1963), covarying the pretest scores is more powerful. The same result occurs by doing 
this with the gain scores if the post and pretest reliability are 1 (perfect). If not it tends to underestimate the covariate. The higher the reliability of the pre and post test the more similar the gain scores will be in the analysis of covariance. For this hypothesis, a regression analysis of covariance was used to investigate the relationship of fidelity in predicting posttest scores. Data for teacher fidelity to the implementation of Reciprocal Mapping was collected three times during the study, weeks two, three and four. Since the objectives for week one included activating prior knowledge, providing background information, providing important vocabulary and administering the pretest, it was not included in the fidelity observation. Likewise, week five was not included in the fidelity check because it was dedicated to reviewing, summarizing, completing artifacts, and posttesting.

\section{Analysis of Hypothesis 4}

Research hypothesis four tested if student and teacher affinity accounted for a significant amount of unique variance in predicting posttest scores while controlling for pretest scores. A regression analysis of variance was conducted to determine if student and teacher affinity was significant. All analyses for hypotheses were performed using The Statistical Package for Social Sciences 21 (SPSS) in order to determine the effectiveness of the intervention.

\section{Limitations}

This study was limited to the schedule(s) currently practiced at the participating schools. Both class size and the time of day that the classes were taught, in both the control and experimental groups, were limited by class size mandates and minutes allowed for each class by current schedule. The study was limited to the students' 
answers to test questions representing the knowledge they gained using either Reciprocal Mapping or traditional instruction. The results of the tests may not accurately reflect the depth of knowledge gained depending on student motivation during the testing window. Due to the unique sample of students available for the study, the results may be generalizable only to similar schools and student populations.

Reading comprehension is a complicated process, and is more than reading a selection of passages and answering multiple-choice questions on one specific day in the academic year. The FCAT Reading test, which was used in this study to determine reading comprehension achievement for both samples is one way to measure reading comprehension, but may have possible limitations. For example, while it is used to determine accountability within school districts in the state of Florida, it does not give a comprehensive idea on reading comprehension achievement in each individual student. Therefore, this study was limited by the scope of the requirements of the FCAT reading assessment.

\section{Summary}

This chapter began with a description of the method, proposed analysis, and design of the study. Hypotheses were presented with anticipated results. Detailed description of the Reciprocal Mapping instructional routine was provided, including a detailed timeline covering a 5-week time period. 


\section{CHAPTER IV}

\section{RESULTS}

This study investigated the effect of the Reciprocal Mapping instructional routine on the comprehension of social studies informational text when compared with a traditional teaching approach for students who struggle with reading skills and comprehension. This chapter explains the findings from the analyses used to determine these results. The design was a pretest-posttest model with the Reciprocal Mapping intervention as the independent variable and student scores on unit posttest as the dependent variable. The results of the study are organized in this chapter into three main sections. First, a description of the sample is presented, followed by the results of testing the hypotheses, and a brief summary of the chapter.

\section{Description of the Sample}

One hundred and thirty eight sixth grade students participated in the study in the two participating schools. The two schools are located in a rural Florida county and serves pre-kindergarten through eighth grade. The schools use the Florida Sunshine State Standards to develop lesson plans and follow pacing guides developed by the district in order to ensure that each school is teaching the same content at the same time throughout the county. Seventy-eight students were in the experimental group that received the Reciprocal Mapping Instructional routine while 61 of the students were in the control group, receiving traditional instruction. The Reciprocal Mapping students were given explicit instruction of the five most common informational text types, their signal words and corresponding graphic organizers associated with them. Students were further instructed in three of these informational text types; compare and contrast, cause and 
effect, and problem and solution, using the textbook and a variety of trade books, Internet passages, and instructional magazines. Students who were high-risk readers, that is students who scored a Level 1 or Level 2 on the reading portion of the Florida Comprehensive Assessment Test (FCAT) were a focus of the study. Students were given a pretest, then were taught either in the control, traditional instruction classroom, or the experimental, Reciprocal Mapping classroom and were then given a posttest assessment using the question bank from the county adopted social studies textbook by McGrawHill, Discovering Our Past: A History of the World Early Ages (Spielvogel, 2013).

\section{Results and Examination of the Hypotheses}

Students who took part in this study were in sixth grade classes that were then randomly assigned to either the traditional group ("control”) or the Reciprocal Mapping ("treatment") group. Traditional group was traditional instruction typically found in general education social studies classrooms. Table 3 shows pretest scores for the control group $(M=4.18, S D=2.23)$ and the treatment group $(M=4.33, S D=1.90)$. The posttest scores for the control group reported a mean of 13.15 and the treatment group had a mean of 14.68. Both the pretest and posttest scores are based on a maximum score of 20. Mean gains for the control group were reported as 8.97 while the treatment group mean gains were 10.35 . Teacher fidelity of implementation had a mean score of 18.33 out of a possible 24 points. Teacher Affinity had a mean score of 18.58 while student affinity had a mean of 16.04 , each out of a possible twenty points. 
Table 3

Means and Standard Deviations of Test Scores, Fidelity, and Affinity Disaggregated by Treatment

\begin{tabular}{cccccc}
\hline & \multicolumn{2}{c}{ No Treatment $(\mathrm{N}=60)$} & & \multicolumn{2}{c}{ Treatment $(\mathrm{N}=78)$} \\
\cline { 2 - 3 } \cline { 5 - 5 } Measures & Mean & SD & & Mean & SD \\
Pretest & 4.18 & 2.23 & & 4.33 & 1.90 \\
Post Test & 13.15 & 3.83 & & 14.68 & 2.25 \\
Gains & 8.97 & 3.63 & & 10.35 & 2.52 \\
Teacher Fidelity & - & - & & 18.33 & 0.47 \\
Teacher Affinity & - & - & & 18.58 & 1.51 \\
Student Affinity & - & - & & 16.04 & 2.12 \\
\hline
\end{tabular}

Note: symbol - reflects that Fidelity of treatment and student and teacher Affinity were not measured for the control group.

The non-treatment group consisted of twenty seven students (45\%) identified as low risk, eighteen students (30\%) identified as Level 3 and fifteen students (25\%) identified as high-risk. The treatment group had a total of twenty five students $(32.1 \%)$ identified as low risk, twenty five students (32.2\%) identified as level 3 and twenty eight students (35.9\%) identified as high-risk. The non-treatment group number of participants was sixty (43.2\%) and the treatment group had seventy eight participants $(56.1 \%)$ as shown in Table 4. 
Table 4

Demographic of Participants $N=138$

\begin{tabular}{cccccc}
\hline & \multicolumn{2}{c}{ No Treatment } & & \multicolumn{2}{c}{ Treatment } \\
\cline { 2 - 3 } \cline { 5 - 6 } & $\mathrm{N}$ & $\%$ & & $\mathrm{~N}$ & $\%$ \\
\hline Low Risk & 27 & 45 & & 25 & 32.1 \\
Level 3 & 18 & 30 & & 25 & 32.1 \\
High-risk & 15 & 25 & & 28 & 35.9 \\
Participants & 60 & 43.2 & & 78 & 56.1 \\
\hline
\end{tabular}

Note. $\mathrm{N}=138$

Cronbach's alpha was run on each of the Affinity measures and Fidelity. The student affinity and teacher affinity had a total of four items in each respective measure. Student affinity reported and alpha of .598 while teacher affinity reported .889 (see Table 5). Teacher fidelity consisted of ten items and had a Cronbach's alpha of .654, upon examining the items contribution to the construct it was decided that items three and four would be removed resulting in a Cronbach's alpha of .719 for the eight items. According to Kline (1999) alpha levels running from $0.7-0.80$ are acceptable while alphas ranging from $0.6 \leq \alpha<0.7$ are marginally acceptable, and an alpha of $0.5 \leq \alpha<0.6$ is considered poor. The poor alpha is likely due to $n=2$, a small sample size that frequently resulting in poor alpha results. Therefore, one needs to be careful when interpreting the results of student affinity. 
Table 5

Internal Consistency of Measures Using Cronbach's Alpha

$N$ of Items $\quad \alpha$

Student Affinity

$4 \quad .598$

Teacher Affinity

4

.889

Teacher Fidelity

8

.745

Hypothesis 1 asked if there was an interaction among three variables, sex, treatment, and level of risk, in predicting posttest scores on the McGraw-Hill social studies unit test, while covarying the pretest scores. There were no significant 2-way or 3way interaction between level of risk and $\operatorname{sex}\left(F=0.95, p=.391\right.$ and $\left.\eta^{2}=.015\right)$, level of risk and treatment $\left(F=1.17, p=.174\right.$ and $\left.\eta^{2}=.028\right)$, and level of risk, treatment, and sex $(F=1$, $p=.37$ and $\left.\eta^{2}=.016\right)$. Due to the lack of interaction it was appropriate to interpret the main effects of treatment. 
Table 6

Summary Table for a Three-Way Analysis of Variance of the Effects of Reciprocal Mapping, Gender, and Risk on Post Test Scores

\begin{tabular}{|c|c|c|c|c|c|c|}
\hline Source & $\mathrm{df}$ & SS & MS & $F$ & $\mathrm{p}$ & $\eta^{2}$ \\
\hline Pretest & 1 & 118.48 & 118.48 & 15.17 & 0 & 0.111 \\
\hline Level of Risk & 2 & 81.66 & 40.83 & 5.23 & 0.007 & 0.08 \\
\hline Male & 1 & 0.06 & 0.06 & 0.01 & 0.93 & 0 \\
\hline Treatment & 1 & 94.24 & 94.24 & 12.06 & 0.001 & 0.091 \\
\hline Level * Male & 2 & 14.77 & 7.38 & 0.95 & 0.391 & 0.015 \\
\hline Level $*$ TX & 2 & 27.71 & 13.86 & 1.77 & 0.174 & 0.028 \\
\hline Male * TX & 1 & 0.88 & 0.88 & 0.11 & 0.738 & 0.001 \\
\hline \multicolumn{7}{|l|}{ Level * Male * } \\
\hline \multicolumn{7}{|l|}{$\mathrm{TX}$} \\
\hline Within Group & 121 & 945.28 & 7.81 & & & \\
\hline Total & 134 & 27668 & & & & \\
\hline
\end{tabular}

Note. Results are for post test scores while controlling for pretest where Reciprocal Mapping had a higher mean than the traditional treatment.

Since the main effect of treatment accounted for a significant proportion of unique variance while controlling for sex and level of risk, research hypothesis two asked if there was a significant difference between the treatment and control groups in posttest gain scores. An independent t-test was conducted to investigate differences in posttest gain scores between the treatment and control group. The mean gain score for the control group $(M=8.97, S D=3.63)$ was significantly lower than that of the treatment group $(M$ 
$=10.35, S D=2.52), p<.05$, indicating that the Reciprocal Mapping treatment accounted for a significant increase in scores for the treatment group as compared to the students who did not receive the treatment Results indicated that this reciprocal mapping techniques may be useful for all reading levels, and could possibly increase scores across varying reading levels (see Table 7).

Table 7

Differences Between the Control and Treatment Group on Posttest Gain Scores

\begin{tabular}{|c|c|c|c|c|c|c|c|}
\hline & \multicolumn{2}{|c|}{ Control (60) } & \multicolumn{2}{|c|}{ Treatment (78) } & \multirow[b]{2}{*}{$t_{(100.408)}$} & \multirow[b]{2}{*}{$p$} & \multirow{2}{*}{$\begin{array}{c}\text { Cohen's } \\
\text { D }\end{array}$} \\
\hline & Mean & SD & Mean & $\mathrm{SD}$ & & & \\
\hline Gain Sore & 8.97 & 3.63 & 10.35 & 2.52 & -2.516 & 0.013 & 0.442 \\
\hline
\end{tabular}

Note: Since Levene's Test for Equal Variances indicated significant differences between the control and treatment group variances the equal variances not assumed was used.

Research hypothesis three tested if teacher fidelity of implementation of the treatment had a statistically significant relationship in predicting posttest scores when controlling for pretest scores. A regression analysis of covariance was conducted to investigate the relationship of fidelity in predicting posttest scores. As one can see from Table 8 there is a statistically significant relationship $(p<.001)$ between the fidelity of implementation in predicting posttest scores, such that as fidelity of implementation increased so does posttest scores. This means that the more closely the Reciprocal Mapping instructional routine is followed by the teachers, the more likely that students will achieve higher scores on social studies content. 
Table 8

Regression Analysis Summary for Teacher Fidelity predicting Posttest Scores While Controlling for Pretest Scores

\begin{tabular}{ccccccc}
\hline Model & Predictors & B & SE B & $\beta$ & t & P \\
\hline Restricted & (Constant) & 13.28 & 0.62 & & 21.51 & .001 \\
& Pretest & 0.32 & 0.13 & 0.27 & 2.48 & .015 \\
& & & & & \\
Full & (Constant) & -34.37 & 12.72 & & -2.70 & .009 \\
& Pretest & 0.22 & 0.12 & 0.18 & 1.76 & .082 \\
& $\begin{array}{l}\text { Teacher } \\
\text { Fidelity }\end{array}$ & 2.63 & 0.70 & 0.39 & 3.75 & .000 \\
\hline Note: $\mathrm{R}_{\text {Change }}^{2}=.146$ with an $\mathrm{F}_{\text {Change }}(1,75)=14.06$ and $\mathrm{p}=.000$ & &
\end{tabular}

Research hypothesis four tested if student and teacher affinity accounted for a significant amount of unique variance in predicting posttest scores while controlling for pretest scores. A regression analysis of variance was conducted and as one can see from Table 9 only teacher affinity accounted for a statistically significant $(p<.001)$ amount of unique variance in predicting posttest scores while controlling for pretest scores. This would indicate that the degree to which the teachers are willing to use and like to use the intervention result in higher posttest scores for the students. 
Table 9

Regression Analysis Summary for Teacher and Student Affinity predicting Posttest Scores While Controlling for Pretest Scores

\begin{tabular}{|c|c|c|c|c|c|c|}
\hline Model & Predictors & B & SE B & Beta & $\mathrm{t}$ & $\mathrm{P}$ \\
\hline & (Constant) & 13.28 & 0.62 & & 21.51 & .000 \\
\hline \multirow[t]{2}{*}{ Restricted } & Pretest & 0.32 & 0.13 & 0.27 & 2.48 & .015 \\
\hline & (Constant) & 22.57 & 3.68 & & 6.14 & .000 \\
\hline \multirow[t]{3}{*}{ Full } & Pretest & 0.22 & 0.12 & 0.19 & 1.80 & .076 \\
\hline & $\begin{array}{l}\text { Teacher } \\
\text { Affinity }\end{array}$ & -0.57 & 0.16 & -0.38 & 3.65 & .001 \\
\hline & $\begin{array}{l}\text { Student } \\
\text { Affinity }\end{array}$ & 0.11 & 0.11 & 0.10 & 1.02 & .309 \\
\hline
\end{tabular}

Results of this study supported the hypotheses proposed in this study. Because no significant 2-way or 3-way interaction between levels of risk, sex, and treatment, the main effects were run. The Reciprocal Mapping treatment accounted for a statistically significant difference in the posttest scores which measured gain in social studies content knowledge. Furthermore, after controlling for pretest, it appeared that the Reciprocal Mapping technique also helped the low risk students perform better on the posttest, or at least did not interfere with gains. In addition, there was a statistically significant relationship between the fidelity of implementation and posttest scores. Finally, teacher affinity accounted for a statistically significant amount of unique variance in predicting 
posttest scores. Chapter V discusses the results and implications of these findings for research, theory, and practice. 


\section{CHAPTER V}

\section{DISCUSSION}

The final chapter provides a summary of the study, an interpretation of the data analyses, and an explanation of the study limitations. Implications for theory, policy, and practice are presented. The chapter concludes with recommendations for future research. The purpose of this study was to investigate student use of the Reciprocal Mapping instructional routine to comprehend informational text and three types of text structure, in seven, sixth-grade, social studies classrooms in a small rural school district.

Since findings show positive results for general education classrooms, which include a wide variety of students, it may benefit teacher preparation programs to include Reciprocal Mapping instructional routine as a strategy that has been shown to increase performance in social studies. Reciprocal Mapping has been used effectively in elementary classes with narrative text (Fine, 2004), and with the results of this study, it appears that Reciprocal Mapping is effective with informational texts found in social studies disciplinary text.

The study also supports the research cited in Chapter II, that the use of graphic organizers has overall positive effects on improving comprehension and writing of informational texts. Educators may consider the inclusion of graphic organizers, in general, and Reciprocal Mapping instructional maps, when teaching disciplinary subjects. In this study, it should be noted that students benefitted from using Reciprocal Mapping graphic organizers during their prewriting drafts. The results of the study show that the use of the Reciprocal Map was an effective intervention and may be considered as a strategy to be taught to beginning and novice teachers, and may have a place in 
professional development programs, especially with the implementation of the Common Core State Standards.

The theoretical bases of this dissertation are strongly evident in the results of the study, including explicit and direct teaching of targeted skills and concepts, the gradual release of responsibility from teacher to the student, and the reciprocity of reading and writing of informational text. Since Reciprocal Mapping is not overly complex or time consuming for the practicing professional to learn, it would appear to be a strategy that could be used in disciplinary classrooms.

It should be noted that the Reciprocal Mapping Instructional routine gives teachers insight into how their students are thinking about the topic of study. This is due to the use of the Reciprocal Mapping graphic organizer that provides the visual access to the teacher. As students add information onto their maps from the variety of informational text they read on each topic, teachers can see the developing knowledge "as it happens in real time." This is especially valuable when one considers consequential validity.

Messick (1989) notes that consequential validity is important to bear in mind in high-stakes testing situations such as FCAT. Consequential validity is "evidence and rationales for evaluating the intended and unintended consequences of score interpretation in both the short and long-term" (Messick, 1989). Consequential validity is important to consider because high-stakes testing is required by NCLB (2001) and states that testing "be valid for the purposes for which the assessment system is used". However, Shepard (1997) examined Messick's definition of consequential validity further by arguing one must investigate both "positive/negative intended and unintended 
consequences of score-based inferences." Further, Lane and Stone (2002) compared and contrasted state assessments intended positive consequences include:

- Increasing student, teacher, and administrator motivation and effort;

- Improving learning for all students;

- Providing professional development support.

Lane \& Stone (2002) and Lane (2005) found that, at times, unintended consequences are possible such as:

- Decreasing confidence and motivation to learn and perform well on assessments;

- Impacting grade promotion, retention, and high school graduation;

- Decreasing teacher and student effort morale

Using Reciprocal Mapping instructional routine allows the teacher to hone in on the positive aspects of immediate and positive student feedback thus avoiding possible negative feedback. Teachers can immediately see if the student needs to be scaffolded more and the level to which the scaffolding is needed. If the students are demonstrating successful knowledge of content acquisition, the teacher can direct appropriate praise. Conversely, if students are not able to demonstrate success, teachers can select from a number of ways to provide support using positive classroom language rather than negative feedback upon completion of task. This will reduce the risk of negative selfesteem issues that may be associated with failing grades. Further, neither student nor teacher has to wait an inordinate amount of time to see success in concept acquisition. 


\section{Summary of Study}

The study focused on high-risk readers, as determined by the Florida Comprehensive Assessment Test, level 1 and level 2 readers, but included all levels of readers. The goal of this study was to determine if the Reciprocal Mapping instructional routine was an effective reading intervention to use with sixth graders in a social studies classroom using a variety of informational text. This quasi-experimental study was conducted over a 5-week period with students who were randomly assigned to the classes. Classroom instruction was provided by veteran teachers in 45 minute sessions at similar times of the academic day. Students were explicitly taught the five most common informational text types with specific emphasis on compare and contrast, cause and effect, and problem and solution. Students were given a pretest in the first week of the study. Both the control and experimental classes used the Florida state adopted text, McGraw-Hill, Discovering Our Past: A History of the World Early Ages (Spielvogel, 2013), and a posttest was administered at the end of week five.

Specifically the research questions were:

Question 1: Is there a significant interaction between sex, treatment (Reciprocal Mapping approach and traditional instruction) and level of risk groups (low, Level 3, and High) in predicting gains on the McGraw-Hill Social Studies unit test, such that the highrisk group will gain more on the test?

Question 2: If there is no interaction or the interaction is ordinal, is there a significant difference between Reciprocal Mapping and traditional treatments in predicting posttest scores? 
Question 3: For the treatment group (Reciprocal Mapping) is there a relationship between the fidelity of implementation in predicting adjusted posttest scores adjusted on the McGraw-Hill pretest scores?

Question 4: Does each of the affinity scales (teacher affinity to the condition, and student affinity of the condition) account for significant amounts of unique variance on predating adjusted posttest scores?

\section{Research Findings}

This study had a treatment group of fifty students identified as low risk, FCAT levels 3,4 , or 5; and twenty eight students identified as high-risk, FCAT levels 1 or 2. The comparison group consisted of 45 students in the low risk category and 15 students in high-risk. The treatment group had 78 participants and the comparison group had 60 students.

Research question one asked if there was a significant interaction between three variables; gender, treatment (Reciprocal Mapping approach and traditional instruction) and level of risk groups on posttest scores while covarying the pretests scores. There was no significant 2-way or 3-way interaction between the level of risk and gender, level or risk and treatment, and level of risk, treatment, and gender. Because there was no interaction it was appropriate to interpret the main effects of the treatment.

Since the main effect of treatment accounted for a significant proportion of unique variance while controlling for gender and level of risk, research question two investigated the difference of the treatment and control groups in posttest gain scores. A statistically significant difference in posttest score gain was found when compared to the control group. 
Results indicate an overall positive effect for the Reciprocal Mapping instructional routine for students who are considered to be struggling readers as determined by results of the FCAT reading test for social studies content. Further, results suggest that the Reciprocal Mapping instructional routine may benefit all levels of readers in sixth grade social studies content. Reciprocal Mapping instruction routine could possibly increase scores for all students in a sixth-grade social studies classroom. Results of the Teacher fidelity to treatment indicated that there was a positive relationship between the consistency with which teachers followed the Reciprocal Mapping instructional routine and posttest scores. Students scores were higher for teachers with high fidelity scores. When examining the results of the affinity to treatment of both the teachers and students, it appears that there is a relationship between teacher's affinity to treatment, but not with student's affinity to treatment. This would indicate that if a teacher likes the Reciprocal Mapping instruction routine, their students are likely to perform better on the posttest scores.

Hypothesis one tested if there was a significant interaction between three variables; sex, treatment (Reciprocal Mapping approach and traditional instruction) and level of risk groups on posttest scores while covarying the pretests scores. There was no significant 2-way or 3-way interaction between the level of risk and sex, level or risk and treatment, and level of risk, treatment, and sex. Because there was no interaction it was appropriate to interpret the main effects of the treatment.

Since the main effect of treatment accounted for a significant proportion of unique variance while controlling for sex and level of risk, Hypothesis two investigated the difference of the treatment and control groups in posttest gain scores. A statistically 
significant difference in posttest score gain was found when compared to the control group. This indicates that at-risk readers scored significantly better than peers in the Reciprocal Mapping instructional routine treatment group.

Research Hypothesis three tested if teacher fidelity of implementation of the treatment was a statistically significant relationship in predicting posttest scores when controlling for pretest scores. A significant relation between the fidelity of implementation and predicting test scores was found; such that as the fidelity of implementation increased, so did the posttest scores. This indicated that when teachers follow the Reciprocal Mapping instructional routine the students scored higher than teachers who do not.

Hypothesis four tested if student and teacher affinity accounted for a significant amount of unique variance in predicting posttest scores while controlling for pretest scores. The results of the analysis showed that only teacher affinity accounted for a statistically significant amount of variance.

\section{Implications of Findings}

Findings suggest that the Reciprocal Mapping instructional routine is an effective teaching practice for students in content area classes aiding with understanding of informational text structure as well as comprehension of informational text. Reciprocal Mapping appears to be an effective strategy for both high-risk readers and proficient readers. Findings also suggest that Reciprocal Mapping instructional routine is equally effective for both male and female students.

As noted in Chapter II, a strength of graphic organizers is that they help students to visualize concepts and how they are related in text. With the use of Reciprocal 
Mapping, students were able to read text and extract pertinent information to include in their maps. By explicitly teaching students specific informational text types, they are able to navigate text more effectively by using target vocabulary, associated key words, and graphic organizers. From this study, students who used the Reciprocal Mapping instructional routine, were able find and remember targeted concepts from social studies text.

Important for many schools is the success that the Reciprocal Mapping instructional routine has in the whole group setting. For this study, Reciprocal Mapping was used during whole group classroom teaching, in classrooms that included general education students, exceptional education students, students who are not native English speakers, and gifted students. The nature of the Reciprocal Mapping instructional routine may allow the teacher to be able to effectively teach all types of students.

\section{Implications for Future Research}

There are several recommendations for future research. The length of the study was relatively short, at five weeks. However, within the five weeks, a full unit of study was completed. Further research of a longer duration in other settings would add to the knowledge base. Research of a longer duration may include a variety of social studies content that includes several chapters and it may indicate that the Reciprocal Mapping instructional routine is an effective intervention with a variety of social studies concepts and content. Other settings may indicate that the Reciprocal Mapping instructional routine is effective in larger schools and urban settings.

Future research might have participants engage with different types of informational text. Reciprocal Mapping is a strategy that has been shown to be 
successful with narrative text, (Fine, 2004) and with three types of informational social studies text in this study. The researcher believes that Reciprocal Mapping is a strategy that may show positive gains across the disciplinary curriculum and with any type of informational text. Further research in different disciplinary classes may bear out the effectiveness of the Reciprocal Mapping instructional routine.

It would be of interest for further research to investigate specific grade/age levels that students appear to be most able to gain knowledge from informational text and its features - and associated with that might be what grade level learns what aspect of informational text the best. In this study, students from sixth grade were able to effectively use a type of graphic organizers, the Reciprocal Map, to gain knowledge from informational text. An area of interest for further research might start at the fourth grade level, since traditionally, this is the grade level that students are often expected to be able to read from textbooks more intensely.

Transfer and generalization has been the subject of many research studies; student ability to gain knowledge in one class, and then to transfer and or generalize that specific knowledge to new or different situations. Further research is needed to examine the possibility of students transferring the concepts learned from this study in the social studies classroom, to other disciplinary classrooms would be of great interest. For example, for studying, reading text on the job, or outside of the school environment would be of interest to the adult learning community.

Florida's recent adoption of national standard, specifically the Common Core State Standards Initiative, which have placed literacy development in disciplinary classrooms emphasizes the importance of reading and writing. Students will be working 
more with informational materials and close examination of text will take on a more prominent role across the curriculum. Students will be expected to develop deep learning in disciplinary classrooms and will write about topics they research providing evidence to support their writings. All students, including at-risk students, have difficulty reading and comprehending informational text due to its relatively difficult text structure and specific vocabulary. However, students have shown that when explicitly taught informational text structure, they are better able to comprehend. Reciprocal Mapping instructional routine was found to be successful when used to teach sixth-grade social studies content. Reciprocal Mapping instructional routine explicitly teaches students informational text structure using an integrated reading and writing approach providing students an expertise needed to read informational text successfully.

\section{Significance of the Study}

The current study significantly contributes to the knowledge base related to literacy development in a variety of ways. First, national standards, specifically the Common Core State Initiative, situate literacy development directly in disciplinary areas (Common Core State Standards Initiative, 2010). This initiative emphasizes the importance of informational reading and writing. The current study contributes to the research base from which educators may draw research-based practices designed to support literacy development within disciplinary areas.

Second, many students, including high-risk readers, struggle when trying to read and comprehend informational text. Research supports the use of informational text which include the embedded text structures (Duke \& Bennett-Armistead, 2003; Hall, Sabey, \& McClellan, 2005; Moss, 2005; Purcell-Gates, Duke, \& Martineau, 2007; 
Reutzel, Read \& Fawson, 2009). Some research related to text structure has been shown to help students comprehend informational text, (Rosenshine \& Meister, 1994; Klingner, Vaughn \& Schumm, 1998; Guthrie, VanMeter, McCann, et al, 1996, Ciardiello, 2002; Williams, Stafford, Lauer, et al, 2009). Most looked at one specific text structure, with little emphasis on examining it within the context of authentic reading and writing. This study adds to the research base by examining a Reciprocal Mapping instructional routine that incorporates the five most common informational text structures in a way that directly supports the literacy development of all students, including those most high-risk in their reading development.

Third, Reciprocal Mapping has shown positive results related to primary students' ability to use and apply text structure with narrative text. The current study extends Reciprocal Mapping research to informational text structures. Additionally, it extends research in this area to sixth-grade students' comprehension of disciplinary text in the area of social studies. 


\section{REFERENCES}

Abadiano, H.R. \& Turner, J. (2002). Reading informational text: The challenges of students with learning disabilities. The New England Reading Association Journal, 38(2), 49-55.

Alexander, P. A., \& Jetton, T. L. (2000). Learning from text: A multidimensional and developmental perspective. In Kamil, M. L., Mosenthal, P. B., Pearson, P. D., \& Barr, R. (Eds.), Handbook of reading research (Vol. 3, pp. 285-310). Mahwah, NJ: Erlbaum.

Alfassi, M. (2004). Reading to learn: Effects of combined strategy instruction on high school students. The Journal of Educational Research, 97(4), 171-184. doi: 10.3200/JOER.97.4.171-185

Alger, C. (2009). Content area reading strategy knowledge transfer from preservice to first-year teaching. Journal of Adolescent \& Adult Literacy, 53(1), 60-69. doi: 10.1598/JAAL.53.1.6

Allington, R. L. (2002). You can't learn much from books you can't read. Educational Leadership, 60(3), 16-19.

Alvermann, D. E. (1982). Restructuring text facilitates written recall of main ideas. Journal of Reading, 8(25), 754-758.

Alvermann, D. E., \& Moore, D.W. (1991). Secondary school reading. In Barr, R., Kamil, M. L., Mosenthal, P., \& Pearson, P. D. (Eds.), Handbook of reading research, (Vol. 11, pp. 951-983). New York, NY: Longman.

American Institutes for Research. (2005). Reading framework for the 2009 National Assessment of Educational Progress pre-publication edition. Retrieved from http://www.nagb.org/content/nagb/assets/documents/publications/frameworks/rea ding09.

Anderson, R.C. \& Pearson, P.D. (1984). A schema-theoretic view of basic processes in reading comprehension. In P.D Pearson (ed.) Handbook of Reading Research. New York, NY: Longman.

Archer, A.L. \& Hughes, C.A. (2011). Explicit Instruction: Effective and Efficient Teaching. New York, NY: Guilford Press.

Armbruster, B.B., \& Anderson,T. H. (1988). On selecting "considerate" content area textbooks. Remedial and Special Education, 9, 47-52. doi: 10.1177/074193258800900109 
Armbruster, B.B., Anderson, T.H. \& Ostertag, J. (1987). Does text structure/summarization instruction facilitate learning from informational text? Reading Research Quarterly, 22(3), 331-346. doi: 10.2307/747972

Armbruster, B. B. (1991). Using Literature in the Content Areas (Reading to Learn). Reading Teacher, 45(4), 324-25.

Ausubel, D.P. (1960). The use of advance organizers in the learning and retention of meaningful very material. Journal of Educational Psychology, 51, 267-272. doi: $10.1037 / \mathrm{h} 0046669$

Baker, L., \& Brown, A. L. (1984). Metacognitive skills and reading. Handbook of Reading Research, 1, 353-394.

Bakken, J.P., Mastropieri, M.A., \& Scruggs, T.E. (1997). Reading comprehension of expository science material and students with learning disabilities: A comparison of strategies. Journal of Special Educaiton, (31) 300-324.

Barone, D. M. \& Morrow, L. M. (2003). Literacy and Young Children: Research-based Practices. New York, NY: Guilford Press.

Batalova, J., \& McHugh, M. (2010). Number and growth of students in US schools in need of English instruction (ELL Information Center Fact Sheet Series, Fact Sheet \#1). In 2010 Migration Policy Institute. Retrieved from http://www.migrationinformation.org/ellinfo/FactSheet_ELL1.pdf

Bear, D.R. (1991). "Learning to fasten the seat of my union suit without looking around": The synchrony of literacy development. Theory Into Practice, 30(3), 149-157.

Bear, D.R., Invernizzi, M., Templeton, S., \& Johnston, F. (2000). Words their way: Word study for phonics, vocabulary, and spelling instruction (2nd ed.). Columbus, $\mathrm{OH}$ : Merrill.

Beck, I., McKeown, M.G. \& Kucan, L. (2002). Bringing Words to Life: Robust Vocabulary Instruction. New York, NY: Guilford Press.

Bednarczyk , A. (1991). The effectiveness of story grammar instruction within a selfinstructional strategy development framework for students with learning disabilities. Unpublished doctoral dissertation. University of Maryland.

Beers, K. B. (2002). When kids can't read: What teachers can do. Portsmouth, NH: Heinemann.

Berliner, D. C., \& Calfee, R. C. (Eds.). (1996). Handbook of educational psychology. Mahwah, NJ: Routledge. 
Bernhardt, E., Destino, T., Kamil, M., \& Rodriguez-Munoz, M. (1995). Assessing science knowledge in English-Spanish bilingual elementary school. Cognosos, 4, 4-6.

Berman, P., \& McLaughlin, M. W. (1976). Implementation of educational innovations. Educational Forum, 40, 345-370.

Borkowski, J. G., Carr, M., \& Pressley, M. (1987). "Spontaneous” strategy use: Perspectives from metacognitive theory. Intelligence, 11(1), 61-75.

Bos, C. S., Anders, P. L., Filip, D., \& Jaffe, L. E. (1989). The effects of an interactive instructional strategy for enhancing reading comprehension and content area learning for students with learning disabilities. Journal of Learning Disabilities, 22, 384-389. doi: 10.1177/002221948902200611

Brown, C. L., \& Broemmel A. D. (2011). Deep scaffolding: enhancing the reading experiences of English language learners. The New England Reading Association Journal, 46(2), 34-39.

Brozo, W.G. (2010). The role of content literacy in an effective RTI program, The Reading Teacher, 64, 147-150. doi: 10.1598/RT.64.2.11

Brozo, W.G. (2010). Alternative Texts and Practices to Engage Male Readers. In To Be a Boy, To Be a Reader (pp. 137-159). Newark, DE: International Reading Association.

Brozo, W.G., \& Puckett, K.S. (2009). Supporting content area literacy with technology. Boston, MA: Allyn \& Bacon.

Bruner, J. (1986). Actual minds, possible worlds. Cambridge, MA: Harvard University Press.

Busching, B., \& Slesinger, B. A. (2002). " It's Our World Too": Socially Responsive Learners in Middle School Language Arts. National Council of Teachers of English.

Burstein, J.H. (2009). Do as I say and do as I do: Using the professor-in-residence model in teaching social studies methods. Social Studies, 100(3), 121-128. doi: 10.3200/TSSS.100.3.121-128

Butler, A., \& Turbill, J. (1984). Towards a Reading-Writing Classroom. Primary English Teaching Association. New South Wales: Australia.

Cakir, M. (2008). Constructivist Approaches to Learning in Science and Their Implications for Science Pedagogy: A Literature. International Journal of Environmental \& Science Education, 3(3). 
Campbell, D., \& Stanley, J. (1963). Experimental and quasi-experimental designs for research. Skokie, IL: Rand McNally.

Caswell, L. \& Duke, N.K. (1998). Non-narrative as catalyst for literacy development. Language Arts, 75(2), 108-117.

Century, J., Freeman, C., \& Rudnick, M. (2008). Measuring fidelity of implementation of instructional materials: A conceptual framework. American Education.

Chall, J.S. (1983). Stages of reading development. New York, NY: McGraw-Hill.

Chang, K.E., Sung, .T., \& Chen, I.D. (2002). The effect of concept mapping to enhance text comprehension and summarization. Journal of Experimental Education, 71, 5-23. doi:10.1080/00220970209602054

Chmielewski, T., Dansereau, D.F. (1998). Enhancing the recall of text: Knowledge mapping training promotes implicit transfer. Journal of Educational Psychology, 90, 407-413. doi: 10.1037/0022-0663.90.3.407

Chularut, P., \& DeBacker, T.K. (2004). The influence of concept mapping on achievement, self-regulation, and self-efficacy in students of English as a second language. Contemporary Educational Psychology, 29, 248-263. doi:10.1016/j.cedpsych.2003.09.001

Ciardiello, A. V. (2002). Helping adolescents understand cause/effect text structure in social studies. Social Studies, 93, 31-36.

Ciborowski, J. (1995). Using textbooks with students who cannot read them. Remedial and Special Education, 16(2), 90-101.

Clark, J.H. (1991). Using visual organizers to focus on thinking. Journal of Reading, 7(34), 526-534.

Clark, K.F. \& Graves, M.F. (2005). Scaffolding students' comprehension of text. The Reading Teacher, 58(6), 570-80. doi: 10.1598/RT.58.6.6

Coiro, J., \& Dobler, E. (2007). Exploring the online reading comprehension strategies used by sixth-grade skilled readers to search for and locate information on the Internet. Reading Research Quarterly, 42(2), 214-257. doi: 10.1598/RRQ.42.2.2

Colarossi, L. G., \& Eccles, J. S. (2003). Differential effects of support providers on adolescents' mental health. Social Work Research, 27, 19-30.

Collier-Meek, M., Fallon, L. M., Sanetti, L., \& Maggin, D. (2013). FOCUS on Implementation. Teaching Exceptional Children, 45(5), 52-59. 
Common Core State Standards Initiative (2010). Common core State Standards for English language arts \& literacy in history/social studies, science, and technical subjects. Washington, DC: National Governors Association Center for Best Practices and the Council of Chief State School Officers. Retrieved from http://www.corestandards.ort/assets/CCSSI_ELA\%20Standards.pdf.

Czerniak, C.M., \& Lumpe, A. T. (1996). Relationship between teacher beliefs and science education reform. Journal of Science Teacher Education, 7, 247-266. doi: 10.1007/BF00058659

Dane, A. V., \& Schneider, B. H. (1998). Program integrity in primary and early secondary prevention: Are implementation effects out of control? Clinical Psychology Review, 18(1), 23-45.

DeWitt, S., \& Freie, C. (2005). Focusing methods on goals: Problems and possibilities, Social Studies, 96(6), 241-245. doi: 10.3200/TSSS.96.6.240-246

DiCecco, V.M., \& Gleason, M.M. (2002). Using graphic organizers to attain relational knowledge from informational text. Journal of Learning Disabilities, 35, 306320. doi: $10.1177 / 00222194020350040201$

Donovan, C.A., \& Smolkin, L.B. (2002). Children's genre knowledge: An examination of K-5 students' performance on multiple tasks providing differing levels of scaffolding. Reading Research Quarterly, 37, 428-465.

Duffy, G.G. (2002). The case for direct explanation of strategies. In C.C. Block \& M. Pressley (Eds.) Comprehension instruction: Research-based best practices (pp. 28-41). New York: Guilford.

Duffy, G. G., Roehler, L. R., Meloth, M. S., Vavrus, L. G., Book, C., Putnam, J., \& Wesselman, R. (1986). The relationship between explicit verbal explanations during reading skill instruction and student awareness and achievement: A study of reading teacher effects. Reading Research Quarterly, 237-252.

Duffy, G. G., Roehler, L. R., Sivan, E., Rackliffe, G., Book, C., Meloth, M. S., ... \& Bassiri, D. (1987). Effects of explaining the reasoning associated with using reading strategies. Reading Research Quarterly, 347-368.

Duke, N.K. (2000a). 3.6 minutes per day: The scarcity of informational texts in first grade. Reading Research Quarterly, 35(1), 202-224. doi: 10.1598/RRQ.35.2.1

Duke, N.K. (2000b). For the rich it's richer: Print experiences and environments offered to children in very low-and very high-SES first grade classrooms. American Educational Research Journal, 37, 441-478.

Duke, N. K. (2004). The case for informational text. Educational Leadership,61(6), 4045. 
Duke, N.K., \& Bennett-Armistead, V.S. (2003). Reading \& writing informational text in the primary grades. New York, NY: Scholastic.

Duke, N.K., \& Pearson, P.D. (2002). Effective practices for developing reading comprehension. In A.E. Farstrup \& S.J. Samuels (Eds.) What research has to say about reading instruction (3rd ed., pp. 205.242). Newark, DE: International Reading Association.

Dusenbury, L., Brannigan, R., Falco, M., \& Hansen, W. B. (2003). A review of research on fidelity of implementation: implications for drug abuse prevention in school settings. Health Education Research, 18(2), 237-256.

Dymock, S. (2007). Comprehension strategy instruction: Teaching narrative text structure awareness. The Reading Teacher, 61(2), 161-167.

Eccles, J. S. (1993). School and family effects on the ontogeny of childrens' interests, self-perceptions, and activity choice. Nebraska Symposium on Motivation, 40, 145-208.

Englert, C.S., Zhao, Y., Dunsmore, K., Collings, N.Y., \& Wolbers, K. (2007). Scaffolding the writing of students with disabilities through procedural facilitation: Using an Internet-based technology to improve performance. Learning Disabilities Quarterly, (3)1, 9-29. doi: 10.2307/30035513

Fang, Z. (2006). The language demands of science reading in Middle School. International Journal of Science Education, 28(5), 491-520. doi: 10.1080/09500690500339092

Fang, Z. (2008). Going beyond the Fab Five: Helping students cope with the unique linguistic challenges of informational reading in intermediate grades, Journal of Adolescent \& Adult Literacy, 51(6), 476-487. doi: 10.1598/JAAL.51.6.4

Fang, Z., Schleppegrell, M.J. \& Cox, B.E. (2003). Understanding the language demands of schooling: Nouns in academic registers', Journal of Literacy Research, 38: 3, 247-273. doi: 10.1207/s15548430j1r3803_1

Faust, M. A., \& Glenzer, N. (2000). "I could read those parts over and over": Eighth graders rereading to enhance enjoyment and learning with literature. Journal of Adolescent \& Adult Literacy, 44(3), 234-239.

Fine, J. (1997). Empowering teachers through a professional development school and classroom action research. In K. Camperell \& R. Telfer (Eds.), Yearbook of the American Reading Forum: Promises, progress and possibilities: Perspectives of literacy education. Vol. 17 (pp.165-179). Dahlonega, GA: American Reading Forum. 
Fine, J. (2004). Reciprocal mapping: Scaffolding student's literacy to higher levels. In A. Rodgers \& E. Rodgers (Eds), Strategies for scaffolding literacy instruction in K-4 classrooms. (pp. 88-104). Portsmouth, NH: Heinemann.

Fisher, D. \& Frey, N. (2008). Better learning through structured teacher: a framework for the gradual release of responsibility. Portsmouth, NH: Heinemann.

Fisher, D., \& Frey, N. (2009). Background knowledge: The missing piece of the comprehension puzzle. Portsmouth, NH: Heinemann.

Fisher, D., \& Frey, N. (2013). Background knowledge: The overlooked factor in reading comprehension. Columbus, OH: McGraw Hill Education.

Flood, J. \& Lapp, D. (1986). Types of texts: The match between what students read in basals and what they encounter in tests. Reading Research Quarterly (21). 284297.

Fuchs, D., \& Fuchs, L.S. (2005). Peer-assisted learning strategies: Promoting word recognition, fluency, and reading comprehension in young children. Journal of Special Education, 39, 34-44. doi: 10.1177/00224669050390010401

Fullan, M. (2001). The meaning of educational change. New York: Teachers College Press.

Gallavan, N.P. \& Kottler, E. (2007). Eight types of graphic organizers for empowering social studies students and teachers. The Social Studies, 98(3), 117-123; doi: 10.3200/TSSS.98.3

Gambrell, L.B. (2005). Reading literature, reading text, reading the Internet: The times they are a'changing. The Reading Teacher, 59(4), 310- 319.

García, O. (2011). Bilingual education in the 21st century: A global perspective. Wiley. com.

Goldman, S. R. (1997). Learning from text: Reflections on the past and suggestions for the future. Discourse Processes, 23, 357-398. doi: 10.1080/01638539709544997

Goldman, S.R., \& Rakeshaw, J.A., Jr. (2000). Structural aspects of constructing meaning from text. In M.L. Kamil, P.B. Mosenthal, P.D.Pearson, \& R Barr (Eds), Handbook of reading research (Vol. 33, pp. 311-335). Mahwah, NY: Erlbaum.

Goodlad, J. (1984). A place called school. New York, NY: McGraw-Hill.

Goswami, U. (2000). Phonological and lexical processes. In M. L. Kamil, P. Mosenthal, P. D. Pearson, \& R. Barr (Eds.), Handbook of reading research (Vol. 3, pp. 251267). Mahwah, NJ: Erlbaum. 
Goudvis, A. \& Buhrow, B. (2011). History lessons. In E. Keene \& S. Zimmermann (Eds), Comprehension going forward (pp. 128-149). Portsmouth, NH: Heinemann.

Graney, M. J. (1992). A framework for using text graphing. System, 20, 161-167. doi:10.1016/0346-251X(92)90022-U

Green, J.A. \& Azevedo, R. (2007). Adolescents' use of self-regulatory processes and their relation to qualitative mental model shifts while using hypermedia. Journal of Educational Computing Research, 36(2), 125-128.

Gunning, T. G. (2003). The role of readability in today's classrooms. Topics in Language Disorders, 23(3), 175-189. doi: 10.1097/00011363-200307000-00005

Guthrie, J.T., Van Meter, P., McCann, A., Wigfield, A., Bennett, L., Poundstone, C., Rice, M.E., Fabisch, E., Hunt, B., \& Mitchell, A. (1996). Growth of literacy engagement: Changes in motivations and strategies during Concept-Oriented Reading Instruction. Reading Research Quarterly, 31, 306-332.

Hall, K.M., Sabey, B.L., \& McClellan, M (2005). Informational text comprehension: Helping primary-grade teachers use informational texts to full advantage. Reading Psychology, 26, 211-234. doi: 10.1080/02702710590962550

Hall, K. M., \& Sabey, B. L. (2007). Focus on the facts: Using information texts effectively in early elementary classrooms. Early Childhood Education Journal, 35(3), 261-268.

Hall, R.H., Hall, M.A. \& Saling, C.B. (1999). The effects of graphical postorganization strategies on learning from knowledge maps. The journal of Experimental Education, 67(2), 101-112. doi: 10.1080/00220979909598347

Harlen, W. (1997). Primary teachers' understanding in science and its impact in the classroom, Research in Science Education, 27, 323-337. doi: 10.1007/BF02461757

Harniss, M., Dickson, S. ,Kinder, D. \& Hollenbeck, K. (2001). Textual problems and instructional solutions: Strategies for enhancing learning from published history textbooks. Reading and Writing Quarterly, 17, 127-150. doi: $10.1080 / 105735601300007598$

Harvey, S. (2010). Comprehension, to what end? In Kenne, E. and Zimmerman, S. (Eds) Comprehension Going Forward. Portsmouth, NH: Heinemann.

Hoffman, J.V., McCartney, J., Abbott, J., Christian, C., Corman, L., Curry, C., Stahl, D. (1994). So what's new in the new basals? A focus on first grade. Journal of Reading Behavior, 26, 47-73. 
Holton, D., \& Clarke, D. (2006). Scaffolding and metacognition. International Journal of Mathematics Education in Science and Technology, 37(2), 127-143.

Holton, D., \& Thomas, G. (2002). Mathematical interactions and their influence on learning. In Perspectives on practice and meaning in mathematics and science classrooms (pp. 75-104). Springer Netherlands.

Hooper, S. R., Costa, L. J. C., McBee, M., Anderson, K. L., Yerby, D. C., Childress, A., $\&$ Knuth, S. B. (2011). A written language intervention for at-risk second grade students: a randomized controlled trial of the process assessment of the learner lesson plans in a tier 2 response-to-intervention (RtI) model. Annals of dyslexia, $1-21$.

Horton, S.C., Lovitt, T.C. \& Bergerud, D. (1990). The effectiveness of graphic organizers for three classifications of secondary student in content area classes. Journal of Learning Disabilities, 23, 12-29. doi: 10.1177/002221949002300107

Individuals with Disabilities Improvement Education Act (2004). http://idea.ed.gov

Inspiration, (2007). Portland, OR: Inspiration Software, Inc. http://www.inspiration.com.

Irwin, M. (2003). Massey Magazine, (14) www.massey.ac.nz/ wwpubafs/magazine/2003.

Jeong, J., Gaffney, J.S., \& Choi, J. (2010). Availability and use of informational texts in second-, third-, and fourth-grade classrooms. Research in the Teaching of English, 44, 435-456.

Jerald, C.D. (2009). Defining a 21st century education. In The Center for Public Education. Retrieved from http://www.centerforpubliceducation.org/ LearnAbout/21st-Century/Defining-a-21stCentury-Education-Full-Report-PDF.pdf

Jobe, R., \& Dayton-Sakari, M. (2002). Info-Kids: How to use nonfiction to turn reluctant readings into enthusiastic learners. Pembroke Publishers: Ontario, Canada.

Jonassen, D.H., \& Carr, C.S. (2000). Mindtools: Affording multiply knowledge representations for learning. In S.P. Lajoie (Ed). Computers as cognitive tools: No more walls (pp. 165-196). Mahwah, NJ: Erlbaum.

Juel, C. and Minden-Cupp, C. (2000), Learning to Read Words: Linguistic Units and Instructional Strategies. Reading Research Quarterly, 35: 458-492. doi: 10.1598/RRQ.35.4.2

Juel, C. Hebard, H., Haubner, J.P., \& Moran, M. (2010). Reading through a disciplinary lens. Educational Leadership (67). 6:12-17. 
Kamil, M.L., Borman, G.D., Dole, J., Kral, C.C., Salinger, T., \& Torgesen, J. (2008). Improving adolescent literacy: Effective classroom and intervention practices: A Practice Guide (NCEE \#2008-4027). Washington, D.C.: National Center for Education Evaluation and Regional Assistance, Institute of Education Sciences, U.S. Department of Education. Retrieved from ies.ed.gov/ncee/wwc

Kamil, M.L., \& Lane, D.M. (1998). Researching the relation between technology and literacy: An agenda for the 21st century. In Reinking, D.R., Labbo, L.D., McKenna, M., \& Kieffer, R. (Eds.) Literacy for the 21st century: Technological transformations in a post-typographic world (pp. 323-342). Mahwah, NJ: Erlbaum.

Kamil, M.L. and Bernhardt, E.B. (2004). The science of reading and the reading of science: Successes, failures, and promises in the search for prerequisite reading skills for science. In E.W. Saul (Ed.), Crossing borders in literacy and science instruction. Arlington, Va: International Reading Association.

Kenne, E.O., \& Zimmermann, S. (2007). Mosaic of thought: the power of comprehension strategy instruction. Portsmouth, NH: Heinemann.

Kim, A., Vaughn S., Wanzek J., \& Wei, S. (2004). Graphic organizers and their effects on the reading comprehension of students with LD: A synthesis of research. Journal of Learning Disabilities, 37, 105- 118. doi:10.1177/00222194040370020201

Kirk, R. E. (1995). Experimental design: Procedures for the behavioral sciences. (3rd ed.).Pacific Grove, CA: Brooks/Cole.

Kline, P. (2000). The handbook of psychological testing. Psychology Press.

Klingner, J.K., Vaughn, S., \& Schumm, J.S. (1998). Collaborative strategic reading during social studies in heterogeneous fourth grade classrooms. The Elementary School Journal, 99, 3-22. doi: 10.1086/461914

Koumy, E., \& Salam, A. (1999). Effects of three semantic mapping strategies on EFL students reading comprehension. (ERIC Document Reproduction Service No. ED 435 193).

Kucan, L., \& Beck, I. L. (1997). Thinking aloud and reading comprehension research: Inquiry, instruction, and social interaction. Review of Educational Research, 67, 271-299.

Kujawa, S., \& Huske, L. (1995). The Strategic Teaching and Reading Project guidebook (Rev. ed.). Oak Brook, IL: North Central Regional Educational Laboratory. 
Kutner, M., Greenbert, E., Jin, Y., Boyle, B., Hsu, Y., \& Dunleavy, E. (2007). Literacy in everyday life: Results from the 2003 national assessment of adult literacy (NCES 2007-480). U.S. Department of Education, National Center for Education Statistics. Retrieved from http://nces.ed.gov/whatsnew/commissioner /remarks2005/12_15_2005.asp

Lane, S. (2005). The Conceptual Framework for the Development of a Mathematics Performance Assessment Instrument. Educational Measurement (12). DOI: $10.1111 /$ j.1745-3992.1993.tb00529.x

Lane, S., \& Stone, C.A. (2002). Strategies for Examining the Consequences of Assessment and Accountability Programs. Educational Measurement (21)1,DOI: 10.1111/j.1745-3992.2002.tb00082.x

Langer, J.A. (1984). Examining background knowledge and text comprehension. Reading Research Quarterly, 19(4), 468-481. doi: 10.2307/747918

Lapp, D., Flood, J., Brock, C., \& Fisher, D. (2007). Teaching Reading to Every Child, (4th ed.), Mahwah, NJ. Lawrence Erlbaum.

Leland, C.H., \& Harste, J.C. (1994). Multiple ways of know: Curriculum in a new key. Language Arts, 71, 337-345.

Leu, F.J., Jr. (2000). Literacy and Technology: Deictic Consequences for Literacy Education in an information age. In Kamil, M.L., Pearson, P.D. \& Barr, R. (Eds.) Handbook of Reading Research, Vol.III. Mahway, NJ: Erlbaum.

Leu, D.J., Jr., Kinzer, C.D., Coiro, J.L., \& Cammack, D.W. (2004). Toward a theory of new literacies emerging from the internet and other information and communication technologies. In Ruddell, R.B., \& Unrau, N.J. (Eds.) Theoretical models and processes of reading (5th Ed., pp. 1570-1613). Newark, DE: International Reading Association.

Levstik \& Barton (2001). Doing history: Investigating with children in elementary and middle schools. Mahwah, NJ: Erlbaum.

Loban, W. (1976). Language development: Kindergarten through grade twelve (Research Report No. 18). Urbana, IL: National Council of Teachers of English.

Loucks, S. F. (1983, April). Defining fidelity: A cross-study analysis. Paper presented at the annual meeting of the American Educational Research Association, Montreal, Quebec, Canada.

Lyda, W. J., \& Duncan, F. M. (1967). Quantitative vocabulary and problem solving. The Arithmetic Teacher, 14, 289-291. 
Mackinnon, G.R., \& Keppell, M. (2005). Concept Mapping: A unique means for negotiating meaning in professional studies, Journal of Educational Multimedia and Hypermedia 14(3), 291-315.

Mantzicopoulos, P., \& Patrick, H. (2010). "The seesaw is a machine that goes up and down": Young children's narrative responses to science-related informational text. Early Education and Development, 21(3), 412-444. doi: $10.1080 / 10409281003701994$

Mason, L.H. (2004). Explicit Self-Regulated Strategy Development Versus Reciprocal Questioning: Effects on Expository Reading Comprehension Among Struggling Readers. Journal of Educational Psychology, 96(2), 283-296. doi: 10.1037/00220663.96.2.283

Mayer, R. E. (2001). Multimedia Learning. New York: Cambridge University Press.

McConachie, S., Hall, M., Resnick, L., Ravi, A.K., Bill, V.L. Bintz, J., \& Taylor, J.A. (2006). Task, text, and talk: Literacy for all subjects. Educational Leadership, $6(2), 8-14$.

McFann, J. (2004). Boys and books. Reading today, 22(1), 20-21.

Messik, S. (1989). Validity. In R.L.Linn (Ed.) Educational measurement New York: Macmillan.

Meuwissen, K.W. (2005). Maybe someday the twain shall meet: exploring disconnections between methods instruction and "Life in the Classroom." The Social Studies, 96(6) 253-258. doi: 10.3200/TSSS.96.6.253-258

Meyer, B. J., \& Poon, L. W. (2001). Effects of structure strategy training and signaling on recall of text. Journal of Educational Psychology, 93(1), 141.

Meyer, B.J., \& Freedle, R.O. (1984). Effects of discourse type on recall. American Education Research Journal, 21(1), 121-143. doi: 10.3102/0002831202100112

Millis, K. K., \& King, A. (2001). Rereading strategically: The influences of comprehension ability and a prior reading on the memory for informational text. Reading Psychology, 22(1), 41-65. doi: 10.1080/02702710151130217

Montelongo, J. A., \& Hernández, A. C. (2007). Reinforcing expository reading and writing skills: A more versatile sentence completion task. The Reading Teacher, 60(6), 538-546.

Moss, B. (1991). Children's nonfiction trade books: A complement to content area texts. The Reading Teacher, 45, 26-32. doi: 10.1080/027027102317345376 
Moss, B. (2005). Making a case and place for effective content area literacy instruction in the elementary grades. The Reading Teacher, 59(1), 46-55.

Moss, B. (2008). The information text gap" The mismatch between non-narrative text types in basal readers and 2009 NAEP recommended guidelines. Journal of Literacy Research, 40(2), 201-219. doi: 10.1080/10862960802411927

Moss, B., \& Newton, E. (2002). An examination of the informational text genre in basal readers. Reading Psychology, 23, 1-13.

Moss, B., \& Hendershot, J. (2002). Exploring sixth graders' selection of nonfiction trade books. The Reading Teacher, 56, 6-17

Mowbray, C. T., Holter, M. C., Teague, G. B., \& Bybee, D. (2003). Fidelity criteria: Development, measurement, and validation. American Journal of Evaluation, 24(3), 315-340.

Nagy,W. E. (1988). Teaching Vocabulary to Improve Reading Comprehension. Newark, DE: International Reading Association.

National Assessment of Adult Literacy (NAAL). nces.ed.gov/naal.

National Assessment Governing Board. (2008). Reading framework for the 2009 National Assessment of Educational Progress. Retrieved from http://www.nagb.org/publications/frameworks/reading09.pdf

National Research Council Committee for a Review of the Evaluation Data on the Effectiveness of NSF-Supported and Commercially Generated Mathematics Curriculum Materials, Mathematical Sciences Education Board, Center for Education, Division of Behavioral and Social Sciences and Education. (2004). On evaluating curricular effectiveness: Judging the quality of K-12 mathematics evaluations. Washington, DC: National Academies Press.

National Reading Panel (NRP) (2000). Teaching children to read: An evidence-based assessment of the scientific research literature on reading and its implications for reading instruction. Washington, DC: National Institute of Child Health and Human Development.

Novak, J. D. (1990). Concept maps and vee diagrams: Two metacognitive tools for science and mathematics education. Instructional Science, 19, 29-52.

O’Brien, D. G. (1998). Multiple literacies in a high-school program for "at-risk" adolescents. In D. E. Alvermann, K. A. Hinchman, D. W. Moore, S. F. Phelps, \& D. R. Waff (Eds.), Reconceptualizing the literacies in adolescents' lives (pp. 2749). Mahwah, NJ: Erlbaum. 
O'Brien, D. G., Stewart, R. A., \& Moje, E. B. (1995). Why content literacy is difficult to infuse into the secondary school: Complexities of curriculum, pedagogy, and school culture. Reading Research Quarterly, 442-463.

O'Donnell, C. L. (2008). Defining, conceptualizing, and measuring fidelity of implementation and its relationship to outcomes in K-12 curriculum intervention research. Review of Educational Research, 78(1), 33.

O’Donnell, A. M., Dansereau, D. F., \& Hall, R. H. (2002). Knowledge maps as scaffolds for cognitive processing. Educational Psychology Review, 14, 71-86. doi:10.1023/A:1013132527007

Ogle, D., \& Blachowicz, C.L.Z. (2002). Beyond literature circles: Helping students comprehend informational texts. In C.C. Block \& M. Pressley (Eds.), Comprehension instruction: Research-based best practice (pp. 259-274). New York: Guilford.

Palincsar, A.S. (2003). Collaborative approaches to comprehension instruction. In A.R. Sweet \& C.E. Snow (Eds.), Rethinking reading comprehension (pp. 99-114). New York, NY: Guilford.

Palmer, R.G. \& Stewart, R. A. (2005). Models for using nonfiction in the primary grades. The Reading Teacher, 57, 38-48

Paivio, A. (1991). Dual coding theory: Retrospect and current status. Canadian Journal of Psychology/Revue canadienne de psychologie, 45(3), 255.

Pappas, C.C. (2006). The information book genre: Its role in integrated science literacy research and practice. Reading Research Quarterly (41). 226-250.

Paris, S.G., Wasik, B., Turner, J.C. (1991). The development of strategic readers. In Barr, R., Kamil, K.L., Mosenthal, P.B., Pearson, P.D. (Eds.) Handbook of reading research, Vol. 2 (pp. 609-640). Hillsdale, NJ: Lawrence Erlbaum.

Pearson, P.D. (1985). Changing the face of reading comprehension instruction. The Reading Teacher, 38(6), 724-738.

Pearson, P.D., Moje, E., \& Greenleaf, C. (2010). Literacy and science, each in the service of the other. Science, 328, 459-463. doi: 10.1126/science.1182595

Pintrich, P. R., \& Zusho, A. (2002). The development of academic self-regulation: The role of cognitive and motivational factors.

Pintrich, P. R., Marx, R. W., \& Boyle, R. A. (1993). Beyond cold conceptual change: The role of motivational beliefs and classroom contextual factors in the process of conceptual change. Review of Educational Research, 63(2), 167-199. 
Pressley, M., \& Wharton-McDonald, R. (2006). The need for increased comprehension instruction. In: M. Pressley (Ed.), Reading instruction that works (pp. 293-346). New York: Guilford Press.

Price, L.H., van Kleeck, A., Huberty, C.J. (2009). Talk during book sharing between parents and preschool children: A comparison between storybook and expository book conditions. Reading Research Quarterly, 44(2), 171-194.

Purcell-Gates, V., Duke, N. K., \& Martineau, J. A. (2007). Learning to read and write genre-specific text: Roles of authentic experience and explicit teaching. Reading Research Quarterly, 42(1), 8-45.

RAND Reading Study Group (2002). Reading for understanding: Toward an R \& D program in reading comprehension. Santa Monica, CA: RAND.

Reutzel, R., Read, S., \& Fawson, P. (2009). Using Information Trade Books as Models for Teaching Expository Text Structure to Improve Children's Reading Comprehension: An Action Research Project. Journal of Reading Education,33.

Reutzel, D.R., Smith, J.A., \& Fawson, P.C. (2005). An evaluation of two approaches for teaching reading comprehension strategies in the primary years using science information texts. Early Childhood research Quarterly, 20, 276-305. doi: 10.1016/j.ecresq.2005.07.002

Richhart, R., Hadar, L., \& Turner, T. (April 2008). Uncovering students thinking about thinking using concept maps. Paper presented at American Education Research Association, New York.

Ritchhart, R., \& Perkins, D. (2008). Making thinking visible. Educational Leadership, 65(5), 57-61.

Robinson, D. H., Katayama, A. D., Dubois, N. F., \& Devaney, T. (1998). Interactiveeffects of graphic organizers and delayed review on concept application. Journal of Experimental Education, 67, 17-31. doi: $10.1080 / 00220979809598342$

Roeser, R., Eccles, J., \& Sameroff, A. J. (1998). Academic and emotional functioning in early adolescence: Longitudinal relations, patterns, and prediction by experience in middle school. Developmental and Psychopathology, 10, 321-352.

Rosenshine, B., \& Meister, C. (1994). Reciprocal teaching: A review of the research. Review of educational research, 64(4), 479-530.

Ruddell, R. \& Unrau, N. (1994). Reading as a meaning-construction process: The reader, the text, and the teacher. In R. Ruddell, M. Ruddell, \& H. Singer (Eds.), Theoretical Models and Processes of Reading. Newark, NJ: International Reading Association. 
Sackes, M., Trundle, K.C. \& Flevares, L.M. (2009). Using children's literature to teach standard-based science concepts in early years. Early Childhood Education Journal, 36(5), 415-422. doi: 10.1007/s10643-009-0304-5. doi: 10.1007/s10643009-0304-5

Sanacore, J., \& Palumbo, A. (2009). Understanding the Fourth-Grade Slump: Our Point of View. The Educational Forum, 73, 67-74.

Scheirer, M. A., \& Rezmovic, E. L. (1983). Measuring the degree of program implementation: A methodological review. Evaluation Review, 7, 599- 633.

Schmar-Dobler, E. (2003). Reading on the internet: The link between literacy and technology. Journal of Adolescent and Adult Literacy, 47, 88-85.

Sen, T. (2011). Fidelity of implementation of research experience for teachers in the classroom. (Doctoral dissertation). Retrieved September 26, 2013 from ASU Dissertations and Theses database. http://hdl.handle.net/2286/R.I.15934

Shanahan, T., \& Shanahan, C. (2008). Teaching disciplinary literacy to adolescents: Rethinking content-area literacy. Harvard Educational Review, 78, 40-61.

Shepard, L.A. (1997). The Centrality of test use and consequences for test validity. Educational Measurement, (16)2.

Smith, F. 1978. Understanding reading. 2d ed. New York: Holt.

Spielvogel, J.J. (2013). Discovering our past: A history of the world early ages. Columbus, OH: McGraw-Hill.

Stanovich, K.E. (1986). Matthew effects in reading: Some consequences of individual differences in the acquisition of literacy. Reading Research Quarterly, 21(4), 360407. doi: 10.1598/RRQ.21.4.1

Strangman, N., \& Hall, T. (2004). Background knowledge. Wakefield, MA: National Center on Accessing the General Curriculum. Retrieved from http://www.aim.cast.org/learn/historyarchive/backgroundpapers/background_kno wledge

Strong American Schools (2008). Diploma to Nowhere. Washington, DC: Author. Retrieved from www.deltacostprojectorg/resources/pdf/DiplomaToNowhere.pdf

Stull, A.T., \& Mayer, R.E. (2007). Learning by doing versus learning by viewing: Three experimental comparisons of learner-generated versus author-provided graphic organizers. Journal of Educational Psychology, 99, 808-820. doi: 10.1037/00220663.99.4.808 
Sternberg, R. J. (1985). Beyond IQ: A Triarchic Theory of Intelligence. Cambridge: Cambridge University Press.

Sternberg, R. J. (1997). A Triarchic View of Giftedness: Theory and Practice. In N. Coleangelo \& G. A. Davis (Eds.), Handbook of Gifted Education (pp. 43-53). Boston, MA: Allyn and Bacon.

Swafford, J. \& Kallus,M. (2002). Content literacy: A journey into the past, present, and future. Journal of Content Area Reading (1) 7 - 18.

Swars, S. L., \& Dooley, C. M (2010). Changes in teaching efficacy during a professional development school-based science methods course. School Science and Mathematics, 110(4), 192-202. doi: 10.1111/j.1949-8594.2010.00022.x

Taylor, B.M., Pearson, P.D., Clark, K.F., \& Walpole, S. (2000). Effective schools and accomplished teachers: Lessons about primary-grade reading instruction in lowincome schools. Elementary School Journal, 101, 121-165. doi: 10.1086/499662

Treiman, R., \& Rodriguez, K. (1999). Young children use letter names in learning to read words. Psychological Science, 10(4), 334-338.

Turner, J. C., \& Meyer, D. K. (2000). Studying and understanding the instructional contexts of classrooms: Using our past to forge our future. Educational Psychologist, 35(2), 69-85.

U.S. Bureau of Labor Statistics (2010). News Release, USDL 10-0533. Retrieved from http://www.bls.gov/news.release/hsgec.toc.htm on Nov. 25, 2010.

Van Kleeck, A., Gillam, R., Hamilton, L., \& McGrath, C. (1997). The relationship between middle-class parents' book-sharing discussion and their preschoolers' abstract language development. Journal of Speech, Language, and Hearing Research, 40(6), 1261-1271.

Venezky, R.L. (2000). The origins of the present day chasm between adult literacy needs and school literacy instruction. Scientific Studies of Reading, 4(1), 19-39. doi:10.1207/S1532799XSSR0401_3

Vygotsky, L. S. (1978). Mind in society. Cambridge, MA: Harvard University Press.

Wade, S. E., \& Moje, E. B. (2000). The role of text in classroom learning. In R. Barr, M.L. Kamil, P.B. Mosenthal, P.D. Pearson, \& R. Barr (Eds.). Handbook of reading research (Vol. III, pp. 609-627). New York: Longman.

Walker, N. T., \& Bean, T. W. (2005). Sociocultural influences in content area teachers' selection and use of multiple texts. Literacy Research and Instruction,44(4), 6177. 
Wallace, R., Pearman, C., Hail, C., \& Hurst, B. (2007). Writing for comprehension. Reading Horizons, 48(1), 41-56.

Wharton-McDonald, R., Pressley, M., \& Hampston, J.M. (1998). Literacy instruction in nine first-grade classrooms: Teacher characteristics and student achievement. Elementary School Journal, 99, 101-128. doi: 10.1086/461918

Wigfield, A., Guthrie, J.T., Tonks, S., \& Perencevich, K.C. (2004). Children's motivation for reading: Domain specificity and instructional influences. Journal of Educational Research, 97(6), 299-309. doi: 10.3200/JOER.97.6.299-310

Williams, J. (2003). Teaching text structure to improve reading comprehension. In Swanson, H.L., Harris, K.R., \& Graham, S. (Eds). Handbook of learning disabilities (pp. 239-305). New York: Guilford Press.

Williams, J. P., Stafford, K. B., Lauer, K. D., Hall, K. M., \& Pollini, S. (2009). Embedding reading comprehension training in content-area instruction. Journal of Educational Psychology, 101(1), 1.

Wood, D., Bruner, J.S., \& Ross, G. (1976). The role of tutoring in problem solving. Journal of Child Psychology and Psychiatry, 17, 89-100. doi: 10.1111/j.14697610.1976.tb00381.x

Wood, K., Vintinner, J., Hill-Miller, P., Harmon, J., \& Hedrick, W. (2009). An investigation of teachers' concerns about vocabulary and the representation of these concerns in content literacy methodology textbooks. Reading Psychology, 30, 319-339. doi:10.1080/02702710802411562

Yopp, R. H., \& Yopp, H.K. (2012). Young children's limited and narrow exposure to informational text, The Reading Teacher, 65(7), 480-490. doi: 10.1002/TRTR.01072

Yopp, R.H., \& Yopp, H.K. (2006). Informational text as read-alouds at school and home. Journal of Literacy Research, 38(1), 37-51. doi:10.1207/s15548430j1r3801_2

Zarnowski, M. (2006). Making sense of history. New York, NY: Scholastic. 
APPENDICES 
Appendix A: Pacing Guide for County's 6th Grade Social Studies

\section{Quarter 1}

Historical Thinking Skills:

\section{Quarter 3}

Geography

India

1. Map Skills/Types

1. Geographic Features

2. Religions

2. Geographic terms

3. Empires \& Dynasties

3. Latitude \& Longitude

4. Six Essential Elements of Geography

Tools of the Historian

1. Historical terms

2. Archaeology

Beginning of Human Society

1. Old Stone Age

2. New Stone Age

\section{Quarter 2}

Mesopotamia

1. Geographic Features

2. Achievements, Events \& Key Figures

3. Contributions of Mesopotamia

Egypt

1. Geographic Features

2. Achievements, Events \& Key Figures

3. Contributions of Egypt

Judaism

1. Geographic Area

2. Major Figures \& Beliefs

4. Achievements, Events, \& Key Figures

5. Contributions China

1. Geographic Features

2. Philosophies

3. Silk Road \& Trade

4. Mongol Empire

5. Key Figures \& Contributions of Classical and Post Classical China

6. Cause \& Effect of Chinese isolation

\section{Quarter 4} Greece

1. Geographic Features

2. Achievements, Events, \& Contributions

3. Key Figures

4. Compare \& Contrast Sparta and Athens

5. Democratic Concepts

6. Wars \& Alphabet Rome

1. Geographic Features

2. Achievements, Events, Key Figures \& Contributions

3. Rise \& Fall of the Roman Empire

4. Social Classes

5. Christianity

6. Influence of Latin Language 
Appendix B: Study Time Frame

\begin{tabular}{|c|c|c|}
\hline Wk. & Control Group & Experimental Group \\
\hline 1 & $\begin{array}{l}\text { Pre-test and Unit Introduction. Unit } \\
\text { introduction includes preview of pertinent } \\
\text { vocabulary, video clip, chapter preview, } \\
\text { worksheets, timeline and What Do You Know } \\
\text { activity. }\end{array}$ & $\begin{array}{l}\text { Pre-test and Unit Introduction. } \\
\text { Briefly review five informational text types } \\
\text { chart. Unit introduction includes preview of } \\
\text { pertinent vocabulary, video clip, chapter } \\
\text { preview, timeline and What Do You Know } \\
\text { activity. }\end{array}$ \\
\hline 2 & $\begin{array}{l}\text { Review unit concepts. Overview lesson one. } \\
\text { Teach vocabulary associated with lesson. } \\
\text { During lecture students take notes on } \\
\text { objectives selected to be covered. Activities } \\
\text { may include reading from the textbook, taking } \\
\text { notes, answering textbook questions, } \\
\text { completing worksheets, answering teacher } \\
\text { questions, viewing videos. }\end{array}$ & $\begin{array}{l}\text { Briefly review five informational text types } \\
\text { chart. Use Reciprocal Mapping to explicitly } \\
\text { teach Compare and Contrast text type, its } \\
\text { ancillary signal words and types of graphic } \\
\text { organizers commonly used. Students will } \\
\text { demonstrate knowledge of Compare/Contrast } \\
\text { after completion of teacher's modeling and } \\
\text { creating individual maps. Students then use } \\
\text { passages from the textbook to reinforce use of } \\
\text { Compare/Contrast. }\end{array}$ \\
\hline 3 & $\begin{array}{l}\text { Review previous week's objective; teach } \\
\text { objectives for lesson two. Teach associated } \\
\text { vocabulary. During lecture have students take } \\
\text { notes on selected objectives. Activities may } \\
\text { include reading from the textbook, taking } \\
\text { notes, answering textbook questions, } \\
\text { completing worksheets, answering teacher } \\
\text { questions, viewing videos. Students may be } \\
\text { asked to write a summary of objectives taught } \\
\text { in lessons one and two. Traditional } \\
\text { assignments include answering questions at } \\
\text { the end of each lesson, writing a summary or } \\
\text { answering teacher questions. }\end{array}$ & $\begin{array}{l}\text { Briefly review five informational text types } \\
\text { chart. Use Reciprocal Mapping to explicitly } \\
\text { teach Cause and Effect text type, its ancillary } \\
\text { signal words and graphic organizers. Students } \\
\text { will demonstrate knowledge of Cause/Effect } \\
\text { after completion of teacher's modeling and } \\
\text { creating individual maps. Students then use } \\
\text { lesson two passages from the textbook to } \\
\text { reinforce Cause/Effect. Give students a variety } \\
\text { of trade books, informational books, Internet } \\
\text { sites in addition to textbook to begin to build } \\
\text { individual maps. Teacher builds Reciprocal Map } \\
\text { to model as students begin to create their own. } \\
\text { Class Reciprocal Map includes lesson one and } \\
\text { two objectives. Maps can be created on using } \\
\text { Inspiration or similar if desired. Students use } \\
\text { their maps to organize objectives as a pre- } \\
\text { writing activity. Assignments may include } \\
\text { Power Point, pamphlet, or Microsoft Word } \\
\text { document. Teacher will circulate and ensure that } \\
\text { students are accurately filling out the graphic } \\
\text { organizers. }\end{array}$ \\
\hline 4 & $\begin{array}{l}\text { Review previous weeks objectives; teach } \\
\text { objectives for lesson three. Teach associated } \\
\text { vocabulary. During lecture have students take } \\
\text { notes on selected objectives. Activities may } \\
\text { include reading from the textbook, taking } \\
\text { notes, answering textbook questions, } \\
\text { completing worksheets, answering teacher } \\
\text { questions, viewing videos. }\end{array}$ & $\begin{array}{l}\text { Briefly review five informational text types } \\
\text { chart. Use Reciprocal Mapping to explicitly } \\
\text { teach Problem and Solution text type, its } \\
\text { ancillary signal words and graphic organizers. } \\
\text { Students will demonstrate knowledge of } \\
\text { Problem/Solution after completion of teacher's } \\
\text { modeling and creating individual maps. Students } \\
\text { then use passages from lesson three in the } \\
\text { textbook to reinforce Problem/Solution. } \\
\text { Continue to build class and individual maps } \\
\text { using a variety of informational text materials. }\end{array}$ \\
\hline
\end{tabular}




\begin{tabular}{|l|l|l|}
\hline & & $\begin{array}{l}\text { Students continue using their maps for class } \\
\text { assignments. Teacher continually circulates to } \\
\text { ensure that students are accurately completing } \\
\text { their maps. Reteach/review if/as needed. }\end{array}$ \\
\hline 5 & $\begin{array}{l}\text { End of unit review. Review instructional } \\
\text { objectives from social studies textbook. Unit } \\
\text { wrap up and review for posttest. Administer } \\
\text { the posttest. }\end{array}$ & $\begin{array}{l}\text { End of unit review. Review instructional } \\
\text { objectives from social studies textbook, using } \\
\text { student made maps from weeks two - four. Use } \\
\text { Reciprocal Maps to finalize artifacts. Review the } \\
\text { three explicitly taught informational text types. } \\
\text { Unit wrap up and review for posttest. Administer } \\
\text { the posttest. }\end{array}$ \\
\hline
\end{tabular}


Appendix C: Five Most Common Informational Text Types

\begin{tabular}{|c|c|c|}
\hline $\begin{array}{c}\text { Informational Text } \\
\text { Type }\end{array}$ & Signal Words & Graphic Organizer \\
\hline Description & $\begin{array}{l}\text { For example } \\
\text { Characteristics } \\
\text { For instance } \\
\text { Such as } \\
\text { Including }\end{array}$ & \\
\hline Sequence & $\begin{array}{l}\text { First, second, third } \\
\text { Next, after that, then } \\
\text { Finally, at the end } \\
\text { Previously }\end{array}$ & \\
\hline $\begin{array}{c}\text { Compare and } \\
\text { Contrast }\end{array}$ & $\begin{array}{c}\text { However, in contrast } \\
\text { Similarly, in the same way } \\
\text { On the other hand, both } \\
\text { Either/or } \\
\text { Like, just as }\end{array}$ & \\
\hline Cause and Effect & $\begin{array}{c}\text { If/then } \\
\text { Because } \\
\text { Consequently } \\
\text { As a result } \\
\text { Due to } \\
\text { Therefore }\end{array}$ & $C$ \\
\hline Problem and Solution & $\begin{array}{l}\text { Problem is } \\
\text { Dilemma is } \\
\text { If/then } \\
\text { As a result } \\
\text { So that }\end{array}$ & PROBLEM \\
\hline
\end{tabular}


Appendix D: Teacher Fidelity to Treatment

\begin{tabular}{|l|l|l|l|}
\hline \multicolumn{1}{|c|}{ Characteristic } & \multicolumn{1}{|c|}{ Mastery 3 } & \multicolumn{1}{|c|}{ Sufficient 2 } & \multicolumn{1}{c|}{ Limited 1 } \\
\hline $\begin{array}{l}\text { Has set to interest } \\
\text { students on social } \\
\text { studies topic of } \\
\text { study. }\end{array}$ & $\begin{array}{l}\text { Has a few questions } \\
\text { to interest students } \\
\text { on topic }\end{array}$ & $\begin{array}{l}\text { Has question or } \\
\text { statement to interest } \\
\text { students in topic. }\end{array}$ & $\begin{array}{l}\text { Does not open with } \\
\text { a question or } \\
\text { statement to interest } \\
\text { students in topic. }\end{array}$ \\
\hline $\begin{array}{l}\text { Has allowed } \\
\text { students to read } \\
\text { trade books on topic } \\
\text { prior to beginning } \\
\text { textbook }\end{array}$ & $\begin{array}{l}\text { Has allowed } \\
\text { students to read } \\
\text { trade books and } \\
\text { make a vocabulary } \\
\text { notebook on topic } \\
\text { prior to beginning } \\
\text { textbook passage. }\end{array}$ & $\begin{array}{l}\text { Has allowed } \\
\text { students to read } \\
\text { trade books on topic } \\
\text { textbook bassages. }\end{array}$ & $\begin{array}{l}\text { Has trade books in } \\
\text { classroom, but may } \\
\text { not have them } \\
\text { displayed in an } \\
\text { interesting manner } \\
\text { or allowed students } \\
\text { time to read them. }\end{array}$ \\
\hline $\begin{array}{l}\text { Has explained the } \\
\text { concept of text } \\
\text { structure }\end{array}$ & $\begin{array}{l}\text { Has explained the } \\
\text { concept of text } \\
\text { structure and } \\
\text { developed chart of } \\
\text { signal words. }\end{array}$ & $\begin{array}{l}\text { Has explained the } \\
\text { concept of text } \\
\text { structure and told } \\
\text { signal words. }\end{array}$ & $\begin{array}{l}\text { Has explained the } \\
\text { concept of text } \\
\text { structure } \\
\text { mentioning some or } \\
\text { not mentioning } \\
\text { signal words. }\end{array}$ \\
\hline $\begin{array}{l}\text { Has provided guided } \\
\text { practice in } \\
\text { identifying the text } \\
\text { structure and } \\
\text { students' ability to } \\
\text { put information on a } \\
\text { map. }\end{array}$ & $\begin{array}{l}\text { Has allowed the } \\
\text { students to work in } \\
\text { collaborative groups } \\
\text { each mapping } \\
\text { different examples } \\
\text { of text structure and } \\
\text { share their work } \\
\text { with the whole } \\
\text { group. }\end{array}$ & $\begin{array}{l}\text { Has allowed the } \\
\text { students to work in } \\
\text { collaborative groups } \\
\text { to map text structure } \\
\text { and share their } \\
\text { work. The same text } \\
\text { is used by each } \\
\text { group. }\end{array}$ & $\begin{array}{l}\text { Has not allowed the } \\
\text { students to work in } \\
\text { collaborative groups } \\
\text { to map text structure } \\
\text { and/or share their } \\
\text { work. }\end{array}$ \\
\hline
\end{tabular}




\begin{tabular}{|c|c|c|c|}
\hline $\begin{array}{l}\text { Characteristic } \\
\text { Materials: has } \\
\text { provided text that } \\
\text { matches the type of } \\
\text { text structure being } \\
\text { studied. }\end{array}$ & $\begin{array}{l}\text { Mastery } \\
\text { Has provided text } \\
\text { from the textbook } \\
\text { that clearly matches } \\
\text { the type of text } \\
\text { structure and topic } \\
\text { of study. }\end{array}$ & $\begin{array}{l}\text { Sufficient } \\
\text { Has provided text } \\
\text { that matches the } \\
\text { type of text } \\
\text { structure that is } \\
\text { from the textbook. }\end{array}$ & $\begin{array}{l}\text { Limited } \\
\text { Has not provided } \\
\text { text that has a clear } \\
\text { example of the type } \\
\text { of text structure. }\end{array}$ \\
\hline $\begin{array}{l}\text { Has identified } \\
\text { vocabulary words } \\
\text { that might be used } \\
\text { on students' } \\
\text { Reciprocal Mapping } \\
\text { map and text. }\end{array}$ & $\begin{array}{l}\text { Has allowed } \\
\text { students to identify } \\
\text { key vocabulary } \\
\text { words that might be } \\
\text { used on students' } \\
\text { Reciprocal Mapping } \\
\text { map and text. }\end{array}$ & $\begin{array}{l}\text { Has identified key } \\
\text { vocabulary words } \\
\text { for students to use } \\
\text { on students' } \\
\text { Reciprocal Mapping } \\
\text { map and text. }\end{array}$ & $\begin{array}{l}\text { Has not identified } \\
\text { vocabulary words or } \\
\text { allowed students to } \\
\text { identify vocabulary } \\
\text { words that might be } \\
\text { used on Reciprocal } \\
\text { Mapping map and } \\
\text { text. }\end{array}$ \\
\hline $\begin{array}{l}\text { Has explained } \\
\text { writing process and } \\
\text { read and given } \\
\text { feedback to support } \\
\text { the students as they } \\
\text { write informational } \\
\text { artifacts. }\end{array}$ & $\begin{array}{l}\text { Has explained } \\
\text { writing process and } \\
\text { read and given } \\
\text { feedback to support } \\
\text { the students as they } \\
\text { write informational } \\
\text { artifacts. }\end{array}$ & $\begin{array}{l}\text { Has read and given } \\
\text { feedback to support } \\
\text { the students as they } \\
\text { write informational } \\
\text { artifacts. }\end{array}$ & $\begin{array}{l}\text { Has not read and/or } \\
\text { given feedback to } \\
\text { students as they } \\
\text { write informational } \\
\text { artifacts. }\end{array}$ \\
\hline $\begin{array}{l}\text { Has supported the } \\
\text { presentation of } \\
\text { information book of } \\
\text { student's social } \\
\text { studies writing. }\end{array}$ & $\begin{array}{l}\text { Has supported the } \\
\text { presentation of } \\
\text { information book of } \\
\text { students social } \\
\text { studies writing to } \\
\text { allow time for } \\
\text { students to socially } \\
\text { interact with } \\
\text { positive comments } \\
\text { as they share their } \\
\text { information book } \\
\text { presentations or } \\
\text { books made from } \\
\text { slides from } \\
\text { information book. }\end{array}$ & $\begin{array}{l}\text { Has supported the } \\
\text { presentation of } \\
\text { information book } \\
\text { either as } \\
\text { presentation or } \\
\text { books, of student's } \\
\text { social studies } \\
\text { writing. }\end{array}$ & $\begin{array}{l}\text { Has not supported } \\
\text { the presentation of } \\
\text { information books } \\
\text { of student's social } \\
\text { studies writing or } \\
\text { allowed time for } \\
\text { students to socially } \\
\text { interact as they } \\
\text { share their } \\
\text { information book or } \\
\text { books made from } \\
\text { information book. }\end{array}$ \\
\hline
\end{tabular}


Appendix E: Teacher Affinity of Reciprocal Mapping

\begin{tabular}{|c|c|c|c|c|c|}
\hline Characteristic & $\begin{array}{l}\text { strongly } \\
\text { disagree } \\
\text { (1) }\end{array}$ & $\begin{array}{l}\text { disagree } \\
\text { (2) }\end{array}$ & neutral (3) & agree (4) & $\begin{array}{l}\text { strongly } \\
\text { agree (5) }\end{array}$ \\
\hline $\begin{array}{l}\text { 1. Reciprocal Mapping is } \\
\text { a strategy the student is } \\
\text { able to apply for learning } \\
\text { each of the informational } \\
\text { text structures in Social } \\
\text { Studies text. }\end{array}$ & $\begin{array}{l}\text { I strongly } \\
\text { disagree that } \\
\text { Reciprocal } \\
\text { Mapping is a } \\
\text { strategy the } \\
\text { student is able } \\
\text { to apply for } \\
\text { learning each } \\
\text { of the } \\
\text { informational } \\
\text { text structures } \\
\text { in Social } \\
\text { Studies text. }\end{array}$ & $\begin{array}{l}\text { I disagree that } \\
\text { Reciprocal } \\
\text { Mapping is a } \\
\text { strategy the } \\
\text { student is able } \\
\text { to apply for } \\
\text { learning each } \\
\text { of the } \\
\text { informational } \\
\text { text structures } \\
\text { in Social } \\
\text { Studies text. }\end{array}$ & $\begin{array}{l}\text { Reciprocal } \\
\text { Mapping is a } \\
\text { strategy may } \\
\text { have helped } \\
\text { the student } \\
\text { learn } \\
\text { informational } \\
\text { text structures } \\
\text { in Social } \\
\text { Studies text. }\end{array}$ & $\begin{array}{l}\text { I agree that } \\
\text { Reciprocal } \\
\text { Mapping is a } \\
\text { strategy the } \\
\text { student is able } \\
\text { to apply for } \\
\text { learning each } \\
\text { of the } \\
\text { informational } \\
\text { text structures } \\
\text { in Social } \\
\text { Studies text. }\end{array}$ & $\begin{array}{l}\text { I strongly agree } \\
\text { that Reciprocal } \\
\text { Mapping is a } \\
\text { strategy the } \\
\text { student is able } \\
\text { to apply for } \\
\text { learning each } \\
\text { of the } \\
\text { informational } \\
\text { text structures } \\
\text { in Social } \\
\text { Studies text. }\end{array}$ \\
\hline $\begin{array}{l}\text { 2. Learning Social Studies } \\
\text { using Reciprocal Mapping } \\
\text { enables the student to } \\
\text { collaborate with peers. }\end{array}$ & $\begin{array}{l}\text { I strongly } \\
\text { disagree that } \\
\text { learning Social } \\
\text { Studies using } \\
\text { Reciprocal } \\
\text { Mapping } \\
\text { enables the } \\
\text { student to } \\
\text { collaborate } \\
\text { with peers. }\end{array}$ & $\begin{array}{l}\text { I disagree that } \\
\text { learning Social } \\
\text { Studies using } \\
\text { Reciprocal } \\
\text { Mapping } \\
\text { enables the } \\
\text { student to } \\
\text { collaborate } \\
\text { with peers. }\end{array}$ & $\begin{array}{l}\text { Learning Social } \\
\text { Studies using } \\
\text { Reciprocal } \\
\text { Mapping may } \\
\text { have enabled } \\
\text { the student to } \\
\text { collaborate } \\
\text { with peers. }\end{array}$ & $\begin{array}{l}\text { I agree that } \\
\text { learning Social } \\
\text { Studies using } \\
\text { Reciprocal } \\
\text { Mapping } \\
\text { enables the } \\
\text { student to } \\
\text { collaborate } \\
\text { with peers. }\end{array}$ & $\begin{array}{l}\text { I strongly agree } \\
\text { that learning } \\
\text { Social Studies } \\
\text { using } \\
\text { Reciprocal } \\
\text { Mapping } \\
\text { enables the } \\
\text { student to } \\
\text { collaborate } \\
\text { with peers. }\end{array}$ \\
\hline $\begin{array}{l}\text { 3. Learning Social Studies } \\
\text { using Reciprocal Mapping } \\
\text { enables the student to } \\
\text { write using evidence } \\
\text { about the content from } \\
\text { the texts. }\end{array}$ & $\begin{array}{l}\text { I strongly } \\
\text { disagree that } \\
\text { learning Social } \\
\text { Studies using } \\
\text { Reciprocal } \\
\text { Mapping } \\
\text { enables the } \\
\text { student to } \\
\text { write using } \\
\text { evidence about } \\
\text { the content } \\
\text { from the texts. }\end{array}$ & $\begin{array}{l}\text { I strongly } \\
\text { disagree that } \\
\text { learning Social } \\
\text { Studies using } \\
\text { Reciprocal } \\
\text { Mapping } \\
\text { enables the } \\
\text { student to } \\
\text { write using } \\
\text { evidence about } \\
\text { the content } \\
\text { from the texts. }\end{array}$ & $\begin{array}{l}\text { Learning Social } \\
\text { Studies using } \\
\text { Reciprocal } \\
\text { Mapping may } \\
\text { have enabled } \\
\text { the student to } \\
\text { write using } \\
\text { evidence about } \\
\text { the content } \\
\text { from the texts. }\end{array}$ & $\begin{array}{l}\text { I strongly agree } \\
\text { that learning } \\
\text { Social Studies } \\
\text { using } \\
\text { Reciprocal } \\
\text { Mapping } \\
\text { enables the } \\
\text { student to } \\
\text { write using } \\
\text { evidence about } \\
\text { the content } \\
\text { from the texts. }\end{array}$ & $\begin{array}{l}\text { I strongly agree } \\
\text { that learning } \\
\text { Social Studies } \\
\text { using } \\
\text { Reciprocal } \\
\text { Mapping } \\
\text { enables the } \\
\text { student to } \\
\text { write using } \\
\text { evidence about } \\
\text { the content } \\
\text { from the texts. }\end{array}$ \\
\hline $\begin{array}{l}\text { 4. Learning Social Studies } \\
\text { using Reciprocal Mapping } \\
\text { enables the student to } \\
\text { discuss Social Studies } \\
\text { content. }\end{array}$ & $\begin{array}{l}\text { I strongly } \\
\text { disagree that } \\
\text { learning Social } \\
\text { Studies using } \\
\text { Reciprocal } \\
\text { Mapping } \\
\text { enables the } \\
\text { student to } \\
\text { discuss SS } \\
\text { content. }\end{array}$ & $\begin{array}{l}\text { I disagree that } \\
\text { learning Social } \\
\text { Studies using } \\
\text { Reciprocal } \\
\text { Mapping } \\
\text { enables the } \\
\text { student to } \\
\text { discuss Social } \\
\text { Studies } \\
\text { content. }\end{array}$ & $\begin{array}{l}\text { Learning Social } \\
\text { Studies using } \\
\text { Reciprocal } \\
\text { Mapping may } \\
\text { have enabled } \\
\text { the student to } \\
\text { discuss Social } \\
\text { Studies } \\
\text { content. }\end{array}$ & $\begin{array}{l}\text { I agree that } \\
\text { learning Social } \\
\text { Studies using } \\
\text { Reciprocal } \\
\text { Mapping } \\
\text { enables the } \\
\text { student to } \\
\text { discuss Social } \\
\text { Studies } \\
\text { content. }\end{array}$ & $\begin{array}{l}\text { I strongly agree } \\
\text { that learning } \\
\text { Social Studies } \\
\text { using } \\
\text { Reciprocal } \\
\text { Mapping } \\
\text { enables the } \\
\text { student to } \\
\text { discuss SS } \\
\text { content. }\end{array}$ \\
\hline
\end{tabular}


Appendix F: Student Affinity of Reciprocal Mapping

\begin{tabular}{|c|c|c|c|c|c|}
\hline Characteristic & $\begin{array}{l}\text { strongly } \\
\text { disagree } \\
\text { (1) }\end{array}$ & $\begin{array}{l}\text { disagree } \\
\text { (2) }\end{array}$ & eutral (3) & gree (4) & $\begin{array}{l}\text { strongly } \\
\text { agree (5) }\end{array}$ \\
\hline $\begin{array}{l}\text { 1. Reciprocal } \\
\text { Mapping is a strategy } \\
\text { I can use to learn each } \\
\text { of the informational } \\
\text { text structures in } \\
\text { Social Studies text. }\end{array}$ & \begin{tabular}{|l|} 
I strongly \\
disagree that \\
Reciprocal \\
Mapping is a \\
strategy I can \\
use to learn \\
informational \\
text structures \\
in Social \\
Studies text.
\end{tabular} & $\begin{array}{l}\text { I disagree that } \\
\text { that } \\
\text { Reciprocal } \\
\text { Mapping is a } \\
\text { strategy I can } \\
\text { use to learn } \\
\text { informational } \\
\text { text structures } \\
\text { in Social } \\
\text { Studies text }\end{array}$ & $\begin{array}{l}\text { Reciprocal } \\
\text { Mapping is a } \\
\text { strategy that } \\
\text { may help me } \\
\text { learn } \\
\text { informational } \\
\text { text structures } \\
\text { in Social } \\
\text { Studies text. }\end{array}$ & $\begin{array}{l}\text { I agree that } \\
\text { that } \\
\text { Reciprocal } \\
\text { Mapping is a } \\
\text { strategy I can } \\
\text { use to learn } \\
\text { informational } \\
\text { text structures } \\
\text { in Social } \\
\text { Studies text. }\end{array}$ & $\begin{array}{l}\text { I strongly } \\
\text { agree that } \\
\text { Reciprocal } \\
\text { Mapping is a } \\
\text { strategy I can } \\
\text { use to learn } \\
\text { informational } \\
\text { text structures } \\
\text { in Social } \\
\text { Studies text. }\end{array}$ \\
\hline $\begin{array}{l}\text { 2. Learning Social } \\
\text { Studies using } \\
\text { Reciprocal Mapping } \\
\text { enables me to } \\
\text { collaborate with } \\
\text { peers. }\end{array}$ & \begin{tabular}{|l|} 
I strongly \\
disagree that \\
learning \\
Social Studies \\
using \\
Reciprocal \\
Mapping \\
enabled me to \\
collaborate \\
with peers.
\end{tabular} & $\begin{array}{l}\text { I disagree that } \\
\text { learning } \\
\text { Social Studies } \\
\text { using } \\
\text { Reciprocal } \\
\text { Mapping } \\
\text { enabled me to } \\
\text { collaborate } \\
\text { with peers. }\end{array}$ & $\begin{array}{l}\text { Learning } \\
\text { Social Studies } \\
\text { using } \\
\text { Reciprocal } \\
\text { Mapping may } \\
\text { have enabled } \\
\text { me to } \\
\text { collaborate } \\
\text { with peers. }\end{array}$ & $\begin{array}{l}\text { I agree that } \\
\text { learning } \\
\text { Social Studies } \\
\text { using } \\
\text { Reciprocal } \\
\text { Mapping } \\
\text { enabled me to } \\
\text { collaborate } \\
\text { with peers. }\end{array}$ & $\begin{array}{l}\text { I strongly } \\
\text { agree that } \\
\text { learning } \\
\text { Social Studies } \\
\text { using } \\
\text { Reciprocal } \\
\text { Mapping } \\
\text { enabled me to } \\
\text { collaborate } \\
\text { with peers. }\end{array}$ \\
\hline $\begin{array}{l}\text { 3. Learning Social } \\
\text { Studies using } \\
\text { Reciprocal Mapping } \\
\text { enables me to write } \\
\text { using evidence about } \\
\text { the content from the } \\
\text { texts. }\end{array}$ & \begin{tabular}{|l} 
I strongly \\
disagree that \\
learning \\
Social Studies \\
using \\
Reciprocal \\
Mapping \\
enabled me to \\
write using \\
evidence \\
about the \\
content from \\
the texts. \\
\end{tabular} & \begin{tabular}{|l} 
I strongly \\
disagree that \\
learning \\
Social Studies \\
using \\
Reciprocal \\
Mapping \\
enabled me to \\
write using \\
evidence \\
about the \\
content from \\
the texts \\
\end{tabular} & $\begin{array}{l}\text { Learning } \\
\text { Social Studies } \\
\text { using } \\
\text { Reciprocal } \\
\text { Mapping may } \\
\text { have enabled } \\
\text { me to write } \\
\text { using } \\
\text { evidence } \\
\text { about the } \\
\text { content from } \\
\text { the texts. }\end{array}$ & $\begin{array}{l}\text { I strongly } \\
\text { agree that } \\
\text { learning } \\
\text { Social Studies } \\
\text { using } \\
\text { Reciprocal } \\
\text { Mapping } \\
\text { enabled me to } \\
\text { write using } \\
\text { evidence } \\
\text { about the } \\
\text { content from } \\
\text { the texts }\end{array}$ & $\begin{array}{l}\text { I strongly } \\
\text { agree that } \\
\text { learning } \\
\text { Social Studies } \\
\text { using } \\
\text { Reciprocal } \\
\text { Mapping } \\
\text { enabled me to } \\
\text { write using } \\
\text { evidence } \\
\text { about the } \\
\text { content from } \\
\text { the texts. }\end{array}$ \\
\hline $\begin{array}{l}\text { 4. Learning Social } \\
\text { Studies using } \\
\text { Reciprocal Mapping } \\
\text { enables me to discuss } \\
\text { Social Studies } \\
\text { content. }\end{array}$ & $\begin{array}{l}\text { I strongly } \\
\text { disagree that } \\
\text { learning } \\
\text { Social Studies } \\
\text { using } \\
\text { Reciprocal } \\
\text { Mapping } \\
\text { enabled me to } \\
\text { discuss Social } \\
\text { Studies } \\
\text { content. }\end{array}$ & $\begin{array}{l}\text { I disagree that } \\
\text { learning } \\
\text { Social Studies } \\
\text { using } \\
\text { Reciprocal } \\
\text { Mapping } \\
\text { enabled me to } \\
\text { discuss Social } \\
\text { Studies } \\
\text { content. }\end{array}$ & $\begin{array}{l}\text { Learning } \\
\text { Social Studies } \\
\text { using } \\
\text { Reciprocal } \\
\text { Mapping may } \\
\text { have enabled } \\
\text { me to discuss } \\
\text { Social Studies } \\
\text { content. }\end{array}$ & $\begin{array}{l}\text { I agree that } \\
\text { learning } \\
\text { Social Studies } \\
\text { using } \\
\text { Reciprocal } \\
\text { Mapping } \\
\text { enabled me to } \\
\text { discuss Social } \\
\text { Studies } \\
\text { content. }\end{array}$ & $\begin{array}{l}\text { I strongly } \\
\text { agree that } \\
\text { learning } \\
\text { Social Studies } \\
\text { using } \\
\text { Reciprocal } \\
\text { Mapping } \\
\text { enabled me to } \\
\text { discuss Social } \\
\text { Studies } \\
\text { content. }\end{array}$ \\
\hline
\end{tabular}


Appendix G: Overview of the Reciprocal Mapping Instructional Routine

\begin{tabular}{|c|c|}
\hline Title & \\
\hline Summary & $\begin{array}{l}\text { Students are explicitly taught an integrated and iterative } \\
\text { reading/writing strategy, using visual representation to } \\
\text { make concrete the reading process they encounter using } \\
\text { social studies informational text. }\end{array}$ \\
\hline \multicolumn{2}{|c|}{$\begin{array}{l}\text { Time Frame: Lessons are fifty minutes, initial explicit instruction of the strategy, } \\
\text { Reciprocal Mapping, and each text type are presented in the fifty minute time frame. } \\
\text { Subsequent lessons include practice of the three text types with informational text used in social } \\
\text { studies classroom. }\end{array}$} \\
\hline \multicolumn{2}{|c|}{$\begin{array}{l}\text { Psychological Framework: Explicit initial instruction, students copy exactly what the } \\
\text { teacher does, I Do. Students then create their own examples copying exactly the process the } \\
\text { teacher showed, You Do, I Help. Once students show mastery of text type, they continue } \\
\text { reading social studies informational text as teacher observes. You Do, I Watch. (Scaffolding). }\end{array}$} \\
\hline \multicolumn{2}{|c|}{$\begin{array}{l}\text { Objectives: Students will be able to recognize three types of informational text } \\
\text { commonly found in informational text, and use graphic organizers to help comprehend social } \\
\text { studies concepts. } \\
\text { 1. Compare and Contrast - most often use a Venn Diagram or type of T-Chart to place te } \\
\text { and to generate written summary. } \\
\text { 2. Cause and Effect - most often use a box (cause) with arrows leading to other boxes } \\
\text { (effect) to place text and generate written summary. } \\
\text { 3. Problem and Solution - will use a problem/solution organizer where they place the } \\
\text { problem, the steps needed to solve it, leading to the solution and generate written } \\
\text { summary. }\end{array}$} \\
\hline \multicolumn{2}{|c|}{$\begin{array}{l}\text { Guiding Questions: CCSS require that students learn to: } \\
\text { 1. Compare and contrast the most important points and key details presented in two text on } \\
\text { the same topic (p. 14). } \\
\text { 2. Describe the relationship between a series of historical events using language that } \\
\text { pertains to time, sequence, and cause and effect (p. 14). } \\
\text { 3. Describe how a text presents information (e.g., sequentially, comparatively, causally). } \\
\text { For students this can mean that they are able to read a variety of informational text } \\
\text { commonly found in sixth-grade classrooms with mastery. Further, they will be able to use } \\
\text { graphic organizers to help them understand informational text as well as their related text } \\
\text { features. }\end{array}$} \\
\hline $\begin{array}{l}\text { Lesson Fo } \\
\text { 1. Show char } \\
\text { projector, } \\
\text { as they list } \\
\text { 2. Teacher sh } \\
\text { grades and } \\
\text { with which }\end{array}$ & $\begin{array}{l}\text { orocal Mapping } \\
\text { mational text types. This should be done with overhead, } \\
\text { ice to display whole group. Students may have individual copy } \\
\text { explicit teacher directions. } \\
\text { he first two text types, these are usually taught in primary } \\
\text { niliar to the students, and will give them background knowledge } \\
\text { hew information from lesson being taught. } \\
\text { ational text type, for this study, the three targeted informational }\end{array}$ \\
\hline
\end{tabular}


text types were compare and contrast, cause and effect, and problem and solution.

4. Teacher explains the use of the targeted graphic organizer, shows signal words, draws the graphic organizer.

5. Teacher models the use of the targeted graphic organizer as she shows how to use it with a commonly experienced real-life situation compatible with age/grade level of students.

6. Students copy teacher's example exactly on their own graphic organizer. The graphic organizer can be teacher-made, student-made, or commercially-made. However, students will copy the exact example modeled by the teacher.

7. Students then use their graphic organizer to write a short paragraph that relates the events that were mapped. For example, if it is a cause and effect example, with the cause "getting sent to the principal's office" and effects such as "getting in trouble, grounded, extra homework" the students' written paragraph, based on the graphic organizer could be: "I was sent to the principal's office yesterday because I was late for class for the third time. My punishment was that I was grounded for the weekend and I had to do extra homework to make up for what I missed during class." The graphic organizer is functioning as a Reciprocal Map that the student uses to write from, including the targeted informational text structure.

8. The teacher then asks the student to create their own example of the targeted informational text type, based on commonly experienced real-life situation, using the graphic organizer.

9. Teacher checks that students have completed this step correctly. It is vitally important that the student understands the informational text type and since a graphic organizer is being used, teachers can clearly see if the students are understanding the concept.

10. Once teacher checks for understanding, the student then uses the graphic organizer to write a short paragraph that relates the events they mapped. This would be similar to Step 7 where the student is using the graphic organizer, now the Reciprocal Map, to guide them as they write their paragraph. This completes the first day of instruction. Days 2 and 3 are the same, with the exception that Day 2 uses informational text that should be at a reading level that all students can master. This could be from an informational picture book, from connected text, a disciplinary magazine, appendices show each text type in detail. Day 3 uses text from the textbook used in the classroom. 
Appendix H: Lesson Plan Compare and Contrast Informational Text Type

\begin{tabular}{|c|c|}
\hline Title & $\begin{array}{c}\text { Effect of Reciprocal Mapping on High-Risk Sixth-Grade } \\
\text { Students' Social Studies Achievement }\end{array}$ \\
\hline Summary & $\begin{array}{c}\text { Students are explicitly taught an integrated and iterative } \\
\text { reading/writing strategy, using visual representation to } \\
\text { make concrete the reading process they encounter using } \\
\text { social studies informational text. }\end{array}$ \\
\hline Time Frame: Fifty minutes, review of five most common text types, initial \\
explicit instruction of compare and contrast informational text, application, writing from \\
the Reciprocal Map, and student practice.
\end{tabular}


explain and model use of this informational text type as she shows the signal words and shows and draws the associated graphic organizer.

4. Teacher models the use of the Compare and Contrast informational text type by showing it (on overhead/document camera) using a commonly experienced real-life situation found in sixth-grade classroom. An example may be to compare a sixth-grade demands with those the students faced in fifth-grade. Other examples may include comparing previously taught skills, such as land forms, desert and arctic (these have clear compare and contrast attributes). Examples may be two different types of pets. At this time, the focus is on the students' acquiring the skill of compare and contrast, so the two items being used should be very easy for the students to see similarities and differences. The important aspect is that the teacher is modeling the use of the Compare and Contrast graphic organizer as she is creating it in view of the students.

5. Students copy the teacher's example exactly onto their own graphic organizer. The graphic organizer can be teacher-made and given to students in advance, student-made as they copy what the teacher is doing, or commercially-made and in use by both the teacher as she models and given to the students to duplicate exactly hers.

6. Students then use their graphic organizer to write a short paragraph that relates the events that were mapped. For example, if the compare and contrast used was desert vs. arctic habitats, once the class has mapped the elements onto their maps, the student writing may be: "Both the desert and arctic habitats support animal life and are not highly populated. However, they are different because the desert is dry and sandy, as opposed to the arctic which is cold and icy." The graphic organizer is functioning as the Reciprocal Map that the students uses to first copy the text from the teacher, then to use for the writing process, including the informational text type itself, in this case, Compare and Contrast.

7. Teacher then asks the students to create their own example of a Compare and Contrast situation, based on commonly experienced information, this could be generated from discussion in step four above. Students will make a Reciprocal Map, exactly like the one the teacher created and they copied, with their own example.

8. Teacher checks that students have completed this step correctly. It is vitally important that the student understands the informational text type and since a graphic organizer is being used, teachers can clearly see if the students are understanding the concept. This graphic organizer becomes the Reciprocal Map as student and teacher engage in the iterative process of creating and refining the maps.

9. Once teacher checks for understanding, the student then uses their Reciprocal Map to write a short paragraph that relates the details that they mapped. This is similar to step six above where the student is using the Reciprocal Map, to guide them as they write their paragraph.

10. Mastery is demonstrated when students are able to write a paragraph that is based on the information in the Reciprocal Map to write compare and contrast text. 
Lesson Plan: Reciprocal Mapping instructional routine and compare and contrast informational text.

1. Review chart of five informational text types. Review the first two types of informational text from Appendix C. Review the text feature signal words and the most commonly used graphic organizers.

2. Display the informational text type Compare and Contrast. Review the use of this type of informational text. Review the text feature signal words most commonly used with it, including both, same as, alike, similarly, as well as, likewise, either...or to show similarities. Signal words for contrasting include different, on the other hand, although, contrary, as opposed to.

3. Review the two most commonly used graphic organizers for Compare and Contrast, Venn Diagram and T-Chart/Boxed T-Chart. Teacher is continuing to explain and model use of this informational text type as she shows the signal words and shows and draws the associated graphic organizer.

4. Teacher shows day one example of both teacher created and student created Reciprocal Maps, as well as written paragraphs. Whole group review.

5. In much the same way as Day 1, the teacher now uses an example of Compare and Contrast informational text that can be easily read by the students. At this time it is important that students are not struggling to read or understand the text. Students are reading informational text that they can master and that allows them to use their cognitive capacity to understand the process at this time, not the text. Therefore, text can be from an informational picture book that models the exact text structure, in this case, a compare and contrast informational text. The teacher could use connected text from a teacher's guide that models the text type. The teacher could use intertextual text examples showing the idea of compare and contrast at a level that is possibly easier for the student to understand. At this point, it is very important to use text the models the text type and is easily read. The teacher will read the text as she completes the map, modeling for the students as they observe.

6. Students then copy the teacher's example exactly onto their own graphic organizer. At this time, the graphic organizer should be the same one used in day one for continuity.

7. Students then use their maps to write a short paragraph that relates back to the compare and contrast informational text read in step five. The Reciprocal Map that the students use to first copy the text from the teacher, then to use for the writing process, including the informational text type itself, Compare and Contrast is the scaffold for success. Teacher checks paragraphs to ensure students' understood and wrote correctly.

8. Teacher then asks the students to read their own example of a Compare and Contrast informational text as described in step five above. Students will read the provided text, make a Reciprocal Map, exactly like the one the teacher created and they copied, with their own example from the Compare and Contrast informational text provided.

9. Teacher checks that students have completed this step correctly. It is vitally important that the student understands the informational text type and since the 


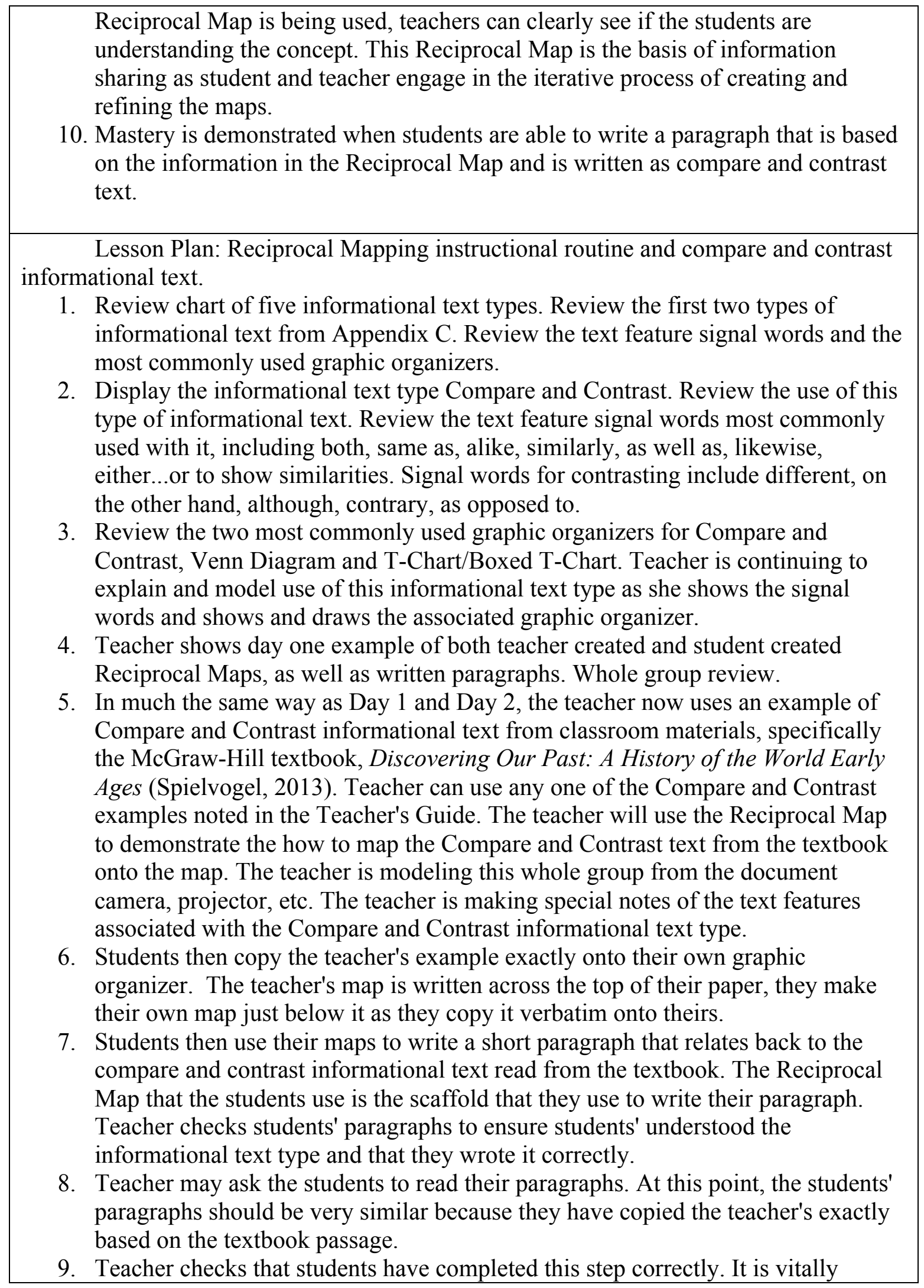


important that the student understands the informational text type and since the Reciprocal Map is being used, teachers can clearly see if the students are understanding the concept. This Reciprocal Map is the basis of information sharing as student and teacher engage in the iterative process of creating and refining the maps.

10. Mastery is demonstrated when students are able to write a paragraph based on the information in the Reciprocal Map and is written as a compare and contrast text type. 
Appendix I: Lesson Plan Cause and Effect Informational Text Type

\begin{tabular}{|l|l|}
\hline Title & $\begin{array}{l}\text { Effect ct of Reciprocal Mapping on High-Risk Sixth Grade } \\
\text { Students' Social Studies Achievement }\end{array}$ \\
\hline Summary & $\begin{array}{l}\text { Students are explicitly taught an integrated and iterative } \\
\text { reading/writing strategy, using visual representation to make } \\
\text { concrete the reading process they encounter using social } \\
\text { studies informational text. }\end{array}$ \\
\hline
\end{tabular}

Time Frame: Fifty minutes, review of five most common text types, initial explicit instruction of compare and contrast informational text, application, writing from the Reciprocal Map, and student practice.

Psychological Framework: Explicit initial instruction, students copy exactly what the teacher is doing, I Do. Students then create their own examples copying exactly the process the teacher showed, You Do, I Help. Once students show mastery of text type, they continue reading social studies informational text as teacher observes. You Do, I Watch. (Scaffolding).

Objectives: Students will be able to identify and use the informational text type cause and effect including ancillary signal words and types of graphic organizers used. Students will be create individual Reciprocal Maps during the iterative instructional setting, using teacher modeling to make concrete cause and effect informational text. Students will be able to use their Reciprocal Map to write cause and effect text.

Guiding Questions: CCSS require that students learn to:

1. Compare and contrast the most important points and key details presented in two texts on the same topic (p. 14).

2. Describe the relationship between a series of historical events using language that pertains to time, sequence, and cause and effect (p. 14).

3. Describe how a text presents information (e.g., sequentially, comparatively, causally).

For students this can mean that they are able to read a variety of informational text commonly found in sixth-grade classrooms with mastery. Further, they will be able to use graphic organizers to help them understand informational text as well as their related text features.

Lesson Plan: Reciprocal Mapping instructional routine and Cause and Effect informational text.

1. Review chart of five informational text types. Review the first two types of informational text from Appendix C. Review the text feature signal words and the most commonly used graphic organizers.

2. Display the informational text type cause and effect. Explain the use of this type of informational text. Explicitly teach the text feature signal words most commonly used with it: if-then, because, since, so, therefore, consequently.

3. Show the a graphic organizers for cause and effect. Teacher is continuing to explain and model use of this informational text type as she shows the signal words and shows and draws the associated graphic organizer.

4. Teacher models the use of the cause and effect informational text type by 





words and shows and draws the associated graphic organizer.

3. Teacher shows day one example of both teacher created and student created Reciprocal Maps, as well as written paragraphs. Whole group review.

4. In much the same way as Day 1, the teacher now uses an example of cause and effect informational text that can be easily read by the students. At this time it is important that students are not struggling with reading and comprehending the text. Give students informational text that they can master and that allows them to use their cognitive capacity to understand the process at this time, not the text. Therefore, text can be from an informational picture book that models the exact text structure, in this case, a cause and effect informational text. The teacher could use connected text from a teacher's guide that models the text type. The teacher could use intertextual text examples showing the idea of cause and effect at a level that is possibly easier for the student to understand. At this point, it is very important to use text the models the text type and is easily read. The teacher will read the text as she completes the map, modeling for the students as they observe.

5. Students then copy the teacher's example exactly onto their own graphic organizer. At this time, the graphic organizer should be the same one used in day one for continuity.

6. Students then use their maps to write a short paragraph that relates back to the cause and effect informational text read in step five. The Reciprocal Map that the students use to first copy the text from the teacher, then to use for the writing process, including the informational text type itself, cause and effect is the scaffold for success. Teacher checks paragraphs to ensure students' understood and wrote correctly.

7. Teacher then asks the students to read their own example of a cause and effect informational text as described in step five above. Students will read the provided text, make a Reciprocal Map, exactly like the one the teacher created and they copied, with their own example from the cause and effect informational text provided.

8. Teacher checks that students have completed this step correctly. It is vitally important that the student understands the informational text type and since the Reciprocal Map is being used, teachers can clearly see if the students are understanding the concept. This Reciprocal Map is the basis of information sharing as student and teacher engage in the iterative process of creating and refining the maps.

9. Mastery is demonstrated when students are able to write a paragraph that is based on the information in the Reciprocal Map and is written as cause and effect text.

Lesson Plan: Reciprocal Mapping instructional routine and cause and effect informational text.

1. Review chart of five informational text types. Review the first two types of informational text from Appendix C. Review the text feature signal words and the most commonly used graphic organizers.

2. Display the informational text type Cause and effect. Review the use of this type 
of informational text. Review the text feature signal words. Review the graphic organizer. Teacher is continuing to explain and model use of this informational text type as she shows the signal words and shows and draws the associated graphic organizer.

3. Teacher shows day one example of both teacher created and student created Reciprocal Maps, as well as written paragraphs. Whole group review.

4. In much the same way as Day 1 and Day 2, the teacher now uses an example of cause and effect informational text from classroom materials, specifically the McGraw-Hill textbook, Discovering Our Past: A History of the World Early Ages (Spielvogel, 2013). Teacher can use any one of the cause and effect examples noted in the Teacher's Guide. The teacher will use the Reciprocal Map to demonstrate the how to map the cause and effect text from the textbook onto the map. The teacher is modeling this whole group from the document camera, projector, etc. The teacher is making special notes of the text features associated with the Cause and effect informational text type.

5. Students then copy the teacher's example exactly onto their own graphic organizer. The teacher's map is written across the top of their paper, they make their own map just below it as they copy it verbatim onto theirs.

6. Students then use their maps to write a short paragraph that relates back to the cause and effect informational text read from the textbook. The Reciprocal Map that the students use is the scaffold that they use to write their paragraph. Teacher checks students' paragraphs to ensure students' understood the informational text type and that they wrote it correctly.

7. Teacher may ask the students to read their paragraphs. At this point, the students' paragraphs should be very similar because they have copied the teacher's exactly based on the textbook passage.

8. Teacher checks that students have completed this step correctly. It is vitally important that the student understands the informational text type and since the Reciprocal Map is being used, teachers can clearly see if the students are understanding the concept. This Reciprocal Map is the basis of information sharing as student and teacher engage in the iterative process of creating and refining the maps.

9. Mastery is demonstrated when students are able to write a paragraph based on the information in the Reciprocal Map and is written as a compare and contrast text type. 
Appendix J: Lesson Plan Problem and Solution Informational Text Type

\begin{tabular}{|c|c|}
\hline Title & $\begin{array}{l}\text { Effect of Reciprocal Mapping on High-Risk Sixth-Grade } \\
\text { Students' Social Studies Achievement }\end{array}$ \\
\hline Summary & $\begin{array}{l}\text { Students are explicitly taught an integrated and iterative } \\
\text { reading/writing strategy, using visual representation to make } \\
\text { concrete the reading process they encounter using social } \\
\text { studies informational text. }\end{array}$ \\
\hline Time Frame: Fifty minutes, review of five most common text types, initial \\
explicit instruction of compare and contrast informational text, application, writing from \\
the Reciprocal Map, and student practice.
\end{tabular}


the signal words and shows and draws the associated graphic organizer.

3. Teacher models the use of the problem and solution informational text type by showing it (on overhead/document camera) using a commonly experienced real-life situation found in sixth-grade classroom. An example may be students forget to bring in their homework. It should be noted that the problem and solution found in informational text, may have multiple steps before a solution is found. It is important to show this type of graphic organizer and to use multiple step examples. At this time, the focus is on the students' acquiring the skill of problem and solution, so the example(s) being taught should be very easy for the students to understand. The important aspect is that the teacher is modeling the use of the problem and solution graphic organizer as she is creating it in view of the students.

4. Students copy the teacher's example exactly onto their own graphic organizer. The graphic organizer can be teacher-made and given to students in advance, student-made as they copy what the teacher is doing, or commercially-made and in use by both the teacher as she models and given to the students to duplicate exactly hers.

5. Students then use their graphic organizer to write a short paragraph that relates the events that were mapped. For example, if the example for problem and solution used was ways to help students get their homework back to school, the paragraph might say, "There are several ways that students can get homework back to school on time. They can put the homework in the backpack the night before or they can put it in the car. Students can use their planner to make sure they have everything they need for school." The graphic organizer is functioning as the Reciprocal Map that the students uses to first copy the text from the teacher, then to use for the writing process, including the informational text type itself, in this case, problem and solution.

6. Teacher then asks the students to create their own example of a problem and solution situation, based on commonly experienced information, this could be generated from discussion in step three above. Students will make a Reciprocal Map, exactly like the one the teacher created and they copied, with their own example.

7. Teacher checks that students have completed this step correctly. It is vitally important that the student understands the informational text type and since a graphic organizer is being used, teachers can clearly see if the students are understanding the concept. This graphic organizer becomes the Reciprocal Map as student and teacher engage in the iterative process of creating and refining the maps.

8. Once teacher checks for understanding, the student then uses their Reciprocal Map to write a short paragraph that relates the details that they mapped. This is similar to step five above where the student is using the Reciprocal Map, to guide them as they write their paragraph.

9. Mastery is demonstrated when students are able to write a paragraph that is based on the information in the Reciprocal Map to write problem and solution text. 
Lesson Plan: Reciprocal Mapping instructional routine and problem and solution informational text.

1. Review chart of five informational text types. Review the first two types of informational text from Appendix C. Review the text feature signal words and the most commonly used graphic organizers.

2. Display the informational text type problem and solution. Review the use of this type of informational text. Review the text feature signal words most commonly used with it. Review the graphic organizer from day one used for problem and solution. Teacher is continuing to explain and model use of this informational text type as she shows the signal words and shows and draws the associated graphic organizer.

3. Teacher shows day one example of both teacher created and student created Reciprocal Maps, as well as written paragraphs. Whole group review.

4. In much the same way as Day 1, the teacher now uses an example of problem and solution informational text that can be easily read by the students. At this time it is important that students are not struggling to read or understand the text. Students are reading informational text that they can master and that allows them to use their cognitive capacity to understand the process at this time, not the text. Therefore, text can be from an informational picture book that models the exact text structure, in this case, a problem and solution informational text. The teacher could use connected text from a teacher's guide that models the text type. The teacher could use intertextual examples showing the idea of problem and solution at a level that is possibly easier for the student to understand. At this point, it is very important to use text the models the text type and is easily read. The teacher will read the text as she completes the map, modeling for the students as they observe.

5. Students then copy the teacher's example exactly onto their own graphic organizer. At this time, the graphic organizer should be the same one used in day one for continuity.

6. Students then use their maps to write a short paragraph that relates back to the problem and solution informational text read in step five. The Reciprocal Map that the students use to first copy the text from the teacher, then to use for the writing process, including the informational text type itself, problem and solution is the scaffold. Teacher checks paragraphs to ensure students' understood and wrote correctly.

7. Teacher then asks the students to read their own example of a Problem and solution informational text as described in step four above. Students will read the provided text, make a Reciprocal Map, exactly like the one the teacher created and they copied, with their own example from the Problem and solution informational text provided.

8. Teacher checks that students have completed this step correctly. It is vitally important that the student understands the informational text type and since the Reciprocal Map is being used, teachers can clearly see if the students are understanding the concept. This Reciprocal Map is the basis of information sharing as student and teacher engage in the iterative process of creating and 
refining the maps.

9. Mastery is demonstrated when students are able to write a paragraph that is based on the information in the Reciprocal Map and is written as problem and solution text.

Lesson Plan: Reciprocal Mapping instructional routine and problem and solution informational text.

1. Review chart of five informational text types. Review the first two types of informational text from Appendix C. Review the text feature signal words and the most commonly used graphic organizers.

2. Display the informational text type problem and solution. Review the use of this type of informational text. Review the text feature signal words most commonly used with it. Review the graphic organizers for problem and solution. Teacher is continuing to explain and model use of this informational text type as she shows the signal words and shows and draws the associated graphic organizer.

3. Teacher shows day one and day two examples of both teacher created and student created Reciprocal Maps, as well as written paragraphs. Whole group review.

4. In much the same way as Day 1 and Day 2, the teacher now uses an example of problem and solution informational text from classroom materials, specifically the McGraw-Hill textbook, Discovering Our Past: A History of the World Early Ages (Spielvogel, 2013). Teacher can use any one of the problem and solution examples noted in the Teacher's Guide. The teacher will use the Reciprocal Map to demonstrate the how to map the problem and solution text from the textbook onto the map. The teacher is modeling this whole group from the document camera, projector, etc. The teacher is making special notes of the text features associated with the problem and solution informational text type.

5. Students then copy the teacher's example exactly onto their own graphic organizer. The teacher's map is written across the top of their paper, they make their own map just below it as they copy it verbatim onto theirs.

6. Students then use their maps to write a short paragraph that relates back to the problem and solution informational text read from the textbook. The Reciprocal Map that the students use is the scaffold that they use to write their paragraph. Teacher checks students' paragraphs to ensure students' understood the informational text type and that they wrote it correctly.

7. Teacher may ask the students to read their paragraphs. At this point, the students' paragraphs should be very similar because they have copied the teacher's exactly based on the textbook passage.

8. Teacher checks that students have completed this step correctly. It is vitally important that the student understands the informational text type and since the Reciprocal Map is being used, teachers can clearly see if the students are understanding the concept. This Reciprocal Map is the basis of information sharing as student and teacher engage in the iterative process of creating and refining the maps.

9. Mastery is demonstrated when students are able to write a paragraph based on the information in the Reciprocal Map and is written as a problem and solution text 
type. 
Appendix K: Teacher Compare and Contrast of Real-life

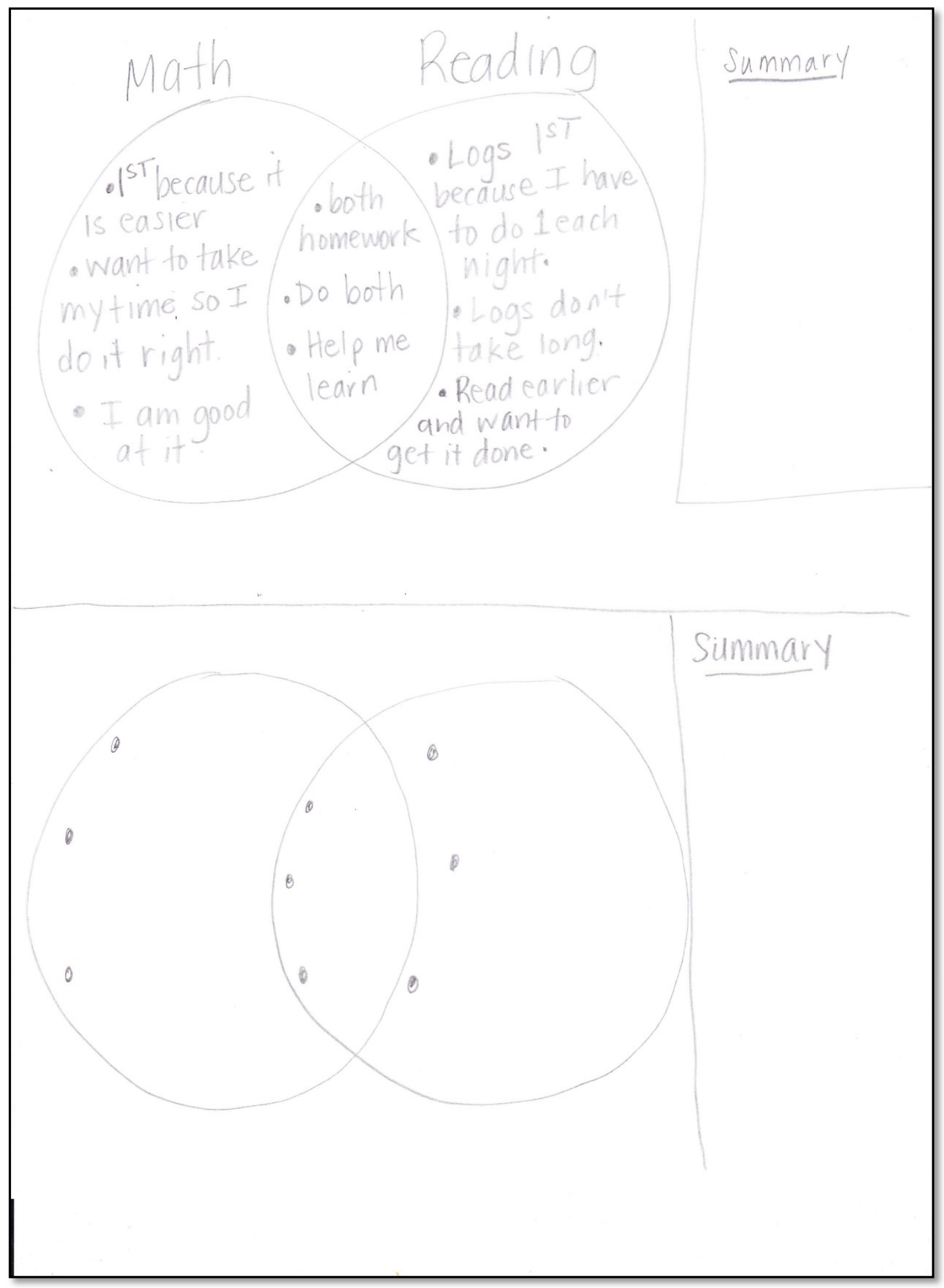


Appendix L: Student Compare and Contrast of Real-life and Reciprocal Real-life,

Example 1: Which Pet?

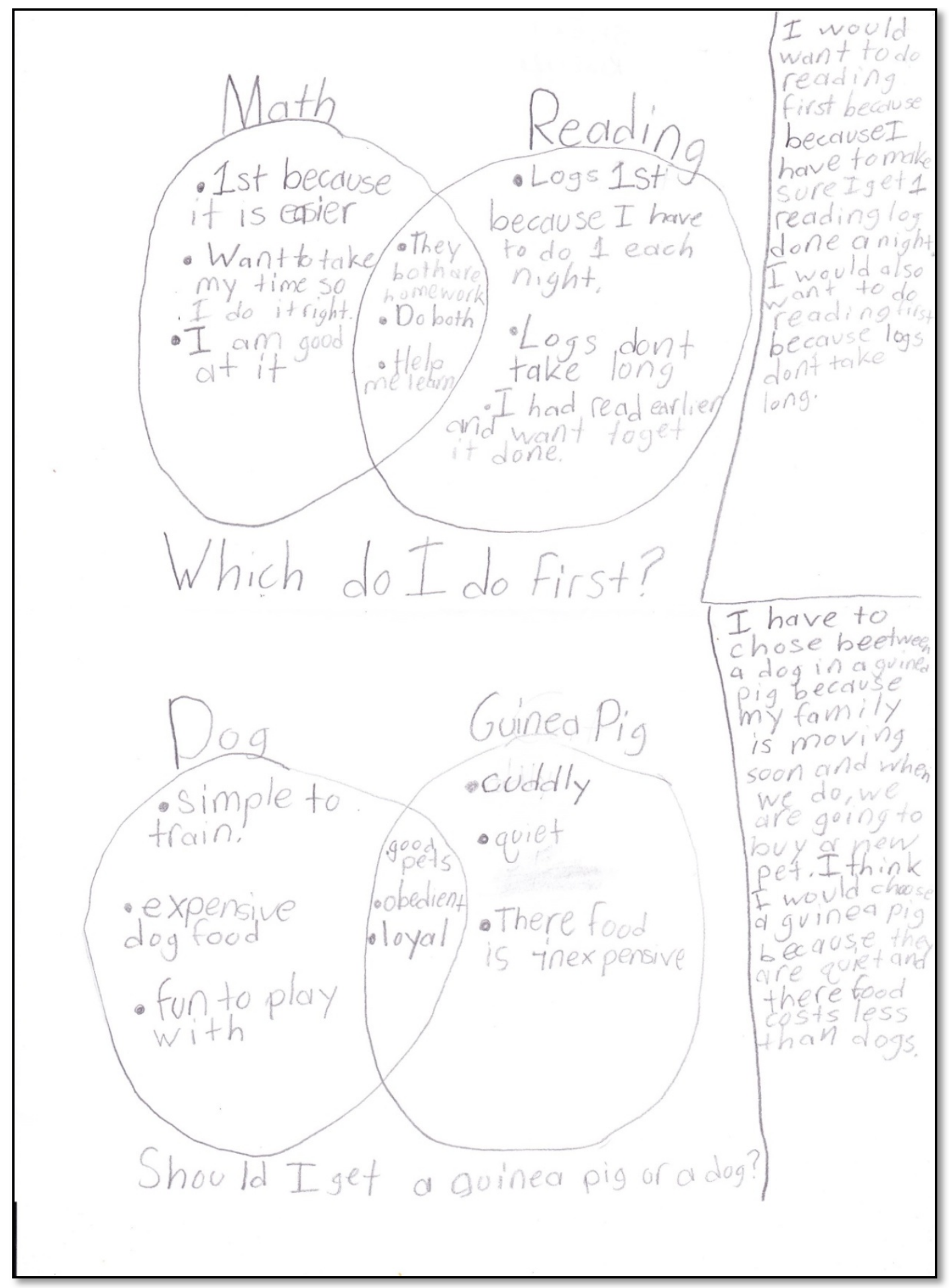


Appendix La: Student Compare and Contrast of Real-life and Reciprocal Real-life,

\section{Example 2: Which Uniform Shirt?}

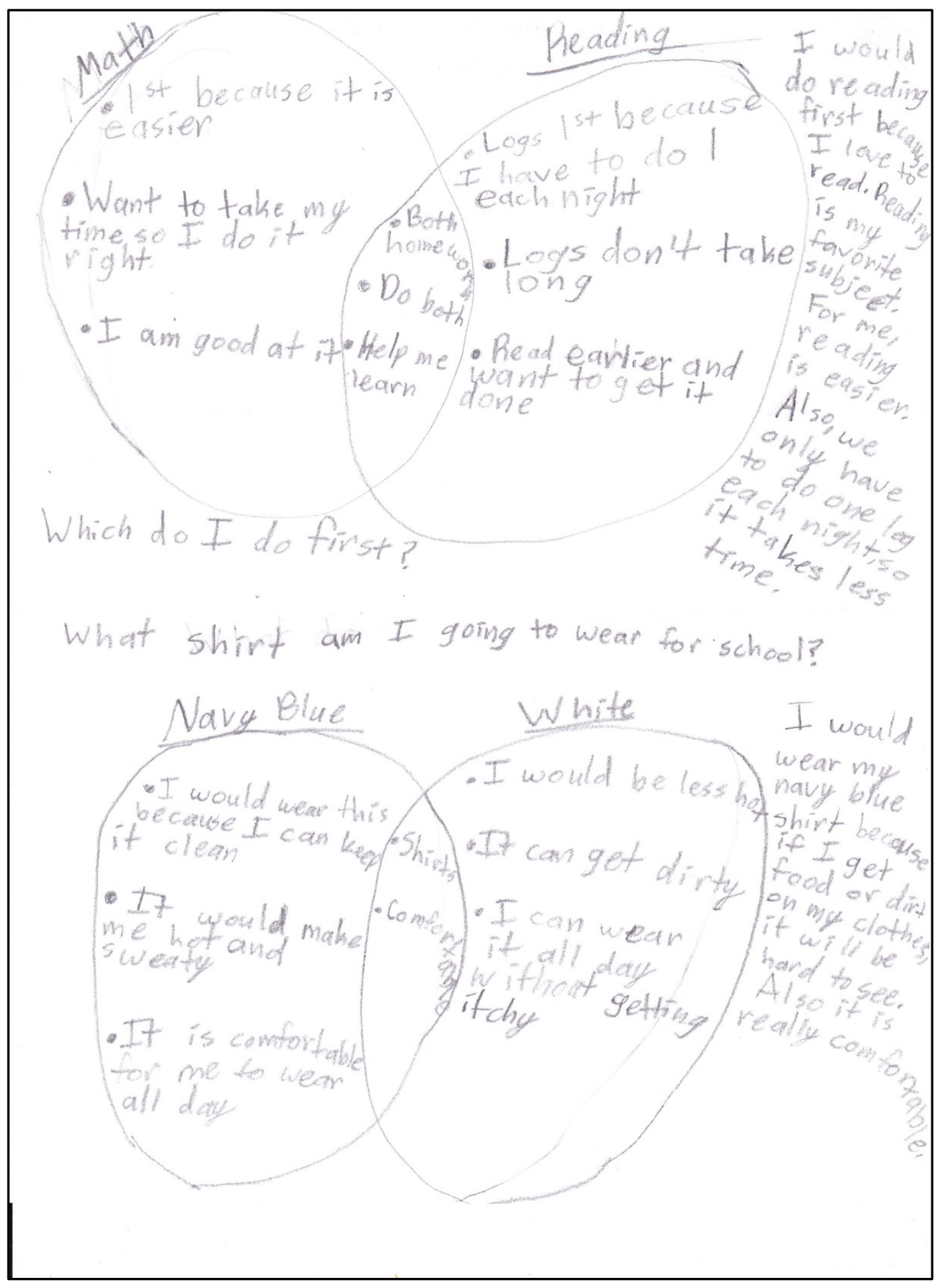


Appendix M: Teacher Compare and Contrast Book/ Passage

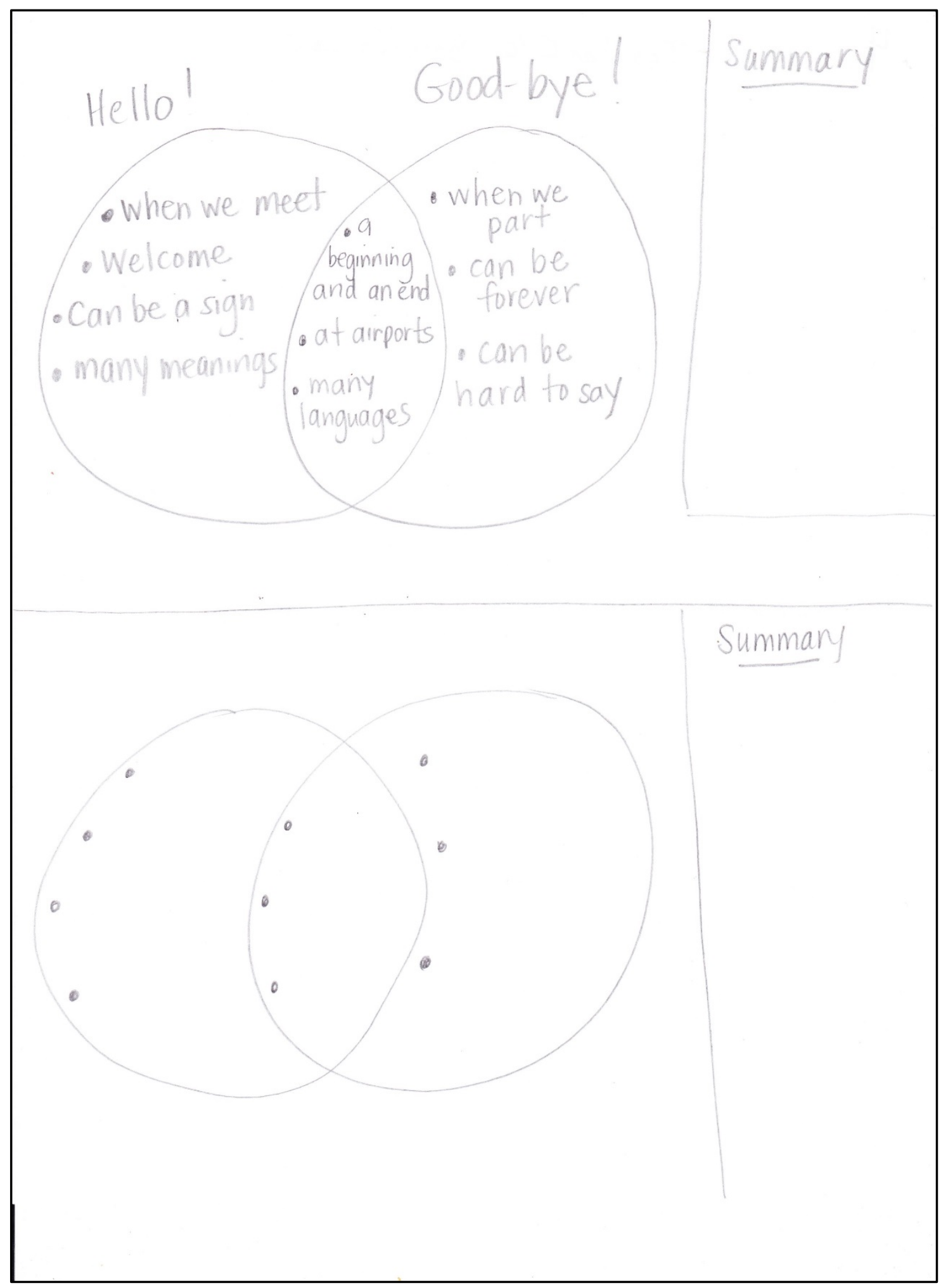


Appendix N: Student Compare and Contrast Book/Passage and Reciprocal Map, Book

Bats and Birds.

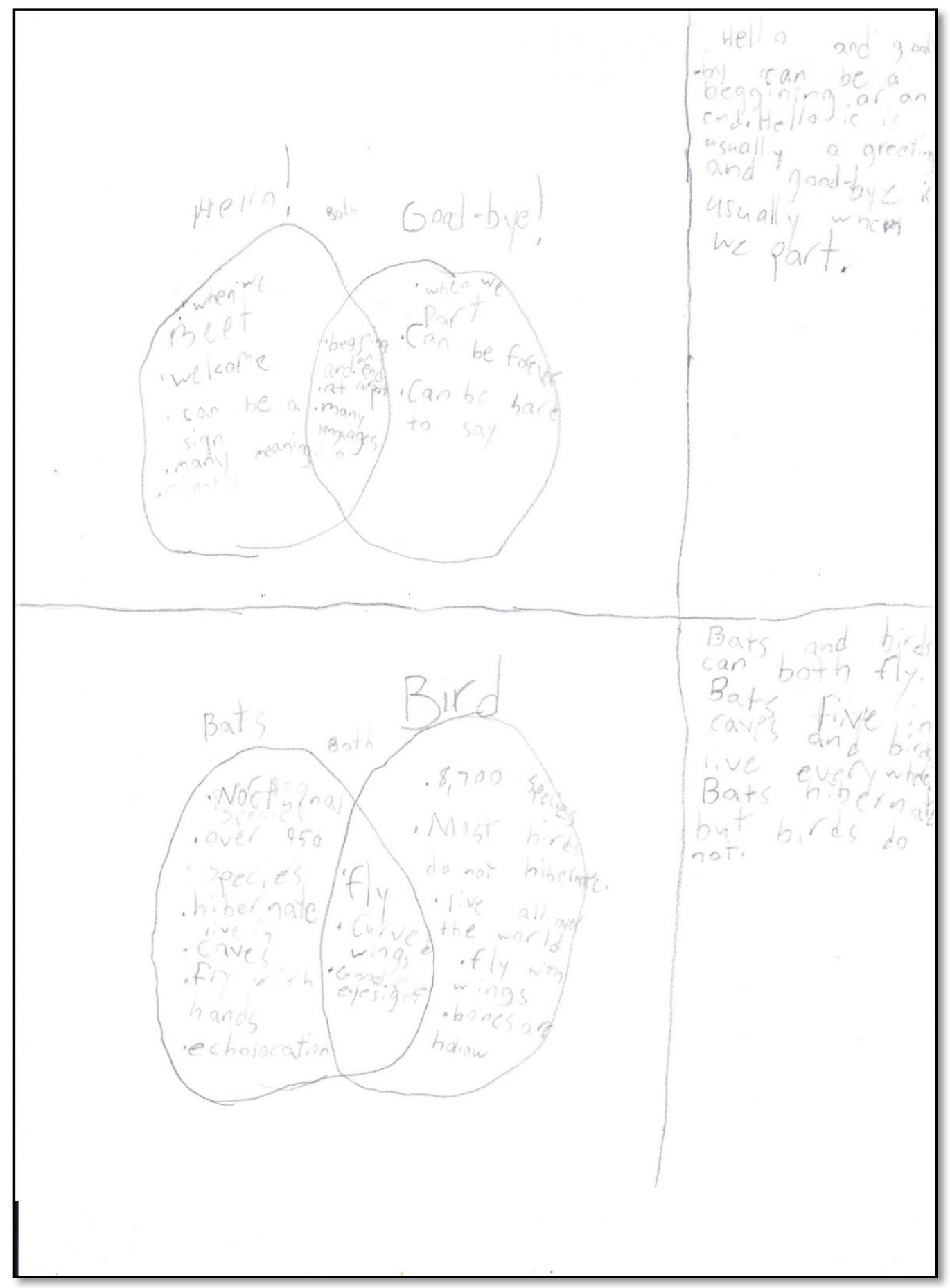


Appendix Na: Student Compare and Contrast Book/Passage and Reciprocal Map, Book

Frogs and Toads.

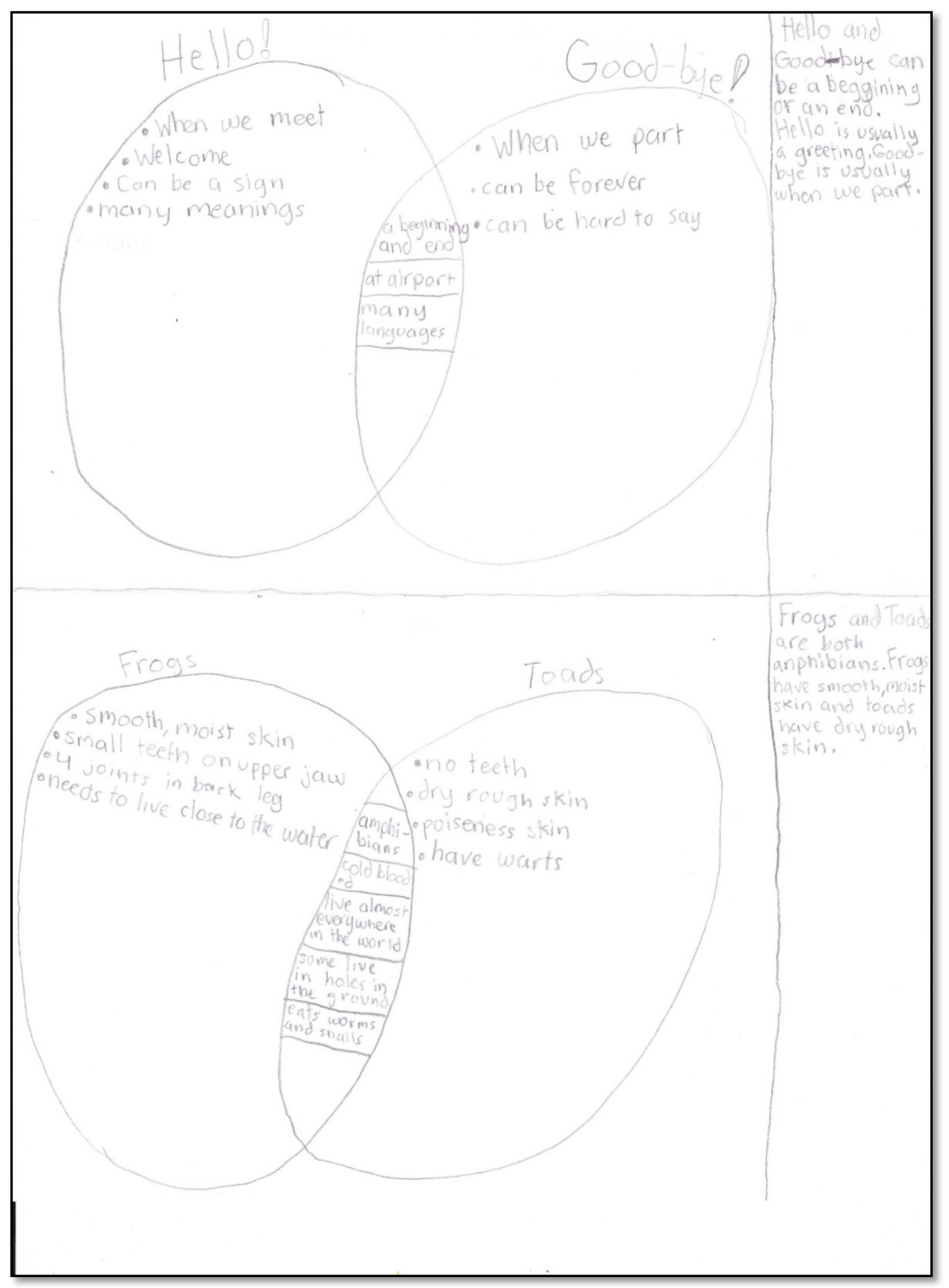


Appendix Nb: Student Compare and Contrast Book/Passage and Reciprocal Map, Book Butterflies and Moths.

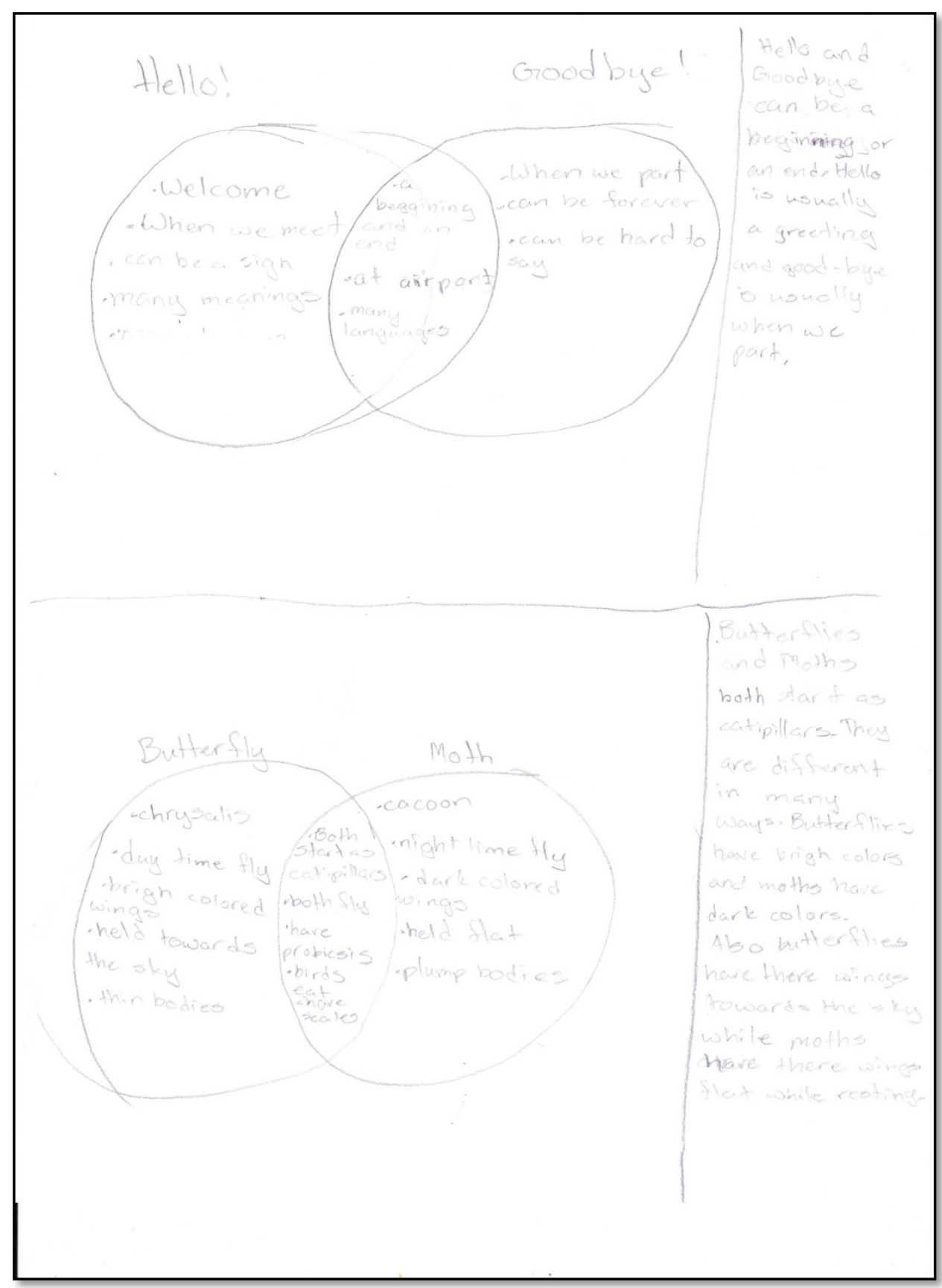


Appendix O: Teacher Compare and Contrast Textbook

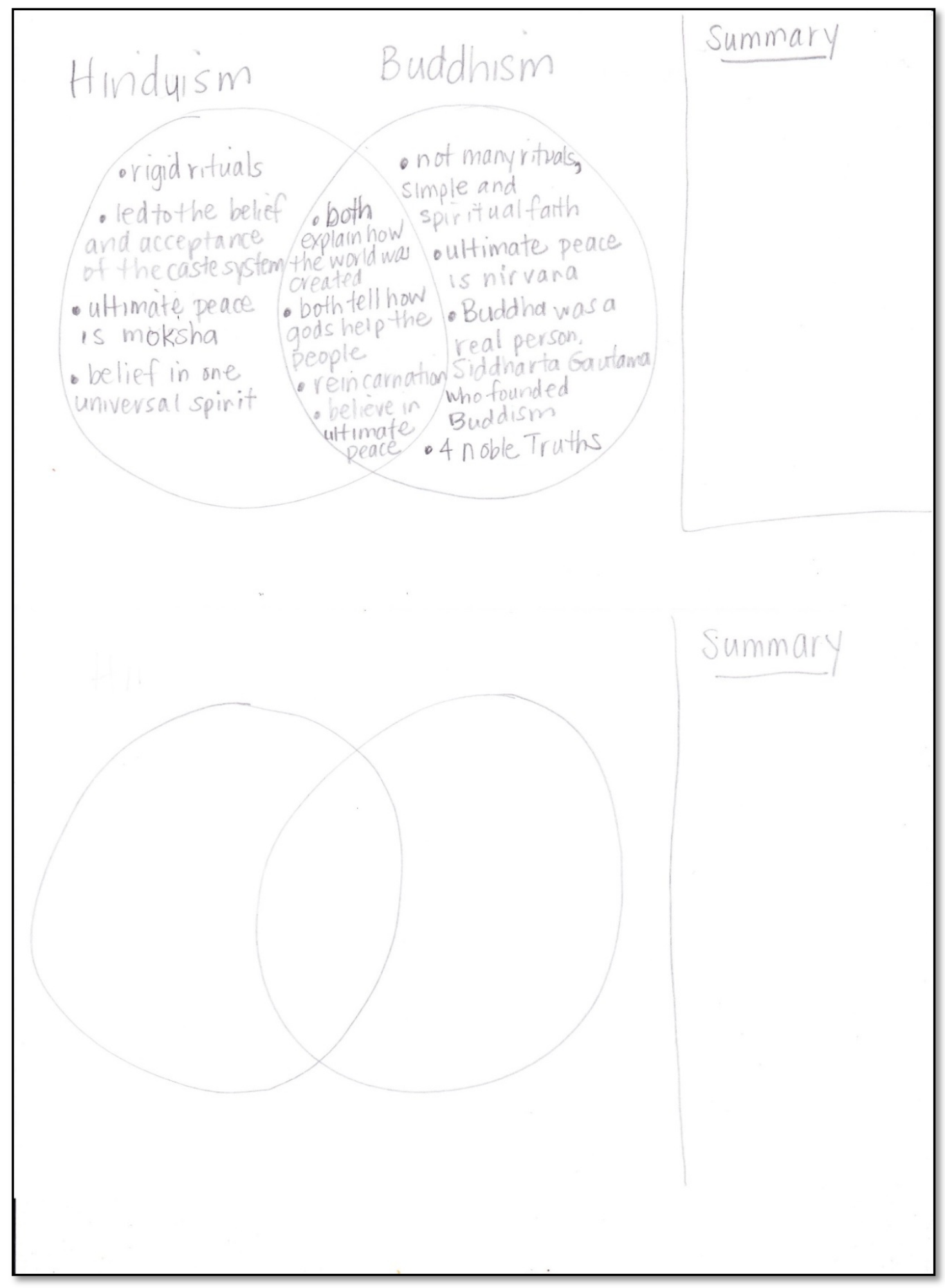


Appendix P: Student Example of Compare and Contrast Textbook and Reciprocal Map

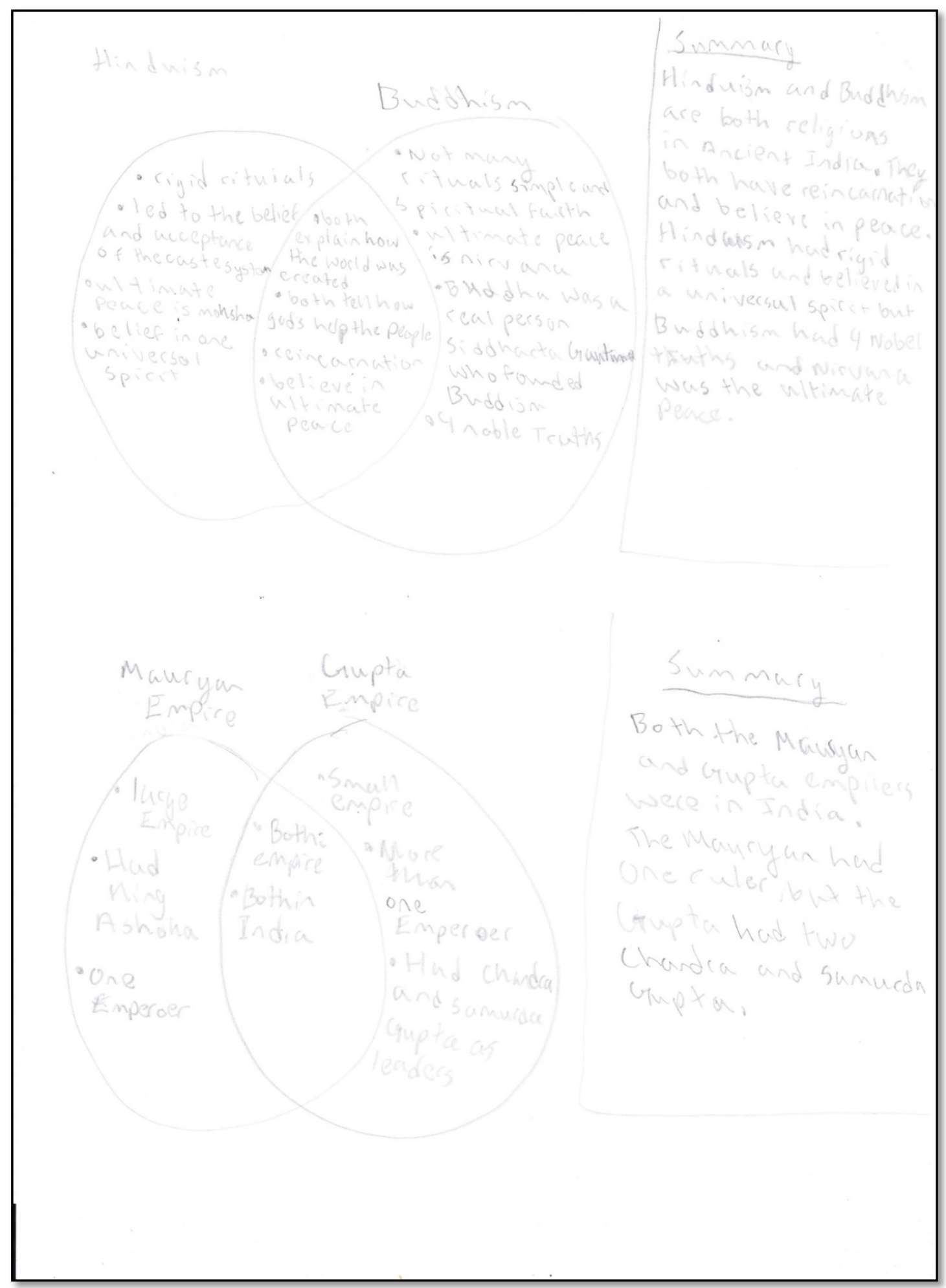


Appendix Q: Teacher Cause and Effect Real-Life

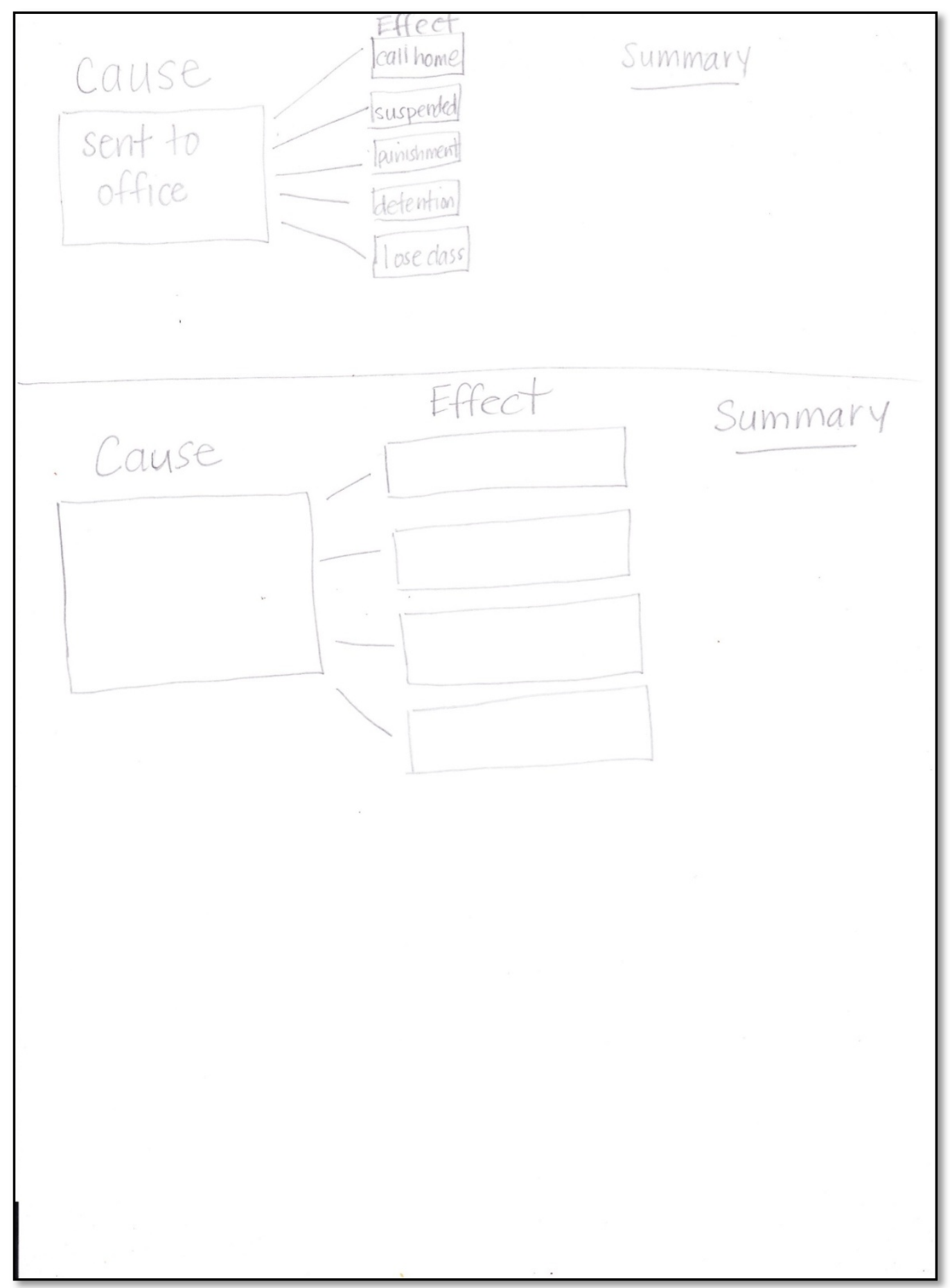


Appendix R: Student Cause and Effect Real-Life and Reciprocal Map Real-Life.

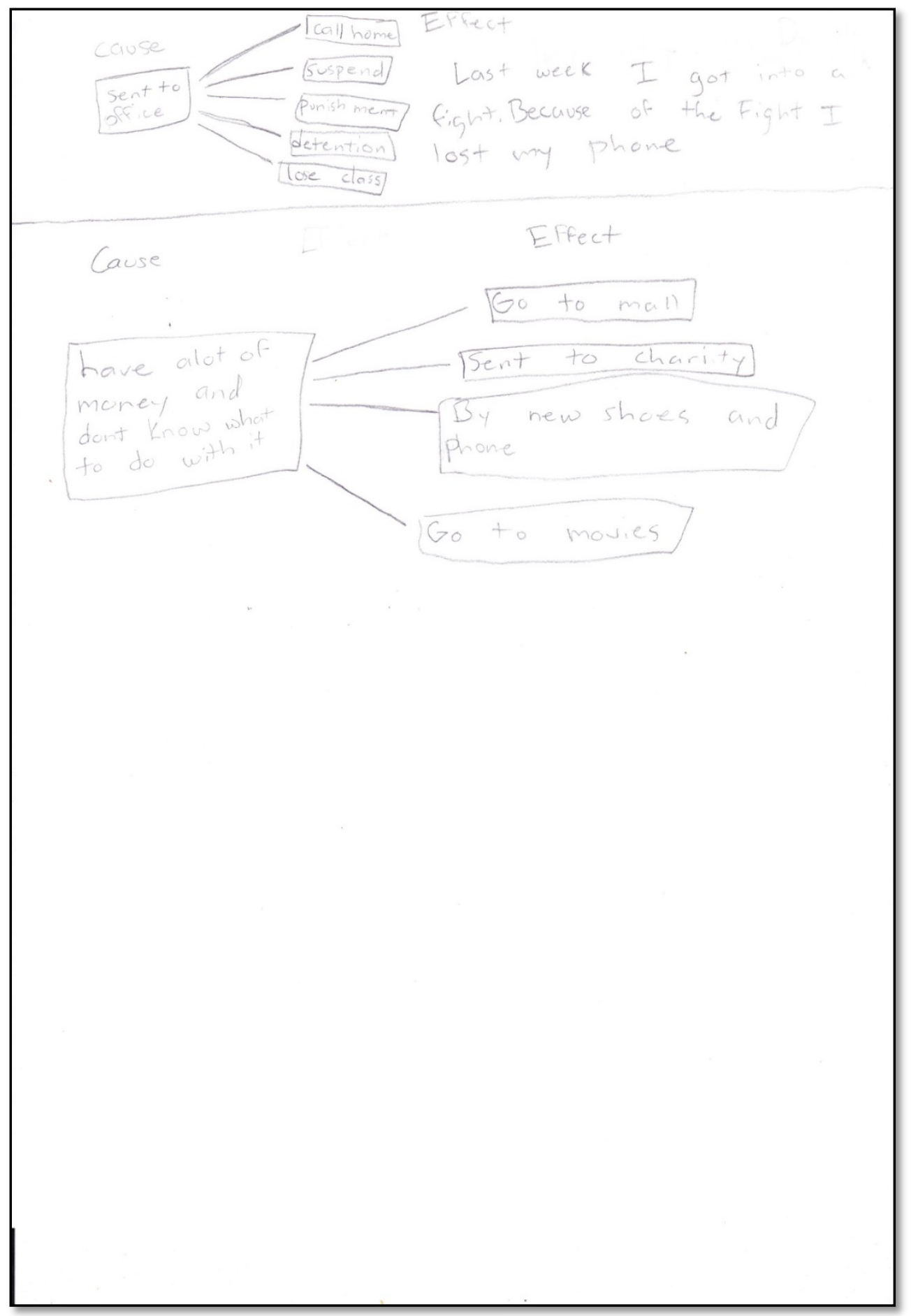


Appendix S: Teacher Cause and Effect Book/Passage

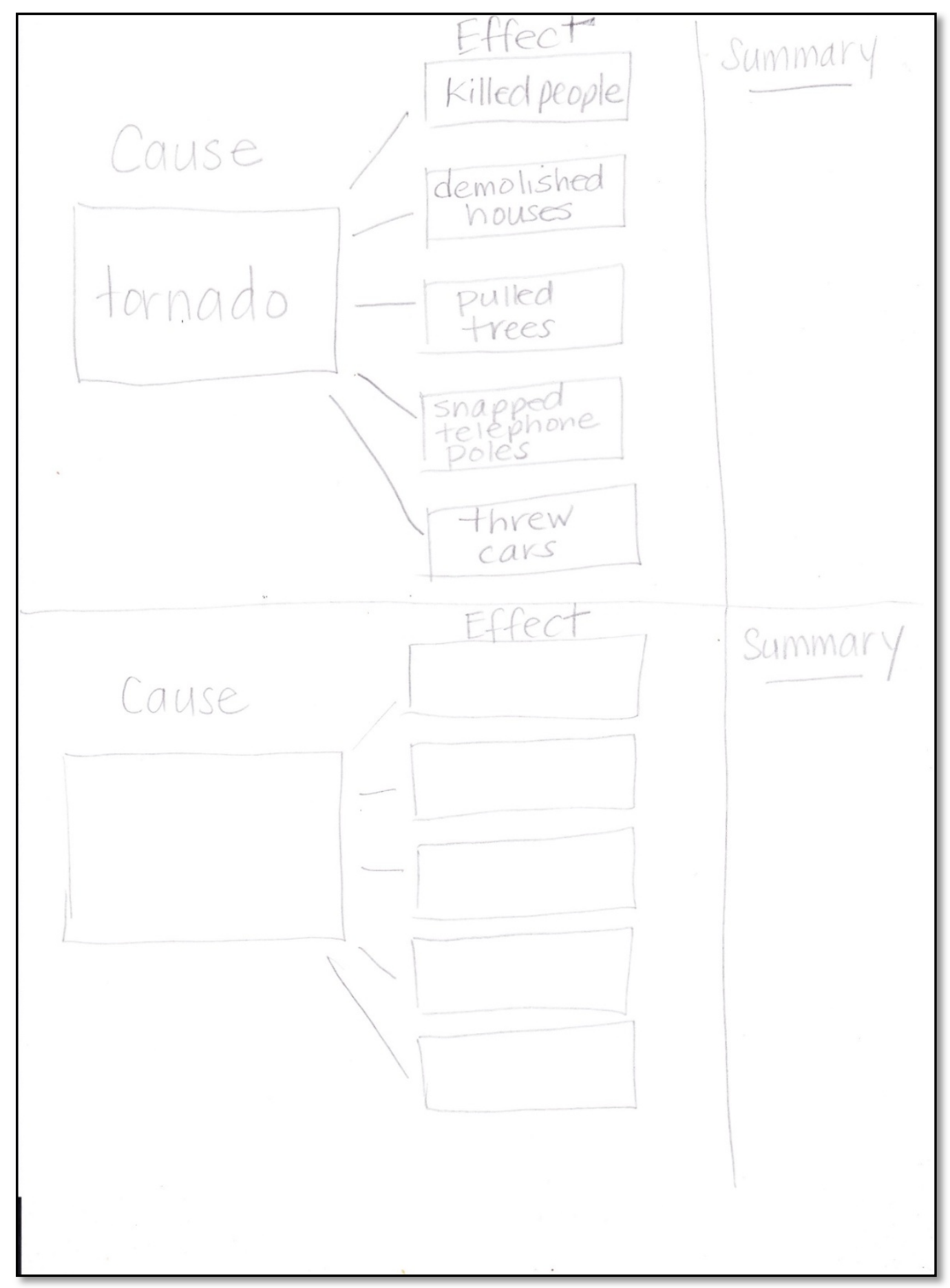


Appendix T: Student Cause and Effect Book/Passage and Reciprocal Map Book/Passage

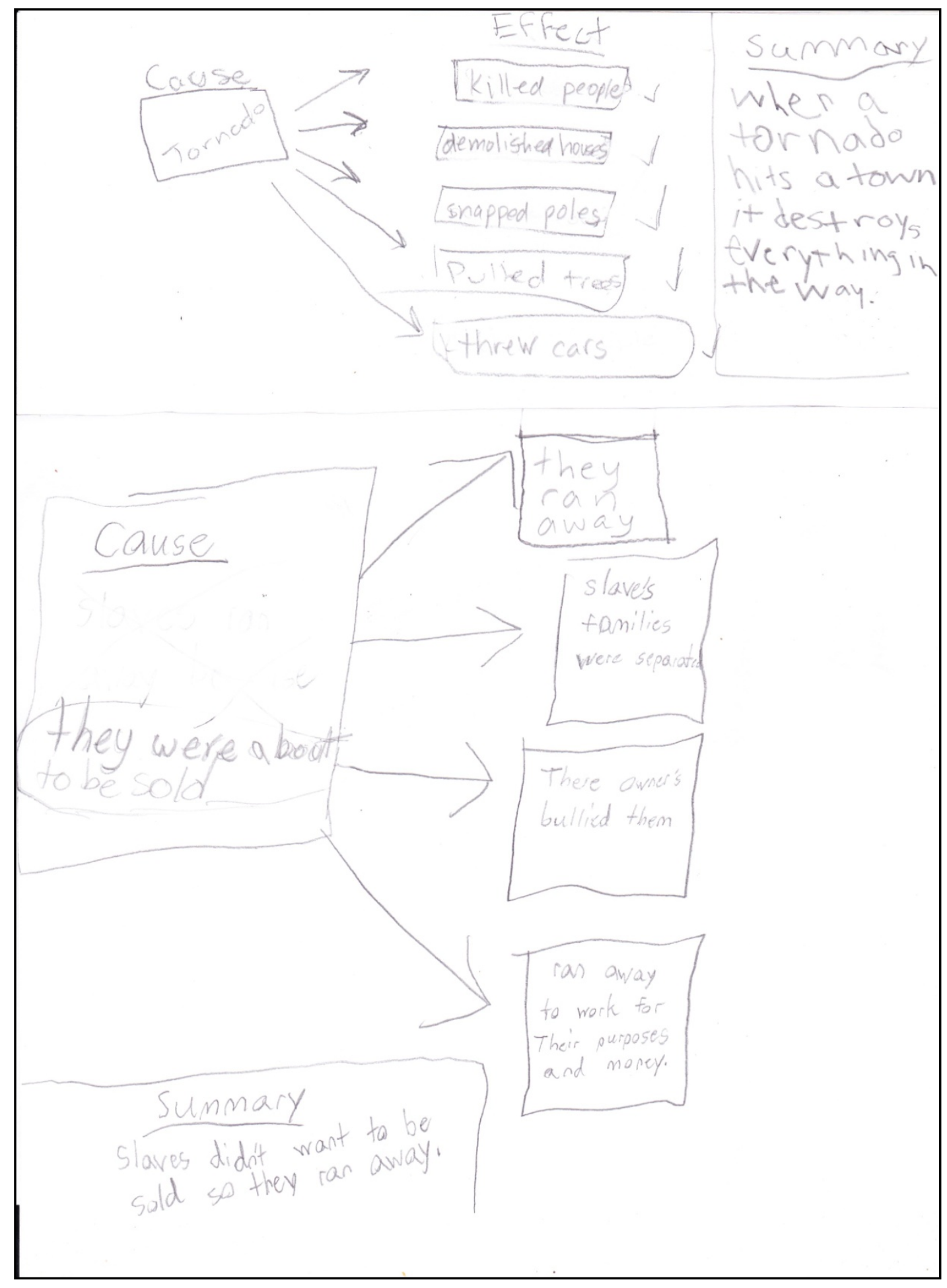


Appendix U: Teacher Cause and Effect Textbook

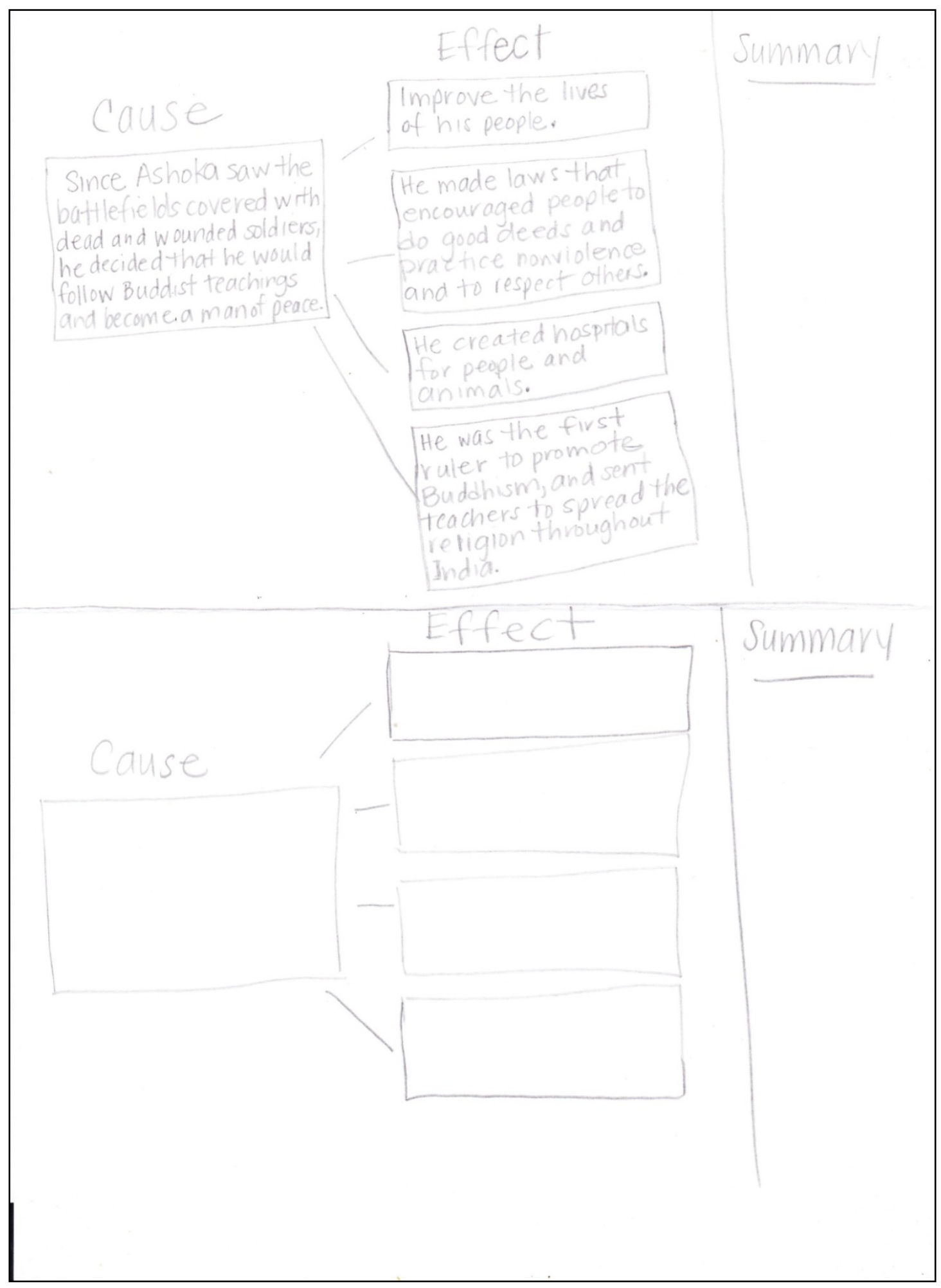


Appendix V: Student Cause and Effect Textbook and Reciprocal Map

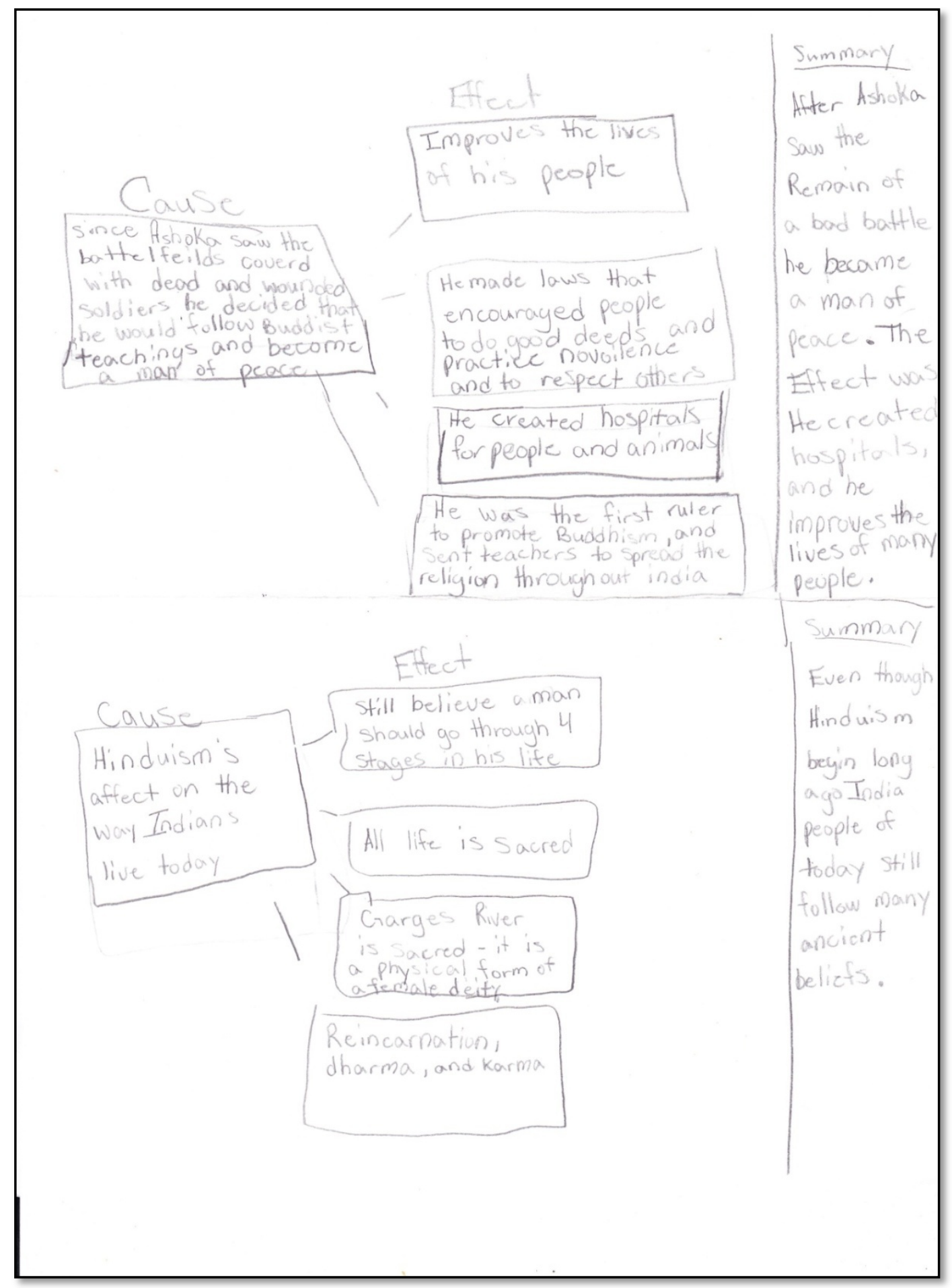


Appendix W: Teacher Problem and Solution Real-life

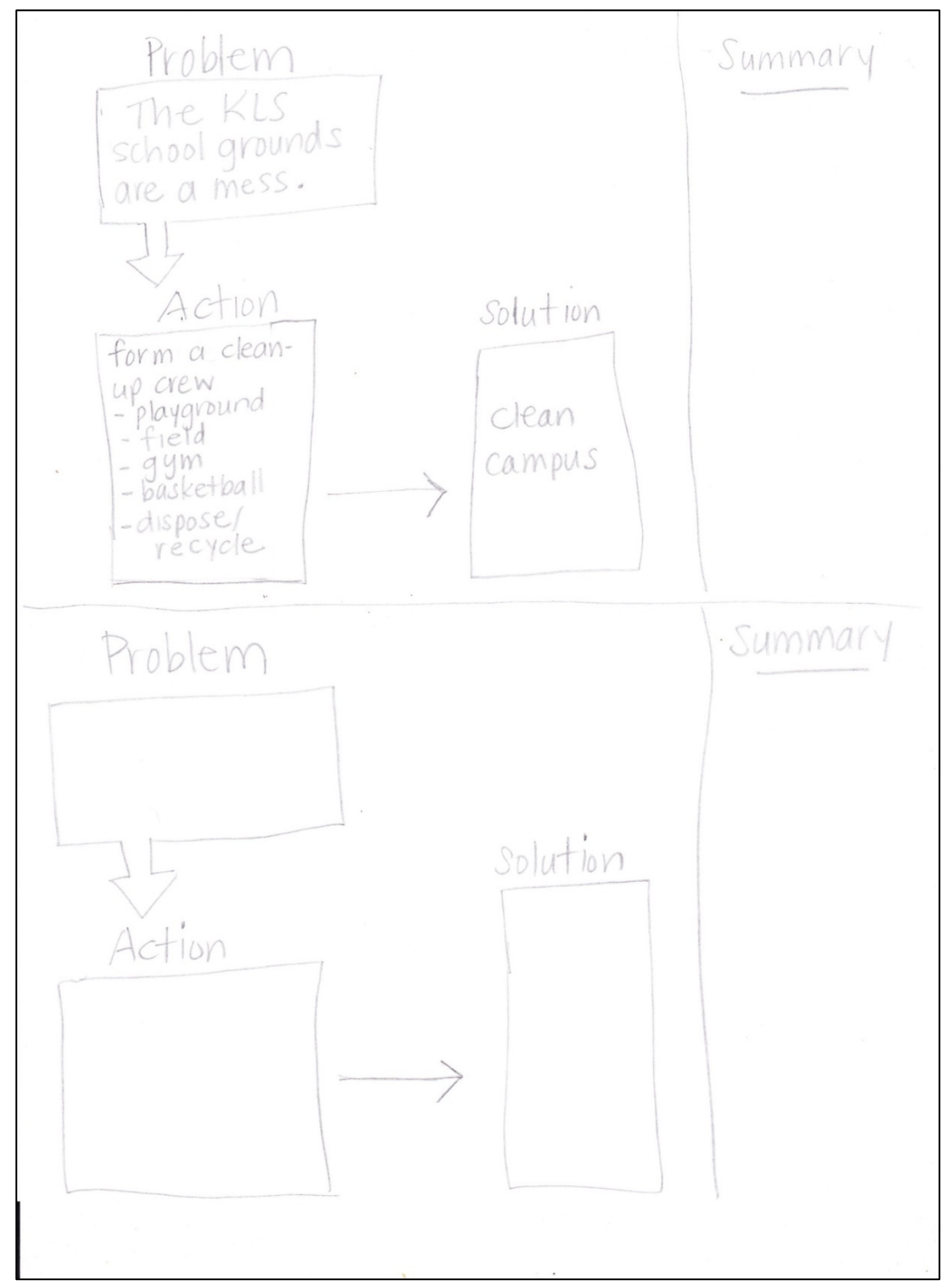


Appendix X: Student Problem and Solution Real-Life and Reciprocal Map

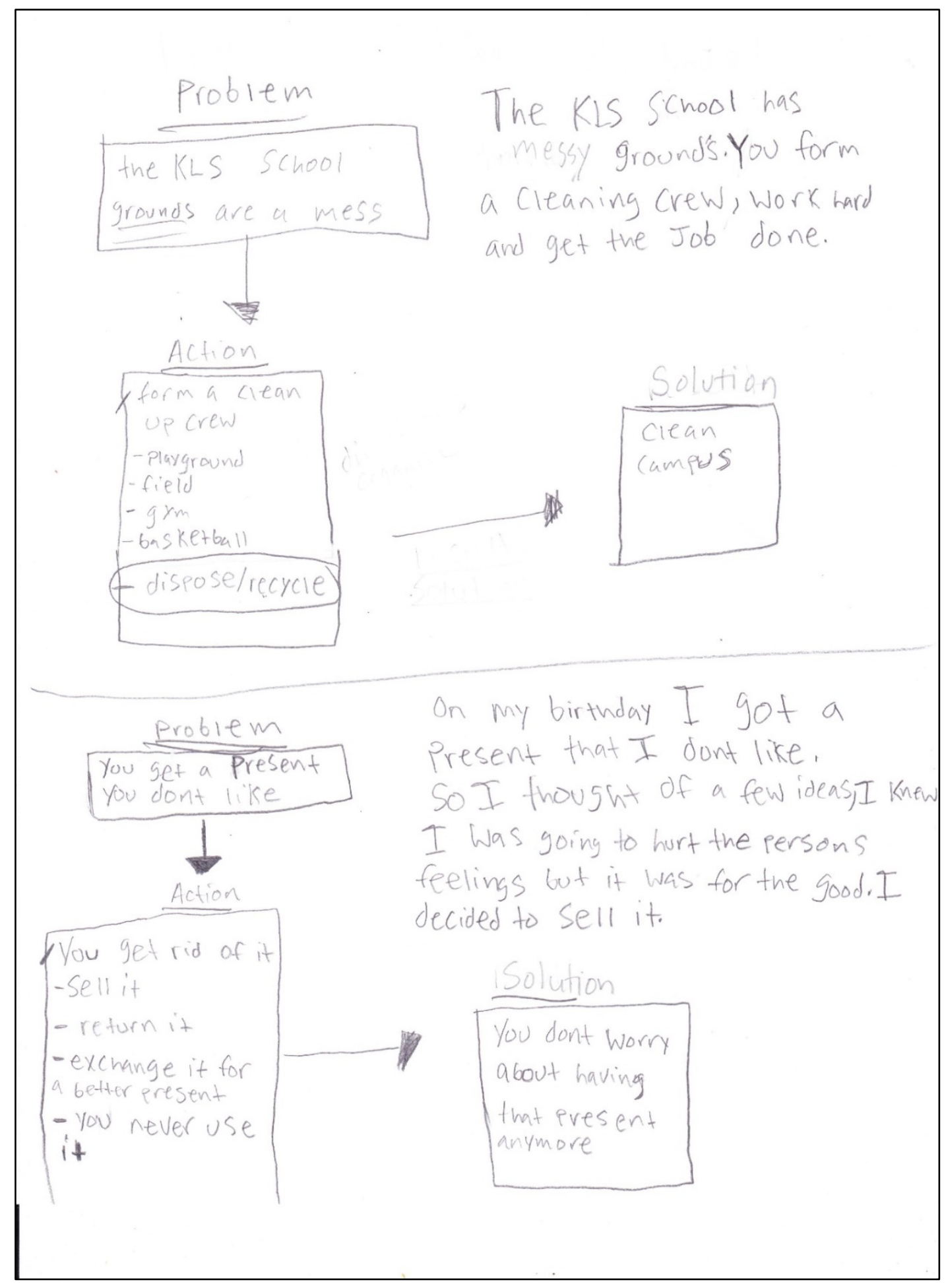


Appendix Y: Teacher Problem and Solution Book/Passage

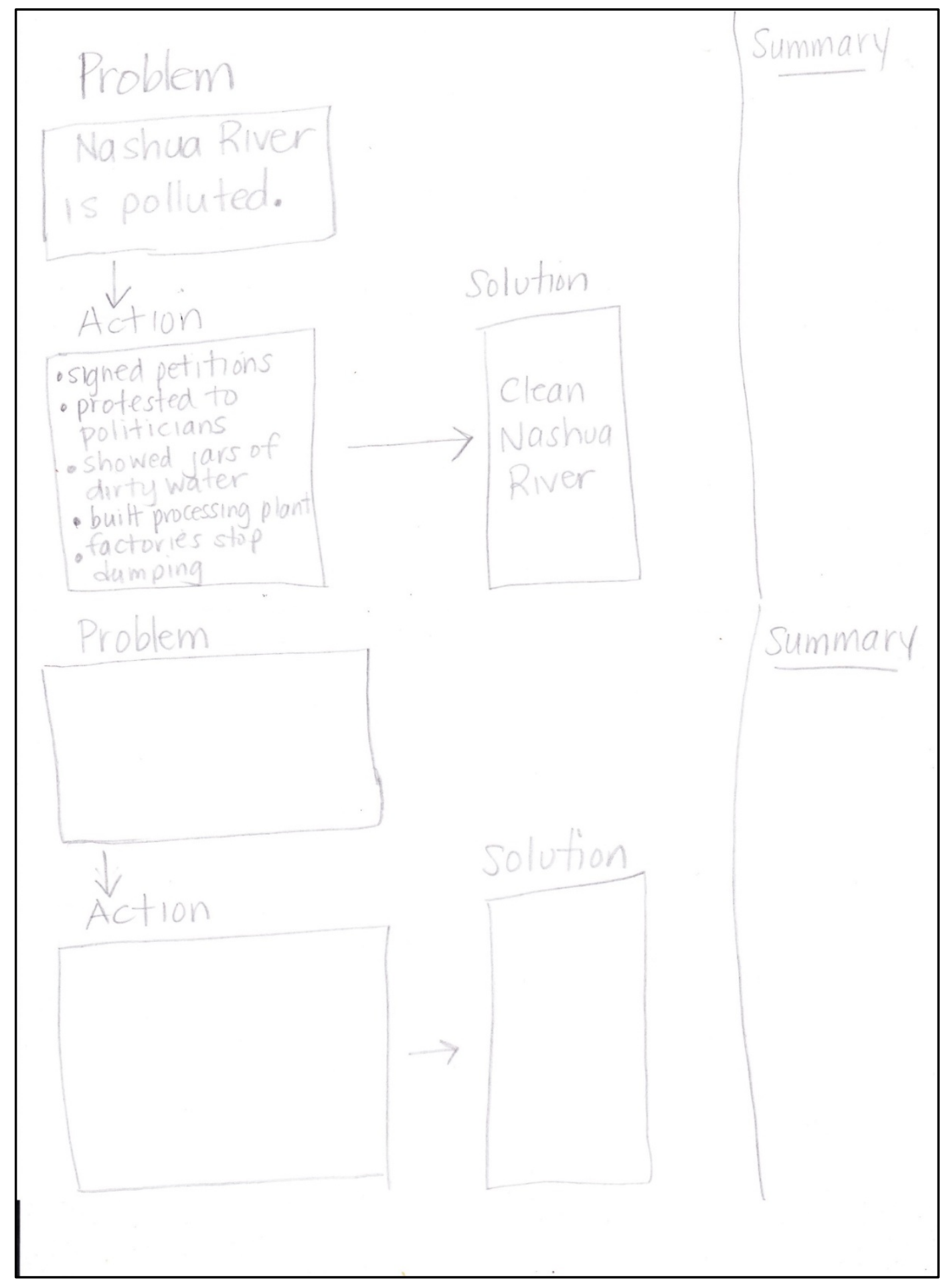


Appendix Z: Student Problem and Solution Book/Passage and Reciprocal Map

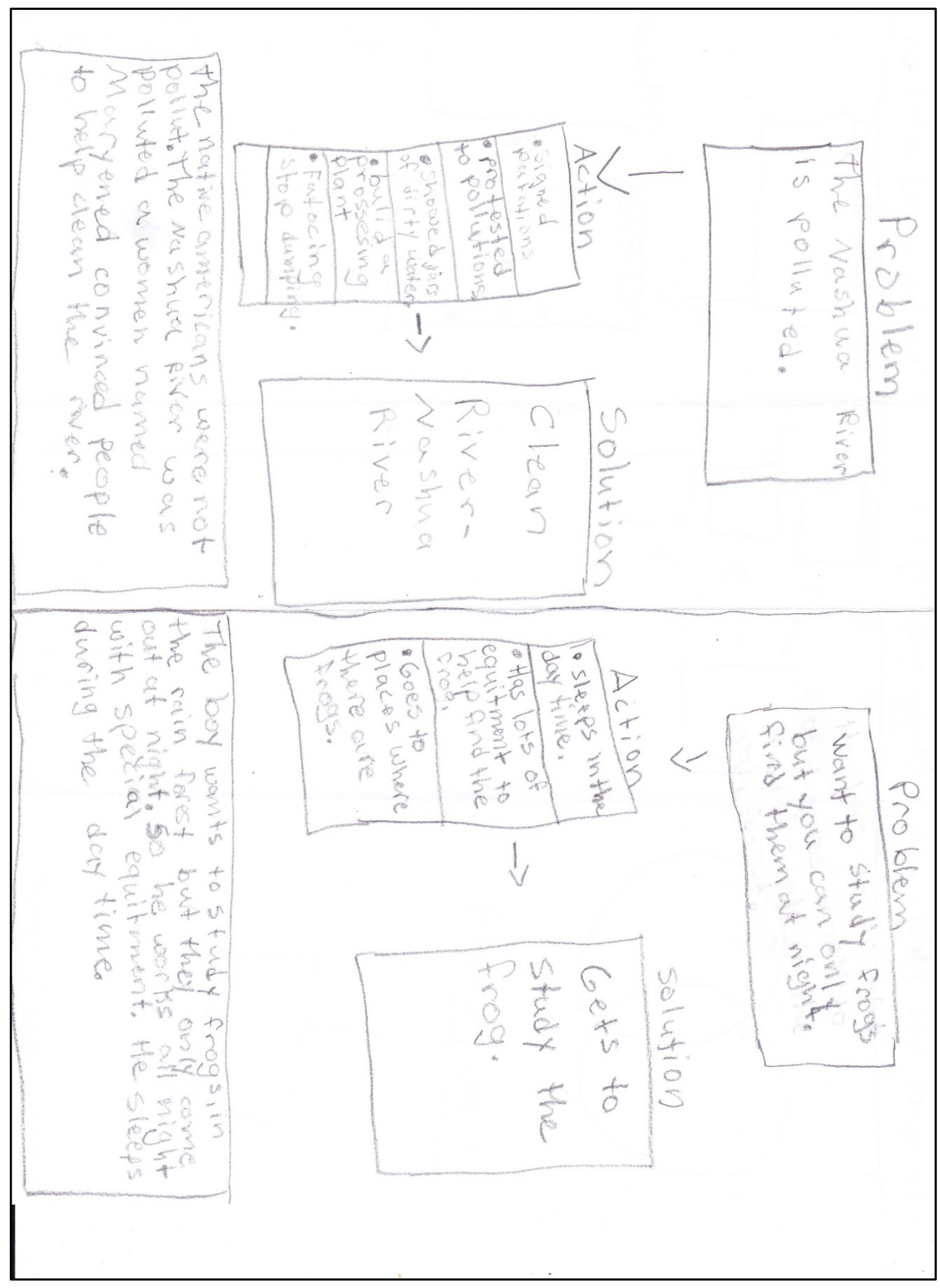


Appendix Teacher Problem and Solution Textbook

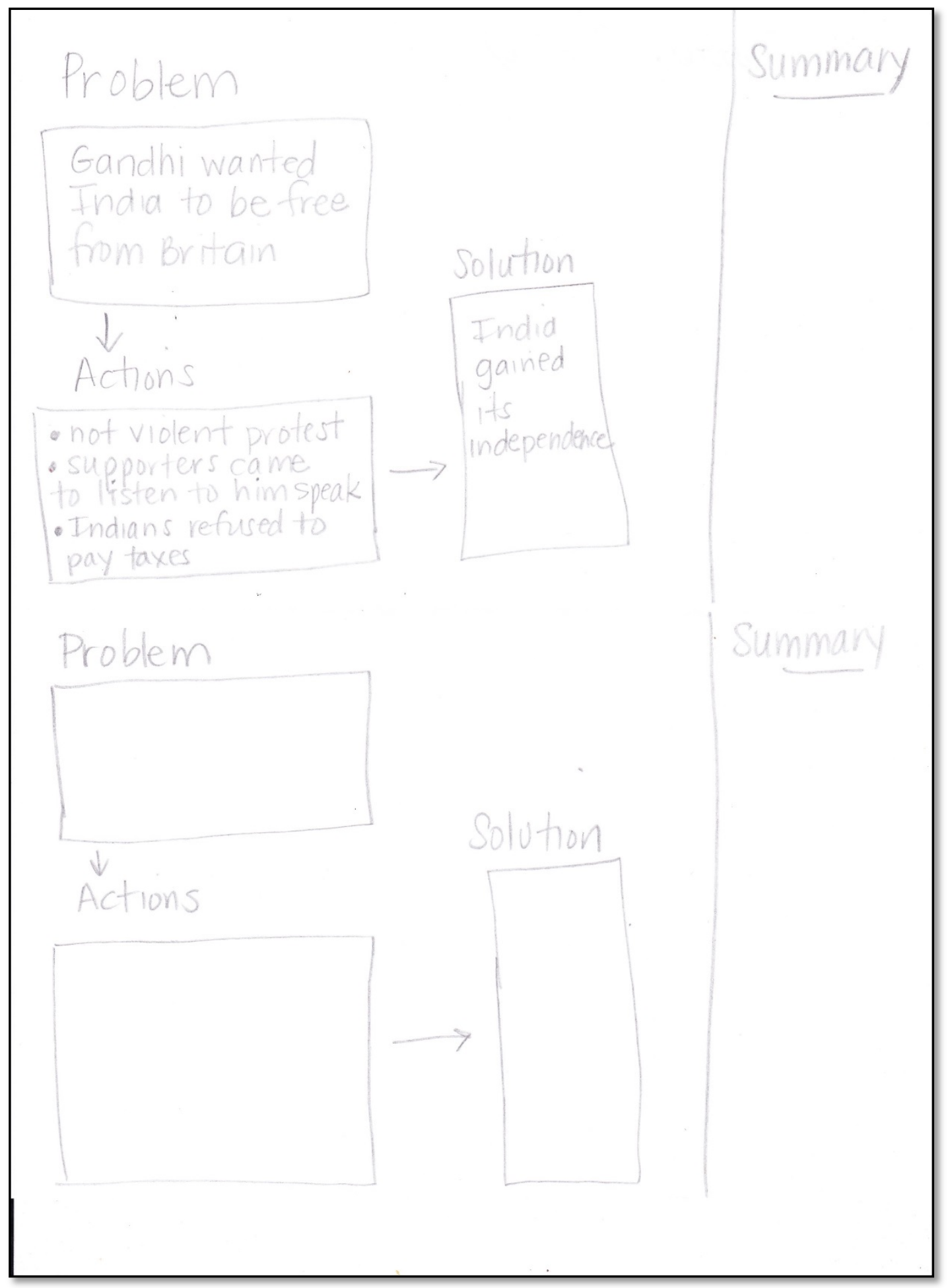


Appendix Student Problem and Solution Textbook and Reciprocal Map

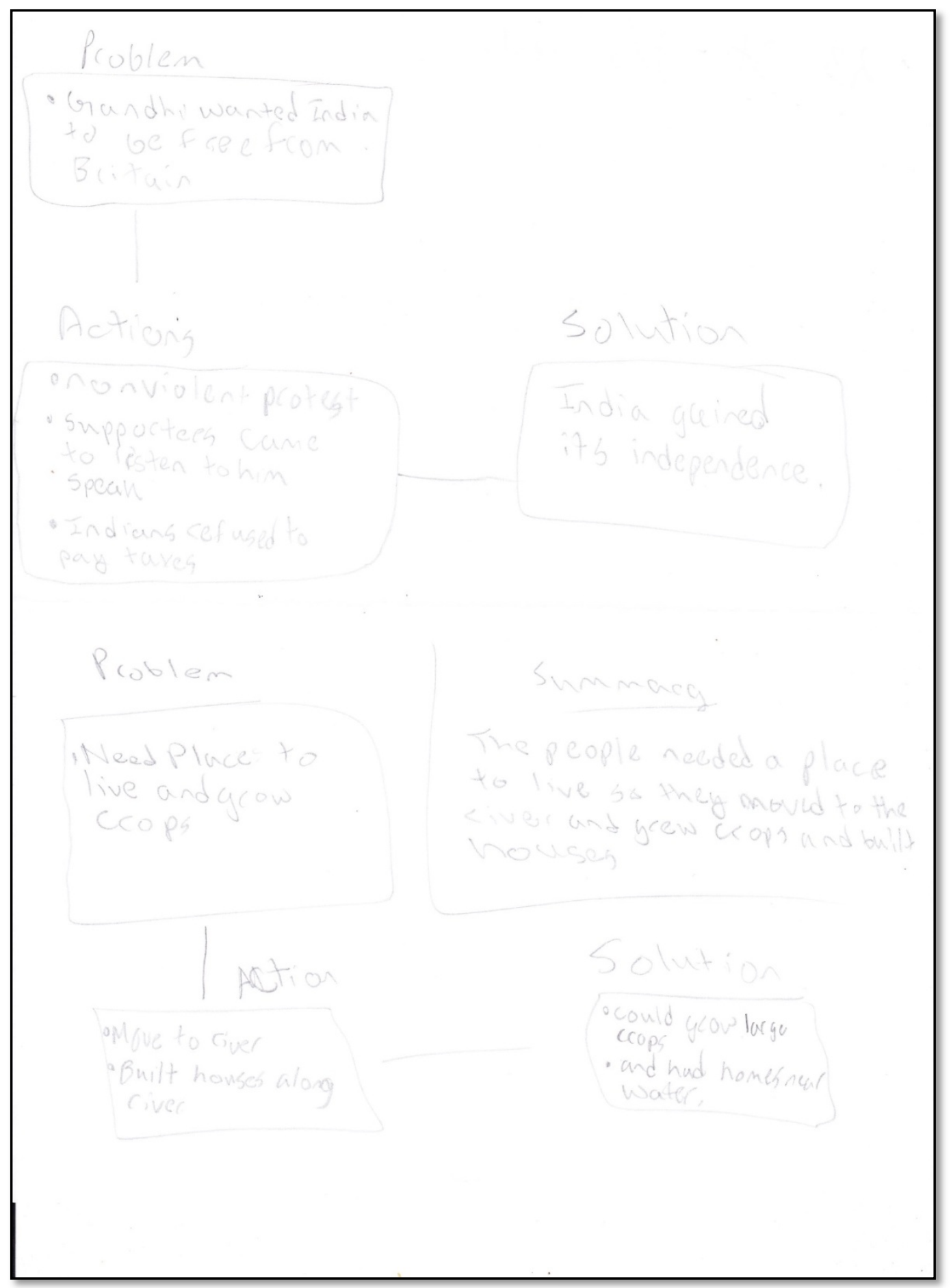




\section{VITA}

\section{TINA CASH}

1984

B.S. Specific Learning Disabilities

Florida International University, Miami, Florida

1989

M.S. Diagnostic Teaching

Florida International University

Miami, Florida

$2011 \quad$ Educational Specialist

Florida International University

Miami, Florida

2013 Doctoral candidate, Curriculum \& Instruction, Reading

College of Education, Department of Teaching \& Learning, ।

Florida International University

Miami, Florida

EXPERIENCE

1985 - 2013 Teacher, Elementary, Exceptional, Gifted, Media and Reading Education Teacher, Key Largo School, Key Largo, Florida

2005 - 2009 Just Read, Florida! Reading First Developer. Aided in program revisions.

2005 Reading 1st - Reading Academy, Dade and Broward Counties.

2006 Reading 1st - Reading Academy, Dade and Pasco Counties.

2007 Reading 1st - Reading Academy, Dade, Broward, and Polk Counties. Council for Educational Change, Broward Co., Florida.

2008 Reading 1st - Reading Academy, Dade, Broward, and Palm Beach.

2009 Reading 1st - Reading Academy, Dade and Broward Counties.

$2010 \quad$ Reading Facilitator for Renaissance Reading.

2011-13 Teaching American History Cadre, District/School Facilitator. 


\title{
PRESENTATIONS
}

Fine, J. \& Cash, T. Reciprocal Mapping: Using author's craft to scaffold comprehension $\&$ composition across the curriculum. Florida Secondary Reading Council conference, Miami, Florida, April 22, 2006.

Fine, J., Cash, T. \& Kennedy, A. Reciprocal Mapping: Visually Representing Text Structure to Improve Students' Reading and Writing. Florida Reading Association, Orlando, Florida, October 21, 2005.

Fine, J. \& Cash, T. Reciprocal Mapping: Using Information text to improve comprehension, cognition, and competence as a writer. Dade Reading Council, Miami, Florida, September 17, 2005.

Fine, J. \& Cash, T. (2005, December). Reciprocal Mapping: Scaffolding Students' Reading and Writing Connections to Informational Text. Paper presented as a cosponsored session of OTER at the American Reading Forum Conference. Sanibel, FL.

\begin{abstract}
AWARDS
Monroe County Teacher of the Year, Burdine's. Monroe County Public Schools, 2003

Key Largo School Teacher of the Year, Burdine's. Key Largo School, Key Largo, Florida, 2003.

The Presidential Awards for Excellence in Mathematics and Science Teaching, Key Largo School, Key Largo, Florida, 2004.
\end{abstract}

